University of South Florida

DIGITAL COMMONS

@ UNIVERSITY OF SOUTH FLORIDA
Digital Commons @ University of

South Florida

8-1-2005

\title{
Impacts of Transit Oriented Development on Public Transportation Ridership- Phase One
}

CUTR

Follow this and additional works at: https://digitalcommons.usf.edu/cutr_nctr

\section{Scholar Commons Citation}

CUTR, "Impacts of Transit Oriented Development on Public Transportation Ridership- Phase One" (2005). Research Reports. 239.

https://digitalcommons.usf.edu/cutr_nctr/239

This Technical Report is brought to you for free and open access by the National Center for Transit Research (NCTR) Archive (2000-2020) at Digital Commons @ University of South Florida. It has been accepted for inclusion in Research Reports by an authorized administrator of Digital Commons @ University of South Florida. For more information, please contact digitalcommons@usf.edu. 


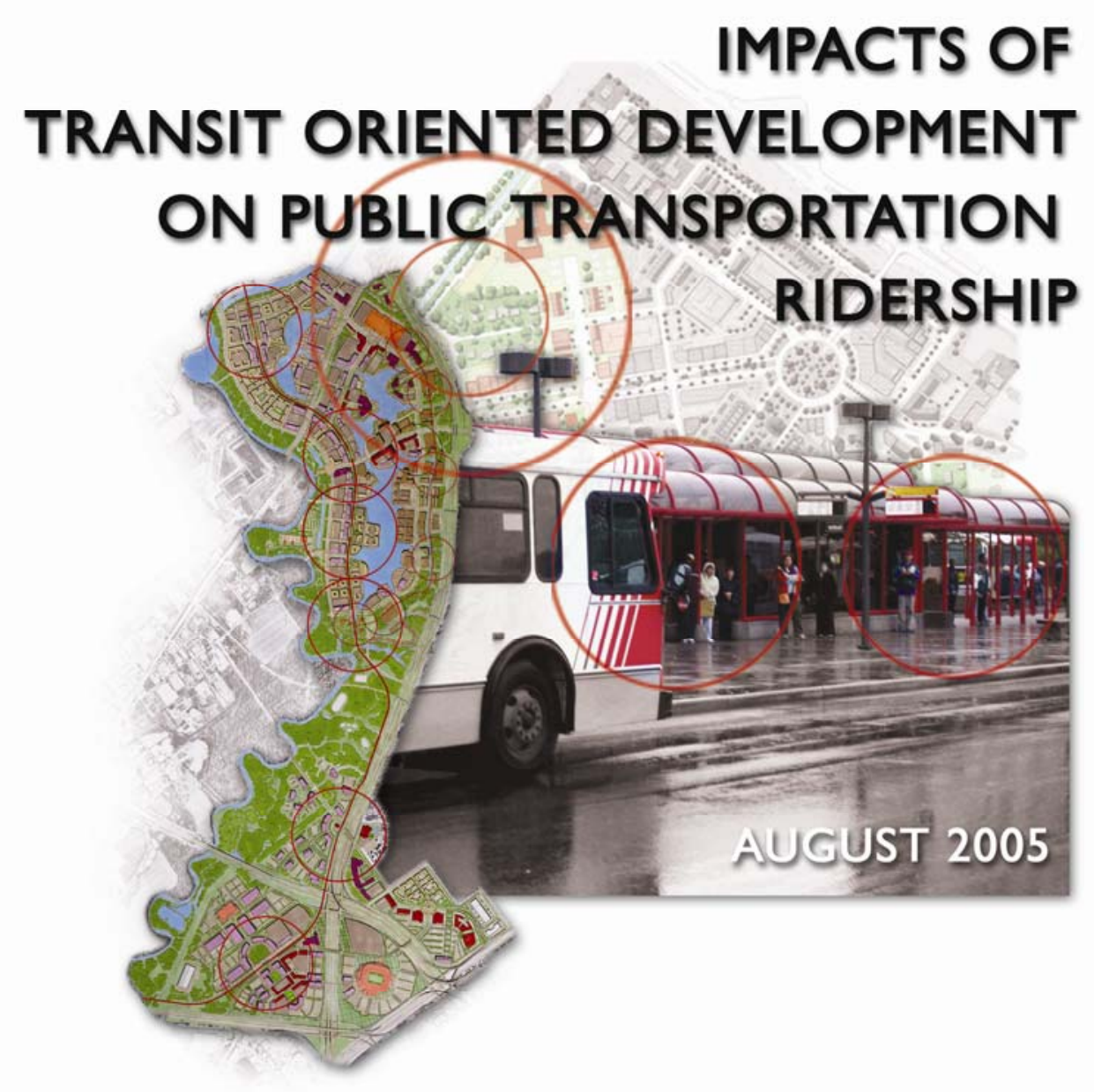

Final Report

FDOT BD549-05

NCTR 576-10 


\title{
Impacts of Transit Oriented Development On Public Transportation Ridership
}

\author{
Final Report \\ Prepared with funding from the \\ National Center for Transit Research \\ Prepared with sponsorship from the Florida Department of Transportation \\ Sara J. Hendricks, Principal Investigator \\ Phil Winters, TDM Program Director \\ Francis Wambalaba, Senior Research Associate \\ Sean Barbeau, Research Associate \\ Martin Catala, Senior Research Associate \\ Keith Thomas, Technology Coordinator

\section{Graduate Student Assistants} \\ E. Spencer Fleury \\ Jennifer Flynn \\ Julie Goodwill
}

August 2005

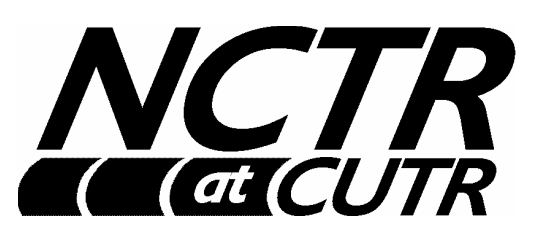

\section{CENTER FOR URBAN TRANSPORTATION RESEARCH}

University of South Florida

4202 E. Fowler Avenue, CUT 100

Tampa, FL 33620-5375

(813) 974-3120, SunCom 574-3120, Fax (813) 974-5168

Edward Mierzejewski, CUTR Director

Joel Volinski, NCTR Director

Philip Winters, TDM Program Director, National TDM and Telework Clearinghouse

The contents of this report reflect the views of the author, who is responsible for the facts and the accuracy of the information presented herein. This document is disseminated under the sponsorship of the Department of Transportation, University Research Institute Program, in the interest of information exchange. The U.S. Government assumes no liability for the contents or use thereof. 
TECHNICAL REPORT STANDARD TITLE PAGE

\begin{tabular}{|c|c|c|c|}
\hline $\begin{array}{l}\text { 1.Report No. } \\
\text { BD549-05 }\end{array}$ & 2. Government Accession No. & \multicolumn{2}{|c|}{ 3.Recipient's Catalog No. } \\
\hline \multicolumn{2}{|l|}{ 4.Title and Subtitle } & \multicolumn{2}{|l|}{ 5.Report Date } \\
\hline \multirow{2}{*}{\multicolumn{2}{|c|}{$\begin{array}{l}\text { Impact of Transit Oriented Development on Public Transportation } \\
\text { Ridership }\end{array}$}} & \multicolumn{2}{|l|}{ August 2005} \\
\hline & & \multicolumn{2}{|c|}{$\begin{array}{l}\text { 6.Performing Organization Code } \\
\text { NCTR 576-10 }\end{array}$} \\
\hline \multicolumn{2}{|l|}{ 7.Author(s) Sara J. Hendricks } & \multicolumn{2}{|c|}{ 8.Performing Organization Report No } \\
\hline \multicolumn{2}{|c|}{ 9.Performing Organization Name and Address } & \multicolumn{2}{|l|}{ 10. Work Unit No. } \\
\hline \multicolumn{2}{|c|}{$\begin{array}{l}\text { National Center for Transit Research } \\
\text { Center for Urban Transportation Research } \\
\text { University of South Florida } \\
4202 \text { E. Fowler Avenue, CUT } 100 \\
\text { Tampa, FL 33620-5375 }\end{array}$} & \multicolumn{2}{|c|}{$\begin{array}{l}\text { 11.Contract or Grant No. } \\
\text { DTRS98-G-0032 }\end{array}$} \\
\hline \multirow{2}{*}{\multicolumn{2}{|c|}{$\begin{array}{l}\text { 12.Sponsoring Agency Name and Address } \\
\text { Office of Research and Special Programs } \\
\text { U.S. Department of Transportation, Washington, D.C. } 20690 \\
\text { Florida Department of Transportation } \\
605 \text { Suwannee Street, MS 26, Tallahassee, FL } 32399\end{array}$}} & \multicolumn{2}{|c|}{$\begin{array}{l}\text { 13. Type of Report and Period } \\
\text { Covered }\end{array}$} \\
\hline & & \multicolumn{2}{|c|}{ 14.Sponsoring Agency Code } \\
\hline \multicolumn{4}{|c|}{$\begin{array}{l}\text { 15.Supplementary Notes Supported by a grant from the Florida Department of Transportation and the U.S. } \\
\text { Department of Transportation }\end{array}$} \\
\hline \multicolumn{4}{|c|}{$\begin{array}{l}\text { 16.Abstract The purpose of Phase I of this study was to develop a research design to better establish the } \\
\text { relationship between transit oriented development (TOD) and travel mode share. The initial hypothesis that } \\
\text { good quality transit combined with good quality TOD would succeed in shifting travelers from single- } \\
\text { occupant vehicle travel to transit was found to be an oversimplification. Good quality transit service is } \\
\text { necessary and good quality TOD is likely helpful and important to shifting mode share but not sufficient. } \\
\text { Other necessary factors include supporting elements of the larger urban spatial structure, disincentives to } \\
\text { driving alone, favorable marketability of TOD for non-transportation reasons, and incentives to use transit. } \\
\text { Research literature suggests that elements of urban form are perhaps not the most important determinants of } \\
\text { travel behavior, specifically mode choice, number of trips taken and length of trips. However, urban form } \\
\text { does appear to exert some kind of influence, and for that reason, it is worthwhile to further specify the } \\
\text { relationship to ascertain how policy initiatives relating to TOD can support the goal to balance mode share in } \\
\text { the direction of greater transit use. To better define the elements of TOD that shape travel behavior, this } \\
\text { study describes a research design for the development of a panel survey, using recently developed cell } \\
\text { phone technology, to track the same individuals and households over time. Using a pre-test post-test design, } \\
\text { the survey data collected for a region in Florida would be a sound investment for improved travel } \\
\text { forecasting, modeling and other uses. }\end{array}$} \\
\hline $\begin{array}{l}\text { 17.Key Words Public } \\
\text { transportation, transit } \\
\text { performance, transit oriented } \\
\text { development, travel behavior }\end{array}$ & \multicolumn{3}{|c|}{$\begin{array}{l}\text { 18.Distribution Statement Available to the public through the National } \\
\text { Technical Information Service (NTIS),5285 Port Royal Road, } \\
\text { Springfield, VA } 22181 \text { ph (703) 487-4650 }\end{array}$} \\
\hline $\begin{array}{l}\text { 19.Security Classif. (of this report) } \\
\text { Unclassified }\end{array}$ & $\begin{array}{l}\text { 20.Security Classif. (of this page) } \\
\text { Unclassified }\end{array}$ & 21.No. of pages & 22. Price \\
\hline
\end{tabular}

Form DOT F 1700.7 (8-69) 


\section{Acknowledgement}

This study benefited greatly from the helpful insight and review by several transportation research colleagues, including Patricia Ball, Xuehao Chu, Edward Mierzejewski, Oliver Page, Steven Polzin, Karen Seggerman, Joel Volinski and Phil Winters. Their assistance and contributions are gratefully acknowledged. 


\section{Table of Contents}

Acknowledgement ..............................................................................................................ii

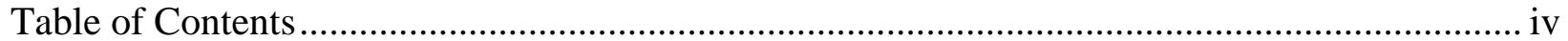

List of Tables and Figures..................................................................................................... vi

Executive Summary ......................................................................................................... vii

Introduction and Study Purpose....................................................................................... 1

Study Method................................................................................................................ 4

Characterizing the Larger Context in which TOD Functions Well ............................................... 7

Varying Goals for TOD Will Determine How Success is Measured ........................................... 7

TOD Will Not Shift Mode Share Without Good Quality Transit.................................................. 7

Urban Spatial Structure Affects How Transit Can Provide Regional Access .............................. 8

Incentives to Drive One's Private Automobile Must Be Removed............................................... 8

Mode Shift to Transit Requires Proper Placement and Design of TOD....................................... 9

Marketability of TOD for Non-Transportation Reasons is Crucial ....................................... 10

Incentives to Use Transit Can Make a Difference ...................................................................... 16

Literature Review on How Urban Form Affects Travel Behavior ................................................. 17

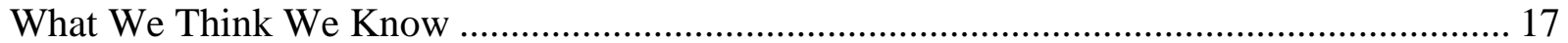

Land Use is Likely Less Important Than Other Factors.......................................................... 18

Land Use Does Play Some Role in Affecting Travel Behavior........................................ 20

Urban Form Characteristics Requiring Further Insight ........................................................... 21

Qualities of Urban Form .................................................................................................... 21

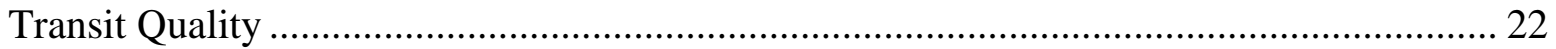

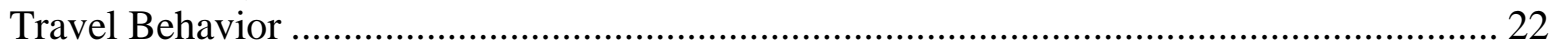

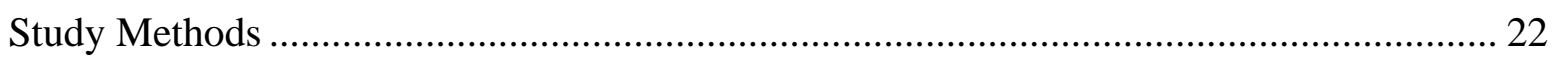

In-Depth Analysis Techniques Used to Evaluate TOD .............................................................. 23

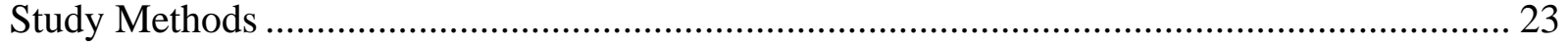

Simple Tests of Correlation ................................................................................................. 24

Linear and Multivariate Statistical Analysis........................................................................... 25

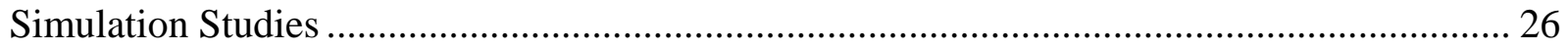

Travel Choice Models..................................................................................................... 26

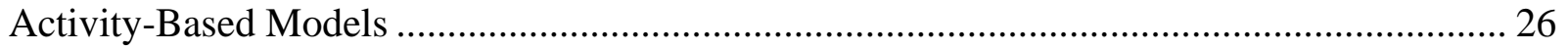

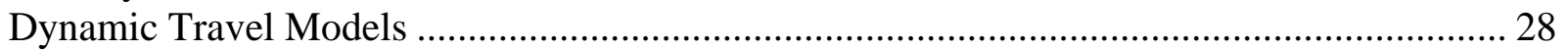

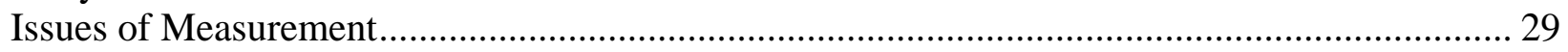

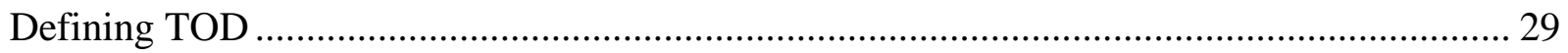

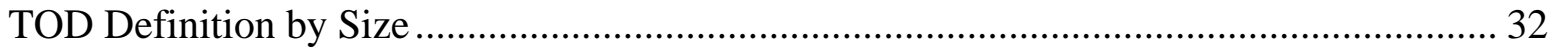

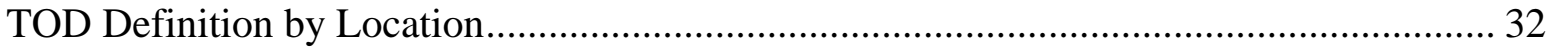

Defining Elements of Travel Behavior ................................................................................... 32

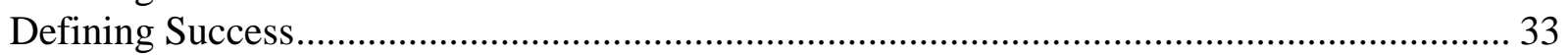

Timing of Measurement........................................................................................................... 36

Isolating the Effects of the Variable of Interest....................................................................... 36

Ensuring Generalizability of Results to the Broader Population ................................................ 37

Availability of Data.......................................................................................................... 37

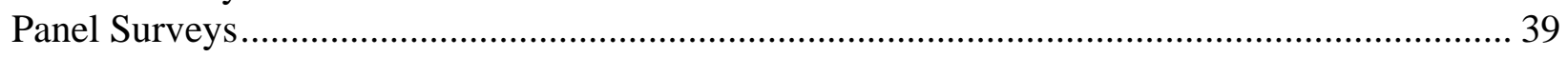

An Overview of Data Forms and Collection Methods .............................................................. 39

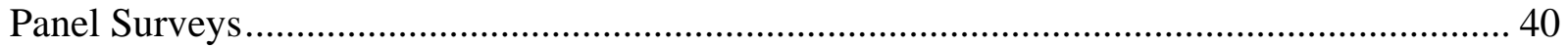


Data Quality Issues of Panel Surveys ..................................................................................... 42

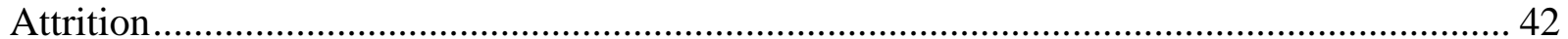

Puget Sound Transportation Panel (PSTP) Survey Design and Study Results ............................ 44

What We Can Learn from PSTP Attrition.............................................................................. 44

Should Florida Conduct a Transportation Panel Survey?.................................................................. 45

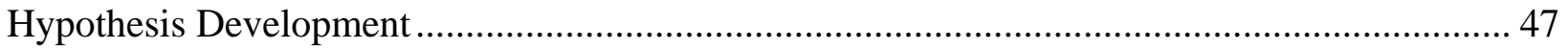

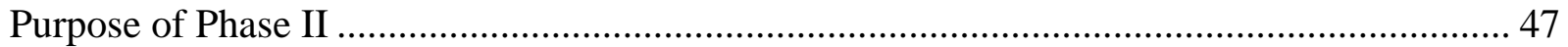

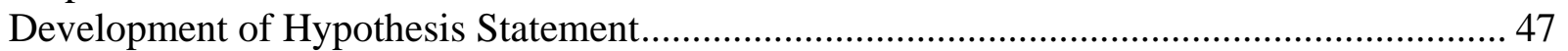

Population of Interest........................................................................................................... 48

Study Group and Unit of Measure..................................................................................... 48

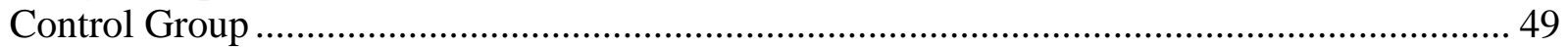

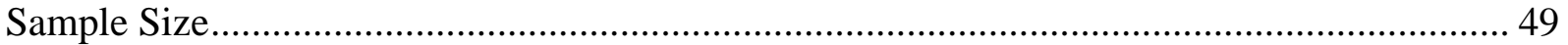

Performance Measures of Interest .......................................................................................... 52

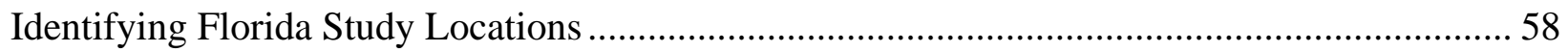

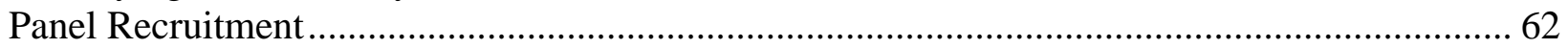

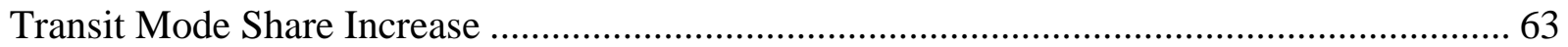

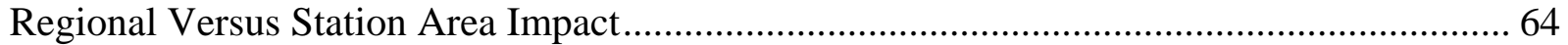

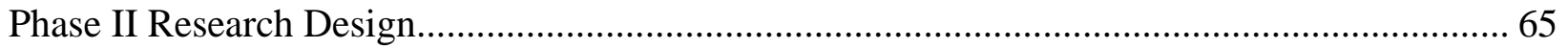

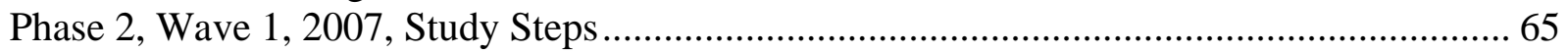

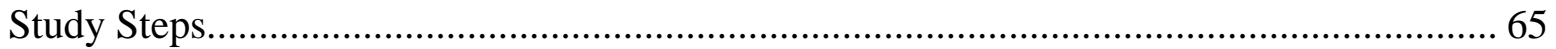

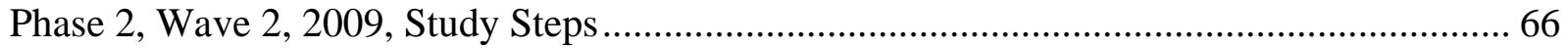

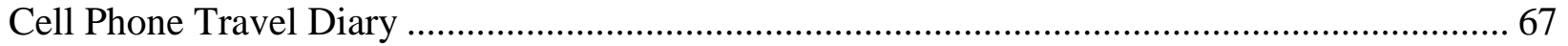

Advantages of Using Cell Phone Technology ...................................................................... 71

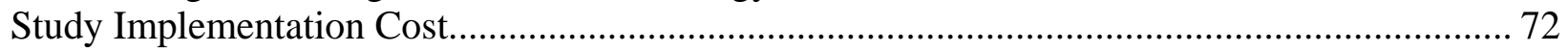

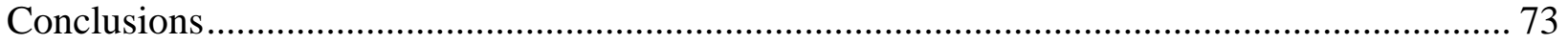

Resolving Issues of Measurement ……………………..................................................... 73

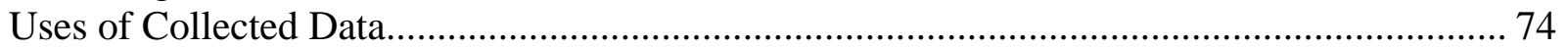

Collecting Data on the Other 80 Percent of Travel Purposes ................................................. 74

Collecting Data Particular to Florida's Urban Form............................................................... 74

Gauging Attitudes and Lifestyles as Explanatory Variables ............................................... 74

Determining Former Mode of New Transit Riders............................................................ 74

Gauging the Effect of Regional Access on TOD Effectiveness ............................................. 74

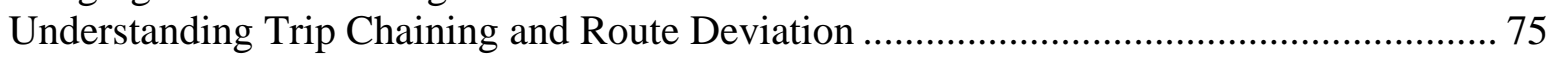

Collection of Travel Data for Use in Activity-Based Models ............................................. 75

Fine Tuning Traffic Calming For Optimal Effect................................................................ 76

Learning How To Support More Walking Trips Through Urban Design .............................. 76

Understanding Longer Term Decisions That Affect Travel Behavior ................................... 76

Developing TOD Within a Bus Service Context.................................................................... 76

Better Specifying Impact of Urban Form on Travel Behavior ............................................. 77

Concluding Remarks........................................................................................................... 77

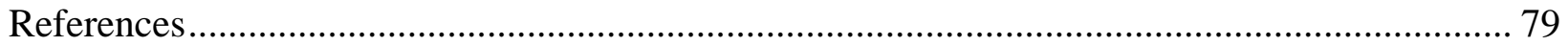




\section{List of Tables and Figures}

Table 1: Taxonomy of Transit Rider Profiles and TOD Qualities Resulting in Transit Ridership 12

Table 2: Variations in TOD Definition from a Sample of Sources ......................................... 30

Table 3: Measures of Transportation Performance of TOD .................................................... 52

Table 4: Inventory of Attributes Influencing Transit Mode Share ......................................... 54

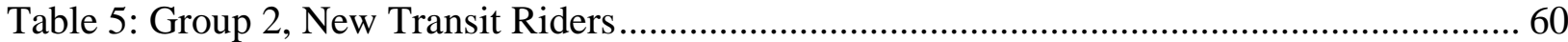

Table 6: Identifying Potential Study Participants .................................................................. 63

Table 7: Phase II Research Design Response to Issues of Measurement ................................ 73

Figure 1: Year 2025 Estimates of Population Aged 65 and Over........................................... 46

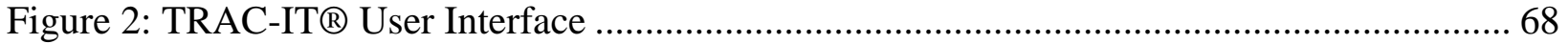

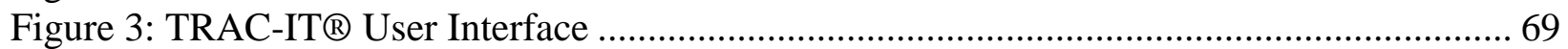




\section{Executive Summary}

The purpose of this Phase I study is to develop a research design for investigating how transit oriented development (TOD) affects travel behavior. There are three travel impacts of primary interest. These are mode share, number of vehicle trips (VT) and vehicle miles of travel (VMT). TOD is land development associated with transit service and designed in such a way to support transit ridership. This study was funded by the National Center for Transit Research (NCTR)with sponsorship from the Florida Department of Transportation (FDOT). The scope of this study included an investigation of TOD nationally but with an emphasis upon the particular circumstances of Florida urban areas. While the research outcome is intended to be applied to a Florida region, it is anticipated that the results will be useful to many urban areas throughout the United States that have developed after the 1940s.

The problem that this study addresses is the increasing traffic congestion and maintenance costs burdening the State Highway System. Public transit has the potential to serve more local traffic, thereby decreasing congestion on state roads used for regional travel purposes. Planning and development policies that are intended to support increasing transit ridership, and reduce the number and length of vehicle trips include those that encourage TOD. However, questions remain about whether and how TOD contributes to decreasing traffic congestion. If more were known about the relationship between land use and travel behavior, more effective policies could be developed. Some are skeptical about the current performance of TOD with respect to increasing transit ridership. The initial hypothesis of this study was that good quality TOD combined with good quality transit service could shift mode share from single occupant vehicle travel to greater transit ridership.

The method of inquiry in this study included a detailed literature review of research relating not only to TOD but addressing the underlying relationship between urban form, land use and TOD upon travel behavior. Analysis included an investigation of the policy environment and the existence of transit-ready developments in Florida. It is concluded that the body of research currently suggests that land use may be less important than other factors in affecting mode choice, VT and VMT. More important factors may be income, attitudes and preferences, and auto ownership, among others. However, while land use characteristics as found in TOD may not be the deciding factor in influencing travel behavior, land use characteristics do play some positive role. Therefore, there is some potential to craft land development policies to decrease traffic congestion. It was also found that in cases where TOD appears to work more successfully, other circumstances exist. These include excellent transit service, an urban spatial structure that supports the ability to provide regional access, the development of a network of TODs across a region, the removal of incentives to drive one's personal vehicle, the addition of incentives to use transit, and the improved marketability of TOD for non-transportation reasons.

In the development of a research design, several issues of measurement were identified. These included the difficulty of finding examples of developments that adequately represent the TOD concept. Other issues included achieving agreement on what TOD is with regard to quality, size and location, whether TOD served only by bus and not rail may constitute a TOD (as would be 
the case for all Florida urban areas except the southeast counties of Miami-Dade, Broward and Palm Beach), defining elements of travel behavior, defining effectiveness, issues of measurement timing, the challenges of isolating the effects of the variable of interest, ensuring the ability to generalize the results to the broader population and the availability of data. The research design proposed for Phase II directly addresses the issue of adequate data availability and proposes a means to resolve the remaining issues.

The research design proposed for Phase II is the development of a multi-year panel survey, using a pre-test post-test design, to be implemented within a selected region in Florida. Broward County is recommended. The main focus of Phase II is to retrieve and organize a suitable database in adequate content, quality, amount and duration, for numerous analysis purposes, including better understanding the relationship between TOD and travel behavior. A panel survey is proposed, which collects longitudinal data for the same individuals over a period of time and lessens data collection requirements. While data from the Puget Sound Transportation Panel have been extensively analyzed worldwide, the conclusions about travel behavior derived from these data may not be adequately transferable to the Florida experience. Florida is different in many ways from the West Coast in terms of its transportation infrastructure, policy environment, development history, unique cultural influences and socioeconomic and household characteristics. It is estimated that in the year 2025 Florida will have the highest proportion of persons over the age of 65 in the nation.

The panel data collected in Florida would include an inventory of physical development conditions of the study area, a written survey of present socioeconomic characteristics, attitudes and preferences of study participants, and a cell phone travel diary of present travel behavior. A new software recently developed, known as TRAC-IT®, uses a global positioning system and personal digital assistance technologies to record travel behavior data of individuals. TRAC-IT® or some software similar to it is recommended for use in the panel survey. It is easy to use, which can extend the length of survey time from the typical one-day survey to an observation period of one week or more. Because this capability enables better capture of travel variations of individuals over time, this technology, in concert with the panel survey design, can also decrease the needed sample size. This report details issues relating to participant recruitment. It also provides estimates of study costs.

While a panel survey would be an expensive undertaking, it would also be an investment in research that could reap numerous pay-offs. In addition to better understanding travel behavior within the context of Florida's urban form and bus service environment, we would gain better insight into travel for noncommute purposes, which is the portion that comprises over 80 percent of all travel. We would also gain a better understanding of trip linking and route deviation behavior, which appears to have a strong impact on mode choice. The panel data would be useful for developing better models to forecast travel demand, such as activity-based models and dynamic travel models, which require longitudinal data. Such a rich data set would reap benefits to Florida and the nation because it would also attract the interest of transportation researchers nationwide and abroad. 


\section{Introduction and Study Purpose}

This project constitutes a Phase I exploratory stage of a study to examine the conditions under which transit oriented development (TOD) switches single occupant vehicle (SOV) users to transit use. The intended outcome of this project has been to develop a research design to explore the effectiveness of TOD in relation to increasing transit ridership. This report was funded by the National Center for Transit Research with sponsorship from the Florida Department of Transportation. As a word of clarification, this report refers to the results and methodologies of numerous other studies. To avoid confusion, this report refers to the analysis and recommendations contained herein as Phase I. The proposed future implementation of the developed research design is referred to as Phase II.

TOD is land development associated with transit service and designed in such a way to support transit ridership. TOD effectiveness is a topic of importance because mounting local traffic is causing the level of service for regional and statewide travel on the State Highway System to deteriorate. The cost of highway maintenance rises with the burden of increasing local traffic. A sensible solution would seem for public transit to serve local traffic more, thereby decreasing congestion on state roads used for regional travel purposes. Much of the existing literature on transit oriented development (TOD) presupposes that TOD is effective for numerous purposes, including increasing transit ridership, reducing traffic congestion and providing mobility options. This body of literature includes manuals and guidebooks. They focus on how to create successful TOD by providing great detail on planning and design features, based upon what seems to have worked in various urban areas. They also provide recommendations for marketsensitive strategies, such as zoning that allows for smaller households with fewer cars, flexible parking standards and location-based mortgages. The success observed about TODs in their totality may be the result of any combination of elements, both known and as yet unidentified. The manuals essentially provide a blue print for copying as many features as possible from the successful TODs in hopes that the effective combinations of synergistic characteristics will carry over to the newer development. These manuals are highly useful from a practical standpoint. They guide decisions that must be made today based upon the limited knowledge we have now.

Alternatively, this Phase I study takes a step back and examines the evidence thus far about TOD effectiveness with the aim to develop a Phase II research design that will more accurately pinpoint the specific features of a TOD that generate effectiveness. The research literature that sheds the most light on the relationship between TOD and transit ridership tries to strip away the effects of culture, economy and demographics and addresses how isolated elements of land use or urban form affect travel behavior. This might reap the most powerful information with regard to TOD policymaking. Many insightful research studies that examine the relationship between travel behavior and a specific land use feature common to TOD, may not necessarily refer to it as "TOD" but the functional intent of the development is the same. It is useful to broaden the examination to studies linking elements of urban form to travel behavior as a means of isolating the impact of single characteristics. This is because TOD definition and measurement is imprecise. It is also because TOD is a combination of characteristics and all TODs are different. The words TOD, land use, and urban form are used throughout this report and although are intimately related, they are not interchangeable. A TOD contains elements of land use. A TOD 
exists within and reflects elements of the larger urban form. The concepts of land use and urban form are frequently used as a means to be more specific of the scale that is being discussed.

There is the claim that nothing will get people out of their cars because driving alone is simply what people prefer. Likewise, people want large single-family detached homes in the suburbs because that is their preference. The argument goes that we should accommodate these apparent market preferences. Efforts to impede them are a misguided, ineffective and costly waste of time. Others claim that any positive impacts of TOD do not justify the costs. For example, the outcome of Downs' (1994) work was a regional model that estimates the relationship between transit quality, transit service affordability, transit accessibility, and mode shift to transit. Downs selected urban areas with one million or more populations and computed the number of TODs necessary to house the growth in population and employment within a ten-year period. Downs concluded that to attract a significant number of private auto users to transit, a large number of TODs would be required as well as a regional transit system that was of such a cost that would likely be unaffordable financially if not politically.

Therefore, why even study TOD? Assuming for a moment that TOD has some positive impact, is it a moot point to examine TOD as a possible policy tool if it is unmarketable and too costly? Boarnet and Crane (2001) conclude that if land use and urban form change travel behavior, it will be because they change the price of travel. How might TOD change the price of travel? It is suspected as a premise of this Phase I study that when the price of undeveloped land (nascent suburbia) begins to reflect its true cost to develop it, the relative attractiveness of TOD will rise and become increasingly marketable. Signs of this are already appearing in Florida with regard to the introduction of Rural Land Stewardship Areas, such as Ave Maria in Collier County. ${ }^{1}$ Regarding costs, very few studies provide a comprehensive analysis and comparison of the costs and benefits of different travel alternatives and transportation systems. All transportation system scenarios will be costly. The question is which scenario is least costly for the benefits derived over time. Three other premises of this Phase I study are included here.

1. While there have already been large investments made over the past 50 years for a highway-oriented system, the transportation costs of maintaining and expanding such a system will escalate in the future as three conditions change. These are that open space on which to expand will dwindle. The cost to widen roadways will increase due to rising cost of land and legal fees. Additionally, increasing population will eventually use up the capacity in the system.

2. The true non-transportation-related costs of a highway-dominant system are underestimated, partly due to measurement difficulties.

3. With the introduction of bus rapid transit (BRT), the high cost of providing a level of transit service that can compete with the time advantages of driving alone will decrease significantly.

\footnotetext{
${ }^{1}$ See Florida Statutes 163.3177(11)(d), which provides statutory direction to the Florida Department of Community Affairs to encourage Rural Land Stewardship Areas (RLSA). See also comments made by Kevin Kelley of the USDA Farm Service Agency and Don Rice of Farm Credit of South Florida at the 2005 Public Policy Workshop, Florida Chapter of the American Planning Association, Tallahassee, February 16, 2005. See also WilsonMiller, Inc. Sustainable Treasure Coast Rural Lands Subcommittee presentation, April 6, 2005, about the application of RLSA in Collier County.
} 
These reasons make TOD a worthwhile option to investigate. For purposes of this study, the more important question is what specific combinations of physical TOD elements work best under particular conditions to begin effecting a change in mode share. 


\section{Study Method}

Study activities for Phase I consisted of the following steps.

1. Internal focus groups with transportation research peers convened both at the beginning of Phase I and after the literature review was complete.

2. The literature review included identifying and synthesizing the following:

- Definitions, standards, and units of measure for TOD

- Features and contexts of effective TODs

- Features of good quality transit that effectively serve TODs

- Impact of urban form, TOD, and land use on travel behavior, as measured primarily by transit mode share, number of vehicle trips and vehicle miles traveled

- Various methods for evaluating TOD effectiveness, including travel behavior modeling and the use of the case study method developed in the social sciences.

- Data collection needs for different methods and comparison of usefulness of outcomes.

3. Phase I focused on locating existing Florida development that approximates the TOD concept as much as can be found. However, the combination of circumstances suspected necessary for success are not easily testable because few suitable examples are found. For example, a TOD with sufficiently limited parking is very difficult to find. Most developments have an overabundance of parking. Locating TOD consisted of the following activities:

- Geographic information systems (GIS) analysis and mapping of selected Florida urban areas identified street networks, transit services, transit centers and locations of any TOD identified by municipal planners. Bus routing was studied to observe any changes over time.

- Site observations were made of selected Florida developments.

- Phone interviews were conducted with transit agency representatives, municipal planners, staff of the Florida Department of Community Affairs and others.

4. Efforts proceeded with examining the homebuyer process through location based mortgages as a possible means of contacting residents before and after they move into transit oriented developments.

5. A research design was developed and a review was conducted of available technologies in support of it. Specifically, researchers pursued the use of global positioning systems (GPS) and personal digital assistance (PDA) technologies as a means to collect survey data that has the potential to be more accurate and comprehensive than conventional survey methods and easier for survey participants to use. Researchers participated in the TRAC-IT® pilot test of the GPS/PDA travel diary by documenting trip data during one week in March, 2005. The travel diaries system using PDAs has appeal because it can easily capture not only commute trips but also non-work trips as well as trip linking and a variety of other information.

Phase I began with the initial hypothesis that good quality TOD combined with good quality transit produces a mode shift from single occupant vehicle (SOV) to transit. Through the study process, it became quickly clear that the circumstances necessary for TOD to effectively shift mode share involve not only the built environment immediately surrounding a transit node, but 
also the transportation system, the policy and regulatory environment, socio-economic and cultural factors and urban spatial structure. The ability to increase mode share of public transit does not lie solely in the characteristics of transit and TOD but also in conditions affecting the economy and land development on a regional scale, demographics, private vehicle usage and ownership rates. Some of these factors can be shaped and controlled with less difficulty than others. The research strongly suggests that TOD can be highly effective in shifting mode share to transit under the right combination of circumstances.

Phase I provides a literature review that focused on two areas. These are research findings regarding TOD effectiveness and secondly, a summary of quantitative methods used to study TOD effectiveness. While research abounds on the subject of TOD performance with respect to transit ridership, this report adds to the effort by focusing upon the status of TOD in Florida and the circumstances that influence its effectiveness. Like many other communities across the nation, cities and towns in Florida are not similar to the major older cities that ordinarily come to mind in a discussion of TOD; however, rapid growth in population and development is taking place in Florida and therein lies an opportunity. This report discusses research design considerations and challenges and provides recommendations that concentrate upon the necessity for basic data collection. While this finding of the need for better data is consistent with other sources, such as the conclusions contained in the Statewide Transit-Oriented Development Study, conducted by Caltrans in 2002, this report recommends an approach to data collection that is different from but complements the recommendations developed for the National Cooperative Highway Research Project (NCHRP) Project 20-45.

This study proposes a Phase II empirical design for the purpose of collecting baseline and future data using travel diary technology that is anticipated to greatly enhance the accuracy, comprehensiveness and ease of information collection. The database would be available for use in future transportation modeling. In much the same way that the Puget Sound Regional Council in Washington State has encouraged the application of the Puget Sound Transportation Panel (PSTP) data for research on travel behavior modeling and mode choice, the State of Florida, through its regional planning councils, could also create such a database that could attract research interest nationwide and abroad in other countries that share similar transportation issues and concerns. Such research would directly benefit Florida. This study also would focus on TODs in one state, the rapidly urbanizing Florida, which represents growth and development patterns of other urban areas nationwide that developed largely after the 1940's. The selection of Florida TODs also would make possible a comparative analysis with other urban areas that have larger, more developed transit systems and the TODs in support of them, such as in Washington, D.C. and San Francisco.

This study would use a disaggregate approach in that it collects microlevel data about individual travelers and households instead of calculating a broad picture of travel characteristics based upon aggregate travel data found in the Census and other sources. This study is also designed to be longitudinal in that it collects the same data over time from the same individuals, tracking changes in travel behavior in relation to their access to TOD. It is recognized that no two transitfriendly developments are alike. Comparisons and contrasts of travel behavior across TOD sites would be conducted only in light of the many differences identified. Each TOD is viewed as an element of the larger system or network. This suggests that individual TODs might and perhaps 
should function differently one from another. Pinpointing the reasons for change will be supplemented through participant surveys and an inventory of changes to the TOD, both physical and policy environment.

It is important to consider that the desired decrease in traffic congestion and the performance indicators used to measure progress may differ with respect to the involved party. The selection of performance indicators points to what actions to take that can deliver progress. A few examples are as follows.

- A highway advocate may seek a reduction of local traffic on thoroughfares designed to carry regional traffic. The performance indicators of interest may not only be increasing transit ridership but also reducing vehicle trips and vehicle miles traveled.

- A transit agency may seek increased farebox revenues with the performance indicator of interest to increase transit ridership.

- A local government may seek an increase in property and sales tax revenues and increased revenues from leases through economic development as well as state regulatory compliance through transportation concurrency. Attracting economic development depends on transportation accessibility and a performance indicator of interest is roadway level of service for both accessibility and concurrency.

- A land developer seeks a profitable development, which depends upon many things, including transportation accessibility and location of the development. Performance indicators of interest include roadway level of service and other transportation services that may attract buyers and tenants.

- All the aforementioned stakeholders must pay attention to the concerns and preferences of individual citizens who vote, pay taxes, spend money and patronize the transportation system. Individual citizens, according to the tenets of microeconomics, will act rationally to pursue their self-interests by continually adjusting to the incremental (marginal) benefits and incremental (marginal) costs of their actions. Results desired of the transportation system by individuals are numerous, including safety, security, reliability, speed, economy, comfort and status. These may be rated differently in importance by individuals. Chosen travel behavior of individuals will optimize their desired results based on performance indicators such as travel time.

Per the requirements of the scope of this study, primary focus will be upon the performance indicator of increasing transit ridership, with some emphasis on reducing vehicle trips and reducing vehicle miles traveled. This is with the recognition that positive performance as measured by these indicators will only be present insofar as it results in meeting the needs of travelers. Borrowing from microeconomic concepts, according to Anderson and McChesney (2003), individuals are the preferred units of analysis, recognizing that it is individuals who evaluate, choose and act. Collective action is comprised of individual preferences and actions shaped by constraints and conditioned by rules for aggregating individual preferences and actions. Likewise, this study focuses upon what travelers actually do (positive rather than normative) based upon the empirical evidence. As Haddock (2003) recognized, prospects are poor for a normative policy formulated in ignorance of its positive underpinnings. 


\section{Characterizing the Larger Context in which TOD Functions Well}

In the absence of definitive studies demonstrating causality and the strength of relationships among influencing factors, for TODs that are generally considered successful, observation and experience suggest numerous preconditions. The following is a brief overview of knowledge about TOD that has guided practice.

\section{Varying Goals for TOD Will Determine How Success is Measured}

The previous section highlighted how the goals of varying stakeholders translate into different performance indicators. However, transportation goals might not be the priority of the power brokers and funders who make the TOD possible and for whom the success of the TOD is financial in nature. Regardless that a TOD may effectively increase transit ridership, if the development operates at a loss, investors will disappear and the TOD will not remain to support transit. Therefore, a practical discussion of how TOD appears effective for increasing transit ridership cannot ignore non-transportation considerations but treat the endeavor in its totality. For example, the New Jersey Transit Oriented Village Initiative, coordinated by NJDOT, seeks not only to increase transit ridership, but recognizes how this relates to economic revitalization and growth of housing stock as major goals (Wells and Renne, 2004).

The institutional environment can have a profound impact on TOD feasibility. For example, joint development is the term commonly used to describe a partnership between a transit agency or local government that owns transit property, and a private developer who builds the TOD. This public-private partnership can result in better design connectivity between transit stations and adjoining buildings or development above transit agency property in the form of negotiated air rights.

\section{TOD Will Not Shift Mode Share Without Good Quality Transit}

No matter what the land use provisions - the best possible TOD can be in place-but if there is poor transit service, the land use qualities will never provide sufficient influence to shift mode share to transit. Basic viability of a transit system to attract ridership depends on its capacity to serve enough people at one time to meet the TOD's demand. Transit must be provided both near one's trip origin and destination, at or near the times required. Information on using the transit service must be available (Phillips and Guttenplan, 2003). Beyond viability and in order for people to choose transit over single occupancy vehicles, transit must be able to effectively compete with the coverage, reliability, speed, convenience, and comfort of driving a car. The size and connectivity of the transit system are necessary elements for high ridership. The more that transit provides coverage across the region and connectivity between origins and destinations, the greater the potential ridership. For example, Washington, D.C. has the highest rail capture rates on record, and also has the most extensive rail network of any system in recent generations. However, availability of transit service is not enough. The service must provide both higher frequency (shorter headways) and greater duration (early morning, peak hour, midday, evening and late evening service) throughout the day and week. Travel time by transit, including the time it takes to get to the station/stop, must be competitive with travel time by car. Transit vehicles must run at faster speeds than car traffic because of the extra time added to stop 
and pick up passengers. Usually this can only be achieved by dedicating separated guideways for transit, such as a rail, busway, or a high occupancy vehicle lane. Fifteen-minute transit headways begin to approximate the convenience of driving a car. Direct connections with minimal need for transferring are critical. Liu et al. (1998) found that the necessity to make an intramodal transfer (such as from one subway line to another) during a trip decreases a traveler's willingness to use transit. The necessity to make an intermodal transfer (such as from bus to rail) causes an even more pronounced decrease in a traveler's willingness to use transit. Beyond these essential features, transit must also compete with the automobile in safety and security, passenger amenities, attractiveness, comfort and privacy. The application of bus rapid transit (BRT) in Florida urban areas may hold some promise in narrowing the service gap between transit and private automobiles.

In addition to ridership, development along a transit corridor ideally creates conditions of a balanced bi-directional flow during both peak and non-peak periods, to maximize transit efficiencies. This means trip origins and destinations at every stop, which include as fine a grain of mixed uses as the market can bear. This supports transit trips not just for work, but also school, shopping, personal business and recreational trips throughout the day.

\section{Urban Spatial Structure Affects How Transit Can Provide Regional Access}

Porter (1997) discusses the necessity of an urban spatial structure that provides a compact form and having a discrete number of significant employment centers in the region that generate bidirectional flows on the transit system. In other words, it is not enough to have one or two TODs but a network of TODs is needed. He explains the importance of employment and residences concentrated in transit corridors, with particular attention given to locating residents near stations linked to employment centers.

\section{Incentives to Drive One's Private Automobile Must Be Removed}

Just as importantly, TOD's ability to shift mode share away from use of the private automobile toward greater transit ridership depends also on the absence of incentives to drive alone. In order to sway motorists from their cars, there must be some combination of the following: absence of idle highway capacity, absence of freeways, absence of parking availability and low priced or free parking at work sites, and absence of cheap fuel. Recent case studies have demonstrated that large improvements in transit market share require both incentives to ride transit, as well as the lack of incentives to use private automobiles. Strategies that focused solely on improving the level or quality of transit service were generally unsuccessful at achieving a marked mode shift to transit. Case studies showing clear transit ridership gains also demonstrated circumstances that removed incentives for private vehicle use, specifically parking unavailability, limited urban freeway capacity and congestion sensitive road pricing. Individuals generally spend between ten and 40 percent of their annual household budgets on private automobile transportation in addition to property investments in homes with parking. One TOD cited as a success story is the Village at Overlake Station in Redmond, WA, which combines good quality TOD, good quality transit service and affordable housing. Its success lay in providing service to those households who cannot afford cars. In the case of lower-income persons, the relatively high cost of driving is a strong disincentive. Charles River Associates (1997) concluded that: 
The auto ownership decision dominates the mode choice hierarchy. Because the decision to own (or lease) a vehicle is so central to the entire choice process, and because this process is ultimately driven by lifestyle choices that are increasingly making the private vehicle ownership decision a "given" for many people, automobile users need more than an incentive to use transit. Put simply, they need a strong incentive not to drive.

While parking unavailability is almost always politically difficult, it is more easily achieved in dense downtowns, where commercial space replaces parking. However, as work locations continue to move to the suburbs, space to provide parking on suburban parcels is abundant. Shiftan et al. (2002) suggest that automobile restraining policies, such as parking unavailability, actually move businesses out of center city and contribute to sprawling development patterns that are difficult for transit to serve. Until the price to build in the suburbs reflects its true costs, urban flight will continue to be a risk.

Government policies are critical to TOD success, mainly parking availability, location and pricing of public parking facilities. Surveys of workers in the San Francisco Bay Area near BART stations showed that 42 percent of station-area residents who had to pay for parking where they work commuted by rail, whereas only 4.5 percent of station-area residents who received free parking commuted by rail. Porter (1997) provides a detailed listing of local government policies and actions that support TOD in 19 cities in the U.S. and Canada.

\section{Mode Shift to Transit Requires Proper Placement and Design of TOD}

First, there must be an achievement in creating the TOD as a destination or place where people want to spend time. This is discussed by Dittmar and Ohland (2003) as a resolution of the tension between the role of a transit station providing access to a regional transportation network and another crucial role of the development surrounding the transit station in providing a vibrant, attractive place to work, recreate and live. There is tension because both roles have features that are at odds with each other but a successful TOD reconciles this role conflict.

Cervero et al. (2004) describe four major physical features that provide location efficiency. First, land development residential density and commercial intensity is required, compact enough for customers to easily walk or bicycle to transit stops. In Arlington County, Virginia, data from 1985 to 2002 show that ridership increases as dwelling units, office and retail space near transit station areas increase. Second, a rich mix of land use choices must provide the needed services and amenities so that residents and employees can conveniently internalize trips without the need for an automobile. Third, there must be centrally and conveniently located transit stations and stops. The farther away a land use is from transit, the lower the ridership. In metropolitan Washington, D.C., for every 100 -foot increase in walking distance from a transit station to a residence, ridership fell 0.65 percent. While the influence of weather and parking availability is not known, data from the San Francisco Bay area, San Diego, and Sacramento showed that ridership fell by 0.85 percent for every 100 -foot increase in walking distance. Fourth, the network of streets and walkways must be scaled to the convenience and comfort of the pedestrian. This includes direct, well connected, safe, and visually interesting sidewalks without 
any gaps or major barriers. Transit share plunges, even within one-quarter mile of the transit station, if there are considerable physical, symbolic, or psychological barriers to walking. Ewing (1996) developed for the Florida Department of Transportation (FDOT) a detailed discussion and check list for physical design features, ranked according to those features that are absolutely necessary ("essentials"), those features that are important ("highly desirables"), and finally those features that are not critical but greatly enhance the walking environment ("nice additions”).

\section{Marketability of TOD for Non-Transportation Reasons is Crucial}

While TODs are generally criticized for offering housing opportunities primarily to the affluent, a small number of TODs include affordable housing, such as Center Commons in Portland. Some motivations for including affordable housing are to create an instant market for the transit service as well as to secure affordable housing loans. As identified by Hendricks (2002), affordable housing development projects in Florida can be profitable.

Even though low income persons own fewer automobiles than middle and upper income persons, they still own some cars, and these cars take a bigger percentage of total personal income. Low income persons have the most to gain financially by being able to discard their cars and so it would seem that this would be an effective incentive not to drive. Good TOD and good transit may offer a solution. Can low income persons be more easily persuaded to delay buying cars or to dispense with their cars? Is targeting low income persons effective in eliminating peak period SOV travel? Is it a good solution? Gardenhire and Sermons (2001) found that while higher income households exhibit a bias toward higher automobile ownership, low income households convert income to automobiles at twice the rate of higher income households. The study found that low income households respond just as poorly to the available transit service as do higher income households. The authors concluded that the mobility solution for lower income households is not to improve transit access but to improve access to private automobiles. However, it is pointed out here that the variables defining transit service in the study were only three, including access to any form of transit, access to rail, and distance to the nearest transit stop. Conditions surrounding these three transit-related variables are not fully characterized and could represent a wide range of service quality, from excellent to poor. It is suspected that low income households in the Gardenhire and Sermons study did not respond well to the available transit service simply because the transit service was ineffective. If transit service fails to provide transportation from desired origins and destinations, then low income persons will not squander their scarce resources on transit service simply because it costs less.

It is unlikely that a developer can create a TOD that provides the mix of attractive housing and commercial opportunities to capture would-be suburbanites, and at the same time provide affordable options for the existing base of transit users. More likely, TODs must be developed for distinct markets.

Table 1 is a taxonomy of existing and potential transit riders that constitute market segments. It illustrates the likely decisions made by those seeking a new residence and illustrates where the opportunities lie. The far left column describes TOD with various combinations of attributes. For simplicity, combinations of just three attributes were selected; however, these three are considered to be those that provide the pivotal quality by whose presence (or absence) will 
determine whether a person of a particular profile will choose to live there. These qualities are parking availability, transit service quality and affordable housing. The top two rows of the table describe different groups of transit riders. To those concerned with the effectiveness of TOD, the interest is primarily in showing new riders. There are three main groups. The two columns under Group 1 are existing transit riders, meaning they were already riding transit before a decision to move to a TOD. Group 1 are "self-selecters" and are often discounted in a discussion of TOD effectiveness to improve transit ridership. In the Table, self-selecters are further divided into low-income transit riders and non-low-income transit riders. The remaining columns are transit riders that began riding transit only after having moved to a TOD. Groups 2A and 2AA are new transit riders who intentionally moved to the TOD because they want to ride transit and these two columns are distinguished from each other by income. Groups 2A and 2AA are also considered self-selecters. Groups 2B and 2BB are new transit riders, divided by income, who moved to the TOD for other reasons and with initially no intention to ride transit. These last columns are perhaps the profiles of transit riders of most interest because they represent that segment in which some elements of land use may have more likely influenced their decision to ride transit. 
Table 1: Taxonomy of Transit Rider Profiles and TOD Qualities Resulting in Transit Ridership

\begin{tabular}{|c|c|c|c|c|c|c|}
\hline & \multicolumn{2}{|c|}{$\begin{array}{l}\text { Group 1: } \\
\text { Existing Transit Riders }\end{array}$} & \multicolumn{2}{|c|}{$\begin{array}{l}\text { Group 2: } \\
\text { New Transit Riders (self-selecting) }\end{array}$} & \multicolumn{2}{|c|}{$\begin{array}{l}\text { Group 2: } \\
\text { New Transit Riders (not self selecting) }\end{array}$} \\
\hline TOD with... & $\begin{array}{l}\text { 1A: Existing transit } \\
\text { rider (self-selecter), } \\
\text { low income }\end{array}$ & $\begin{array}{l}\text { 1B: Existing transit } \\
\text { rider (self-selecter) }\end{array}$ & $\begin{array}{l}\text { 2A: New transit } \\
\text { rider, moves to TOD } \\
\text { with intention to } \\
\text { ride transit, low } \\
\text { income }\end{array}$ & $\begin{array}{l}\text { 2AA: New transit } \\
\text { rider, moves to TOD } \\
\text { with intention to } \\
\text { ride transit }\end{array}$ & $\begin{array}{l}\text { 2B: New transit } \\
\text { rider, moved to } \\
\text { TOD initially for } \\
\text { reasons other than } \\
\text { transit, low income }\end{array}$ & $\begin{array}{l}\text { 2BB: New transit } \\
\text { rider, moved to } \\
\text { TOD initially for } \\
\text { reasons other than } \\
\text { transit }\end{array}$ \\
\hline $\begin{array}{l}\text { 1. Ample parking, } \\
\text { Good transit }\end{array}$ & $\begin{array}{l}\text { Will be priced out } \\
\text { of market }\end{array}$ & Can afford TOD & $\begin{array}{l}\text { Will be priced out of } \\
\text { the market }\end{array}$ & $\begin{array}{l}\text { This is a higher } \\
\text { income tenant }\end{array}$ & $\begin{array}{l}\text { Will be priced out } \\
\text { of the market }\end{array}$ & $\begin{array}{l}\text { This is a higher } \\
\text { income tenant }\end{array}$ \\
\hline $\begin{array}{l}\text { 2. Ample parking, } \\
\text { Underdeveloped } \\
\text { transit }\end{array}$ & $\begin{array}{l}\text { Will be priced out } \\
\text { of the market, low } \\
\text { performing }\end{array}$ & $\begin{array}{l}\text { Tenant will not } \\
\text { choose to live here }\end{array}$ & $\begin{array}{l}\text { Will be priced out of } \\
\text { market, Tenant will } \\
\text { not choose to live } \\
\text { here }\end{array}$ & $\begin{array}{l}\text { Tenant will not } \\
\text { choose to live here }\end{array}$ & $\begin{array}{l}\text { Will be priced out } \\
\text { of market }\end{array}$ & $\begin{array}{l}\text { Tenant will choose } \\
\text { to live here, low } \\
\text { performing }\end{array}$ \\
\hline $\begin{array}{l}\text { 3. Ample parking, } \\
\text { Good transit, } \\
\text { Affordable housing }\end{array}$ & $\begin{array}{l}\text { Ideal for 1A, } \\
\text { expensive for } \\
\text { developer and } \\
\text { municipality }\end{array}$ & $\begin{array}{l}\text { Tenant will not } \\
\text { choose to live here }\end{array}$ & $\begin{array}{l}\text { Ideal for 2A, } \\
\text { expensive for } \\
\text { developer and } \\
\text { municipality }\end{array}$ & $\begin{array}{l}\text { Tenant will not } \\
\text { choose to live here }\end{array}$ & $\begin{array}{l}\text { Ideal for 2B, } \\
\text { expensive for } \\
\text { developer and } \\
\text { municipality }\end{array}$ & $\begin{array}{l}\text { Tenant will not } \\
\text { choose to live here }\end{array}$ \\
\hline $\begin{array}{l}\text { 4. Ample parking, } \\
\text { Underdev. transit, } \\
\text { Affordable housing }\end{array}$ & $\begin{array}{l}\text { Affordable, low } \\
\text { performing, } \\
\text { subsidized housing }\end{array}$ & $\begin{array}{l}\text { Tenant will not } \\
\text { choose to live here }\end{array}$ & $\begin{array}{l}\text { Affordable, low } \\
\text { performing, } \\
\text { subsidized housing }\end{array}$ & $\begin{array}{l}\text { Tenant will not } \\
\text { choose to live here }\end{array}$ & $\begin{array}{l}\text { Affordable, low } \\
\text { performing, } \\
\text { subsidized housing }\end{array}$ & $\begin{array}{l}\text { Tenant will not } \\
\text { choose to live here }\end{array}$ \\
\hline $\begin{array}{l}\text { 5. Limited or no } \\
\text { pkg., Good transit }\end{array}$ & $\begin{array}{l}\text { May be priced out } \\
\text { of market }\end{array}$ & $\begin{array}{l}\text { Can easily afford } \\
\text { TOD }\end{array}$ & $\begin{array}{l}\text { May be priced out of } \\
\text { market }\end{array}$ & $\begin{array}{l}\text { Tenant will choose } \\
\text { to live here }\end{array}$ & $\begin{array}{l}\text { May be priced out } \\
\text { of market }\end{array}$ & $\begin{array}{l}\text { Tenant will not } \\
\text { choose to live here }\end{array}$ \\
\hline $\begin{array}{l}\text { 6. Limited/no pkg., } \\
\text { Underdeveloped } \\
\text { transit }\end{array}$ & $\begin{array}{l}\text { May be priced out } \\
\text { of market, low } \\
\text { performing unless } \\
\text { completely } \\
\text { walkable } \\
\text { community }\end{array}$ & $\begin{array}{l}\text { Tenant will not } \\
\text { choose to live here, } \\
\text { low performing } \\
\text { unless completely } \\
\text { walkable } \\
\text { community }\end{array}$ & $\begin{array}{l}\text { May be priced out of } \\
\text { market, low } \\
\text { performing unless } \\
\text { completely walkable } \\
\text { community }\end{array}$ & $\begin{array}{l}\text { Tenant will not } \\
\text { choose to live here, } \\
\text { low performing } \\
\text { unless completely } \\
\text { walkable } \\
\text { community }\end{array}$ & $\begin{array}{l}\text { May be priced out } \\
\text { of market, low } \\
\text { performing unless } \\
\text { completely } \\
\text { walkable } \\
\text { community }\end{array}$ & $\begin{array}{l}\text { Tenant will not } \\
\text { choose to live here, } \\
\text { low performing } \\
\text { unless completely } \\
\text { walkable } \\
\text { community }\end{array}$ \\
\hline $\begin{array}{l}\text { 7. Limited/no pkg., } \\
\text { Good transit, } \\
\text { Affordable housing }\end{array}$ & $\begin{array}{l}\text { Ideal for 1A, } \\
\text { Efficient for } \\
\text { developer and } \\
\text { municipality }\end{array}$ & $\begin{array}{l}\text { Tenant will not } \\
\text { choose to live here }\end{array}$ & $\begin{array}{l}\text { Ideal for } 2 \mathrm{~A} \text {, } \\
\text { efficient for } \\
\text { developer and } \\
\text { municipality }\end{array}$ & $\begin{array}{l}\text { Tenant will not } \\
\text { choose to live here }\end{array}$ & $\begin{array}{l}\text { Tenant might not } \\
\text { choose to live here }\end{array}$ & $\begin{array}{l}\text { Tenant will not } \\
\text { choose to live here }\end{array}$ \\
\hline $\begin{array}{l}\text { 8. Limited/no pkg., } \\
\text { Underdeveloped } \\
\text { transit, Affordable } \\
\text { housing }\end{array}$ & $\begin{array}{l}\text { Affordable, low } \\
\text { performing }\end{array}$ & $\begin{array}{l}\text { Tenant will not } \\
\text { choose to live here }\end{array}$ & $\begin{array}{l}\text { Tenant will choose } \\
\text { not to live here }\end{array}$ & $\begin{array}{l}\text { Tenant will not } \\
\text { choose to live here }\end{array}$ & $\begin{array}{l}\text { Tenant might not } \\
\text { choose to live here }\end{array}$ & $\begin{array}{l}\text { Tenant will not } \\
\text { choose to live here }\end{array}$ \\
\hline
\end{tabular}


The following is a description of hypothesized transit rider profiles comprising Table columns.

- Column 1A describes the majority of transit riders in Florida.

- Column 1B describes transit riders who choose to do so and these represent examples from older and/or larger cities as well as where there are successful TODs.

- Column 2A describes the pent up demand for good quality transit and TOD and the market that might demonstrate greatest potential for new transit riders.

- Column 2AA might describe those individuals who want to make a lifestyle change because their personal values include a strong environmental ethic and are willing to take risks and bear some personal inconvenience for the sake of "doing the right thing”. This idealistic group is likely a small but consistent percentage of the population. The primary stumbling block in attracting and retaining this group is lack of good quality regional transit service, which can be done effectively only in areas of high density, urban infill, etc. Middle and higher income markets move to a new residence for more living space, excellent schools, safe child-friendly environment, etc. The environmentalists will move to a TOD of limited parking if they can access these remaining amenities.

- Column 2B represents low income persons who move to TOD for reasons other than proximity to transit. This is likely one of the larger groups of transit riders among Group 2 because the majority of low income households have cars and there may be any number of other reasons to move into the TOD, not the least of which may be the availability of affordable housing, proximity to extended family or proximity to a job.

- Column 2BB represents individuals who move into the TOD due to qualities other than proximity to transit. They later discover and use transit service. The primary stumbling block in attracting and retaining this group is lack of adequate land development density surrounding the TOD.

The following is a description of TOD profiles comprising Table rows.

- Row 1 describes a very expensive TOD with both good quality transit and ample parking. It is high performing with respect to transit ridership, caters to high income tenants and is typically only found in affluent sections of large older cities, such as Manhattan.

- Row 2 describes a TOD that is perhaps typical of that found in Florida, with underdeveloped transit service and ample parking.

- Row 3 describes a rarity, with ample parking, good transit and affordable housing, this scenario is costly to the developer and to the city.

- Row 4 describes a TOD that might be found in Florida, with ample parking, underdeveloped transit service, and affordable housing. Because low income households tend to have access to cars, this would be a poor performing TOD with respect to transit ridership.

- Row 5 describes the ideal for a middle income market, with limited parking and good quality transit. An example of this was not found in Florida.

- Row 6 describes a TOD with limited parking and underdeveloped transit. Conceptually, this may fit the intent of a Multimodal Transportation District in 
Florida, where the pedestrian environment has highest priority. The closest example of this might be Winter Park.

- Row 7 describes a scenario ideal for the lower income market, with limited parking, good quality transit and affordable housing; however, this is also not typical of Florida communities due to an affordable housing shortage coupled with good quality transit. There is typically underinvestment in low income communities.

- Row 8 describes a place where no one would want to live because it provides limited or no transportation service.

The twelve shaded cells in the Table are of most interest. The following is a description of these cells, identified by cell (row, column).

Cells $(1,1 \mathrm{~B})$ and $(5,1 \mathrm{~B})$ describe what good TOD exists; however it is not generally found in Florida. Cell $(1,1 \mathrm{~B})$ is more like Manhattan and cell $(5,1 \mathrm{~B})$ is more like Portland. Cell $(7,1 \mathrm{~A})$ would be ideal for lower income but is less easily found due to statewide and nationwide chronic affordable housing shortages and underdeveloped transit services.

Where affordable housing can be found, underdeveloped transit is usually the case. Cell $(4,1 \mathrm{~A})$ describes this scenario, which is the most likely found in Florida comprising most transit ridership. Note this is also an area where transit service is still underdeveloped and where the term "captive riders" comes from because these are riders who use transit only because they have no choice.

The above four cells, $(4,1 \mathrm{~A}),(7,1 \mathrm{~A}),(1,1 \mathrm{~B})$ and $(5,1 \mathrm{~B})$ represent existing and potential transit ridership that is generally discounted from evaluation of TOD's ability to increase transit ridership because these represent self-selected riders.

Turning our attention to scenarios that represent new transit riders, cells (1,2AA) and $(1,2 \mathrm{BB})$ describe affluent TODs where there is potential success for attracting new transit riders. These represent TODs where the right combination is happening and should be emulated in places where there is an affluent market. Regarding cell (1,2BB), the only situation where there is a new transit rider who initially did not intend to use transit is where there is already both good transit and ample parking because the tenant will have initially sought out a residence that has ample parking. Transit access was not their initial reason to move to the TOD, so the TOD has to appeal for other reasons. On the other hand, the rule of thumb for TOD is to limit parking, because ample parking will kill all motivation to use transit except where parking is scarce at the trip destination; however, the TOD needs to provide parking to attract these affluent would-be transit riders. This conundrum describes the difficulty of attracting new riders.

Cell (2,2BB) describes what may be happening in some Florida TODs, where there is ample parking and underdeveloped transit, but the development has other redeeming qualities that make people choose to live there for reasons other than riding transit. This type of TOD will be expected to perform poorly in attracting new transit riders. 
Cells $(4,2 \mathrm{~A})$ and $(4,2 \mathrm{~B})$ describe lower income TOD that has ample parking and underdeveloped transit. This may be typical of Florida lower income housing and will be underperforming because we know that lower income households do their best to have access to a car in localities where transit service is poor. Nonetheless, cell $(4,2 \mathrm{~A})$ describes a low income household that wants to get rid of its car and is willing to ride transit to economize. Cell $(4,2 \mathrm{~B})$ describes a low income household that moved to the TOD for reasons other than using transit, then discovered transit later as a way to economize.

Cell (5,2AA) represents where a more promising opportunity lies in attracting those individuals who want to discard their cars and ride transit. This TOD will attract middle income persons. It will have limited parking and good quality transit. This is the type of TOD for which municipalities and developers should aim. This would be a small but sure market.

Cells (7,2A) and (7,2B) described the ideal for lower income households. These represent existing urban infill areas in typical Florida cities that begin to approach the densities needed to potentially support transit. If we invested in our downtown and urban areas, this would produce potentially the greatest return on investment in terms of transit ridership. However, politically, investment dollars typically do not flow as readily to lower income areas. One of the conclusions drawn from the New Jersey Transit Village Initiative, where housing is expensive, is that incentives need to be developed to encourage the inclusion of middle-income and family-sized units in new housing developments. Household diversity may be lost as a result of zoning decisions based primarily on generating tax revenue.

Cell $(7,2 \mathrm{~B})$ is somewhat less likely to ride transit simply because they might not choose to live in this TOD. These are individuals not looking initially to ride transit, and so they will be looking for a place to park a car. This TOD would have limited parking and might not attract as many tenants in the first place.

The Table shows that developers should tailor build different TODs for distinct markets based on income. Would-be suburbanites will not move to a lower-income urban infill TOD. The Table describes three markets, high income (Row 1), middle income (Row 5) and lower income (Row 7), but this is surely an oversimplification and shown for illustrative purposes only.

The Table also shows that the TOD generating potentially the highest rate of new riders is where good quality transit, affordable housing and limited parking come together. Investment in lower income neighborhoods requires political will.

Lastly, the marketability of TOD to some customer base is crucial to its success. Those who question the ability of TOD to shift mode share to transit commonly cite "selfselection" as the main reason for finding larger percentages of transit riders within walking distance of TODs. These transit riders were already riding transit before they worked in or moved to the TOD, meaning less net increase in transit ridership as a result 
of the physical characteristics of the TOD. Individuals who did not previously ride transit but who moved to a TOD for the purpose of accessing transit are also considered self selecters. In other words, it was a prior conscious decision on their part to use transit rather than some physical element of the TOD attracting them to do so. Cervero et al. (2004) argue that this is not necessarily a bad sign but an indication of the sorting by markets that take place in pursuit of desirable places to live and work. Studies have shown an overall higher percentage of transit ridership generated from development near transit stations, demonstrating the marketability of TOD.

\section{Incentives to Use Transit Can Make a Difference}

Unless transit already provides a higher level of service than the private automobile, it is generally not enough to have a network of well-placed TODs with good design and high quality transit serving it. Additionally, government and individuals alike have made large investments in the highway system. Many governments provide plentiful and free parking. Businesses provide free parking for employees. Alternatively, carefully tailored incentives offered by individual employers, business improvement districts, property managers and regional commuter assistance programs can effectively tip the balance away from private automobile use, especially for certain segments of the population (Hendricks, 2004). These include some combination of transit subsidies provided to home buyers, tenants and employees, guaranteed emergency ride home services, preferential parking for vanpools, staggered work scheduling to correspond to transit scheduling and others. The Trip Reduction Model and Manual (Winters et al., 2003) was developed to gauge the effectiveness of various combinations of trip reduction incentives as provided by employment sites. The model shows that various combinations of incentives at employment sites can make significant differences in shifting private automobile drivers to transit.

Another example of an institutional condition is the set of business practices that can encourage or thwart the market for TOD and transit use. For example, Lund et al. (2004) found that California workers who live near rail found that taking transit to work varied dramatically according to whether employers allowed them to flex their work schedules to accommodate transit service schedules. Other business practices include employer provided transportation benefits. Subsidized transit passes encourage transit ridership; subsidized parking discourages ridership.

This section has provided a brief overview of the contextual factors that affect the success of TOD to shift mode share toward transit. The next section discusses more in depth the role of the physical features of the TOD itself and what research has found with regard to the explanatory power of various elements to shift mode share. 


\section{Literature Review on How Urban Form Affects Travel Behavior}

An assessment by Boarnet and Crane (2001) conclude that much is still not known about the relationship between travel behavior and urban form. This assessment specifically holds true for the effectiveness of TOD. A review of the research indicates that this relationship is like a giant jigsaw puzzle. Research has found some but not all of the pieces. We also do not yet know how all these pieces fit together. Not only is the state of knowledge about the land use/transportation relationship still growing but the personal values and the cultural, political and social factors that underpin travel behavior continue to evolve, with many undergoing historic trend reversals (Polzin et al., 2003a). Consequently, defining these changing factors can be accomplished through dynamic modeling, discussed later as a potential application of future results from later phases of this study.

Literature reviews and syntheses are a first step in most research designs. Ewing and Cervero (2001) conducted a literature review and synthesis of 50 recent empirical studies on how the built environment affects travel demand and found that transit mode choice was among those components most extensively studied. They conclude that of all travel variables, mode choice is most affected by local land use patterns. Ewing and Cervero's study also characterizes the difficulties inherent in defining the land use/travel behavior relationship. For example, the inability to control for other variables confounded their attempts to prove pedestrian-friendly site level features (commonly characterizing TOD) were significant to mode choice.

Boarnet and Crane (2001) note that earlier research regarding the influence of urban form on travel behavior was conducted for the purpose of predicting travel flows for given land use patterns. They observe that more recent research has become prescriptive-how to influence travel behavior by manipulating urban form. Alternatively, Handy (1996a) categorizes research on this topic into two purposes. First, there are studies that attempt to quantify the extent to which auto travel can be reduced. Second, there are studies that explain how variables affect auto travel. These include those that attempt to explain why individuals might choose to drive less or choose a travel mode.

\section{What We Think We Know}

The body of research literature about travel behavior, urban form, and TOD concludes that there is definitely some kind of relationship between land use and travel behavior. This tells us that there probably are opportunities to devise land use policies that can influence travel behavior. However, land use variables are likely not the strongest determinants. The effect of land use variables may be contingent upon the presence of other factors or their influence may be preceded in the travel decision making process by other considerations. While some empirical research studies net results that are inconclusive or that conflict with other studies, they still provide clues and useful insight to future study designs and directions. The summary below provides an overview of assertions made based upon evidence from reliable research processes. 
We know with a strong degree of confidence from data compiled by the previous Nationwide Personal Transportation Study (NPTS) and the more recent National Household Travel Survey (NHTS) that approximately 80 percent of all travel is nonwork related. Non-work travel is poorly understood. Boarnet and Sarmiento (1996) conclude that the link between nonwork automobile travel and land use is weak. One caution regarding this conclusion is that it is predicated on certain definitions of land use. Land use is defined in terms of variables measuring densities for population, total employment, retail employment, service employment and prevalence of a grid street pattern within a study participant's residence characterized by four-way intersections. These aspects of land use may or may not be key factors in affecting travel behavior or they may be too generally defined or measured in too aggregate a form to correspond with the characteristics near to a study participant's residence. Are the variables reliable proxies for land use policies that reduce travel costs, as is the focus of their study? Boarnet and Sarmiento caution that their participant sample was taken from an auto-dependent area where few other travel modes existed.

Boarnet and Sarmiento (see also Crane and Crepeau, 1998) observe from their results that some features intended to reduce travel might actually stimulate it, such as the increased access that a grid street system provides. Boarnet and Sarmiento also concluded that land use variables are endogenous to residential location choice. In other words, people choose residential location (such as a TOD or suburbia) based upon their desired travel behavior. Monocentric urban models assume that residents trade off land prices with accessibility to a work place location. Choosing cheaper land farther from activity centers will result in a longer commute. Residential location and commute costs are chosen simultaneously in such models. Boarnet and Sarmiento argue that more complete models of travel behavior should treat land use characteristics near to study participants' residences as endogenous variables and both residential location and work place location as endogenous choice variables.

\section{Land Use is Likely Less Important Than Other Factors}

Land use may be less important than other factors in affecting mode choice, number of vehicle trips and vehicle miles traveled. Hanson (1982) used a step-wise regression procedure that indicated socioeconomic factors explained more of the variation in travel behavior than did spatial characteristics. Likewise, results of linear regression equations used by Kitamura et al. (1994) suggested that the models associating neighborhood characteristics to travel behavior explained only a small portion of the overall variation. Other researchers found a host of other factors affected travel behavior. For example, Handy (1996b) found that trip purpose affects travel behavior. Cao et al. (2005) found that utility walking trips should be distinguished from recreational walking in transportation models because factors that influence the two differ. Pedestrian travel is important to an investigation of TOD because transit use relies on a supportive walking environment. They found that a predetermined desire to walk for utility has more explanatory power than elements of the built environment. Cao et al. also found that elements that reduce utility walking are the presence of young children, being female, older age, higher income and full-time employment status. Handy and Clifton (2001) found evidence that utilitarian walkers enable themselves to walk to meet their travel 
needs by residential location choice and not by factors of the built environment. Bagley and Mokhtarian (2002) found in their analyses that attitudes and lifestyle variables had greatest impact on travel demand among all explanatory variables, including land use related variables. Cervero (1993) found evidence to suggest that proximity to transit was a stronger determinant of transit use by TOD residents than land use mix and quality of walking environment. However, Ewing et al. (1994) found that good accessibility is not enough to induce residents to switch from auto to non-auto modes but it does reduce vehicle trip distances. Cervero et al. (2004) later concluded that decisions to use transit are explained or "nested" within earlier decisions to choose home location, work location, and whether to own a car. Jonnalagadda et al. (2001) found that automobile availability has a major influence on the choice of motorized versus nonmotorized or transit versus nontransit modes of travel. Where there are more workers than automobiles in a household, the higher the probability that workers choose non-automobile modes. They found that the greater the household size, the greater the tendency to rideshare.

In addition to mode choice, the number of trips taken by individuals in a population also influences the level of traffic congestion. Kulkarni (1996) found evidence that the number of trips made by travelers is explained more by income than by land use. In Florida, the Department of Transportation (FDOT) District IV Office (1995) conducted a study to investigate the effect of multi-use site design on trip generation and internal trip capture. The results are relevant to this study because in Florida there are few TODs but rather other more prevalent forms of development that contain elements of a TOD, including "new towns" and multi-use developments. The study found that a high percentage of internal trips were observed at all six multi-use sites included in the study. However, there appeared to be little effect on daily vehicle trip generation rates for the multi-use sites overall. All but one of the sites included residential units.

Two recent studies addressed the question regarding increases in transit ridership over time as areas with TOD and transit mature. Polzin and Page (2003b) found little evidence of transit ridership increases in light rail transit "new start" systems in the last two decades that could be associated with system maturity, transit-friendly synergies, or even self-selection. Lund et al. (2004) conducted a study of TOD in California following up a study by Cervero (1993) ten years before. They also found little evidence of an increase in transit ridership due to the maturation of TODs. Their results suggest that elements found to be significant to transit ridership are self selection, flextime offered by employers at the work site, no free parking offered at the work site, service improvements that increase speed of transit, and pedestrian connectivity at the destination end of a trip.

Trip chaining, or the linking of trips has been a topic of interest to several researchers who suspect that trip chaining influences other decisions regarding travel behavior. For example, Jonnalagadda et al. (2001) found evidence that trip chaining affects mode choice. In their study of TOD, Niles and Nelson (2001) suggest that access to retail is a motivation for a significant portion of trip chaining. McGuckin and Murakami (1999) documented that trip linking or chaining is a standard element of travel behavior and there are also gender differences in travel behavior. Women chain trips more than men. Approximately 28 percent of women's weekday work-to-home trips and 43 percent of 
women's home-to-home trips are characterized by two or more stops. And yet, as noted earlier, women tend to walk for utility purposes less. The willingness to walk is an important element of TOD. Liu et al. (1998) simulated transit system performance under various scenarios of intermodal and intramodal transfers and found that the necessity to make a transfer on a transit line can substantially reduce transit ridership and the reduction is greater if it is an intermodal transfer. Jonnalagadda et al. (2001) found that the incorporation of tour characteristics, such as the number of stops, is found to have a significant impact on mode choice, which is unaccounted for in traditional models. Driving alone is preferred when stops are required.

Studies show that transit mode share is higher in TODs; however, there is debate whether the transit riders are self selecting, meaning whether they were riding transit before they moved to the TOD and so there is no net gain in mode share for transit. As a result of this, some studies estimate that mode shift to transit may be overstated by as much as 40 percent. However, other researchers say that self selection is good because it concentrates persons who want to live and work in a TOD setting. This maximizes the likelihood that the TOD will be a financial success.

\section{Land Use Does Play Some Role in Affecting Travel Behavior}

While land use characteristics as found in TOD may not be the deciding factor in influencing travel behavior, land use characteristics do play some role in influencing travel behavior. Boarnet and Crane (2001) assert in their review of neighborhood design features that the only element that reduces car trips and vehicle miles traveled, with proven causality, is traffic calming. Parsons Brinckerhoff Quade and Douglas, Inc. (PBQD,1993) found in their well-known Land Use Transportation Air Quality (LUTRAQ) project in Portland, Oregon that pedestrian oriented design is positively associated (causality not claimed) with reduced automobile use. While Schwanen and Mokhtarian (2005) explored the influence of personal preferences on travel distance and mode, they concluded that the built environment does play some role in possibly shaping and at least constraining a person's travel preferences. Frank and Pivo (1994) suspect that different aspects of urban form are significant predictors for different types of trip characteristics (mode, trip purpose, trip length, etc.) and these relationships are nonlinear. Consistent with this supposition, Handy (1996b) found in her study of pedestrian decision making that elements of the built environment play a greater role in walking for utility than for recreation. Cao et al. (2005) found that after self selection, factors that demonstrate an association with utility walking are characteristics of the destination, such as destinations of interest, walking distance and walking safety relative to vehicular traffic.

While Cervero (1993) earlier concluded that proximity might play a greater role in transit use, Ewing and Cervero (2001) later claimed evidence to support that transit use depends primarily on local densities and secondarily on the degree of land use mixing. They also computed travel demand elasticity values to account for the effects of higher densities, mixed land uses and pedestrian-friendly designs on vehicle miles traveled and vehicles trips. They found that while the typical elasticity values for each variable are not large in absolute terms, these values are significantly different from zero in most cases. When 
summed across the factors of regional accessibility, density, land use mix and design, these values suggest fairly large cumulative effects on travel demand.

What goes on outside the TOD can have an impact on travel behavior within the TOD. Handy (1993) recognized that the scale at which geographic characteristics are taken into account in research affects the characterization of the land use/travel behavior link. Especially for non-work trips that are longer than a few miles, characteristics of land use at the regional level affect travel behavior. More specifically, Cervero and Gorham (1995) found evidence to suggest that mode split depends not only on characteristics of the neighborhood but also on the character of the larger region. Likewise, PBQD (1993) observed that pedestrian-friendly neighborhoods surrounded by auto-oriented neighborhoods do not reduce auto travel as much as pedestrian-friendly neighborhoods that are surrounded by pedestrian-friendly neighborhoods.

\section{Urban Form Characteristics Requiring Further Insight}

Attitudes and perceptions of travelers have gained more recent attention as a potential strong influence on travel choices than elements of urban form and socioeconomic characteristics. For example, Kitamura et al. (1994) found evidence to suggest that land use may be a proxy for attitudes that determine residential location and subsequently travel behavior. However, researchers have also continued to explore and identify areas not sufficiently understood with regard to the relationship between urban form and travel behavior. A summary of these topics follows.

\section{Qualities of Urban Form}

- Qualities outside and adjacent to the TOD influence transportation performance within the TOD (Handy, 1993). Related to this is the TOD's transportation performance contingent upon the strength of access to a regional network of other TODs. Most generally expressed, a TOD does not operate in a vacuum and understanding a TOD's regional context is essential. Niles and Nelson (1999) argue that regional impacts achieved by a TOD are the more important measure of effectiveness yet require many more conditions to be met.

- Most people will not walk farther than $1 / 4$ mile to a destination. The urban design challenge is putting enough desired destinations within a short walking trip to facilitate walking. Most TODs as we know them in the United States do not succeed in doing this. (Boarnet and Crane, 2001)

- We do not know very much about how urban design affects trip chaining (Boarnet and Crane, 2001)

- Boarnet and Crane (2001) believe the key question is how urban form and land use design change the price of travel.

- Land use density is considered one of the essential elements of a TOD. However, Kuzmyak et al. (2003) suspect that density may be a proxy for other attributes. This raises questions about whether researchers are accurately identifying what they seek to measure. 
- The grid street system has commonly been considered important to increase pedestrian accessibility; however, it has also been shown to increase auto trips (Crane and Crepeau, 1998). This points to the possibility that some features of urban form may be effective to reduce vehicle trips only if they are present in combination with other features.

\section{Transit Quality}

- TOD has generally been identified as a land development strategy that works well only in the presence of rail and not bus transit. However, these assumptions are not proven. The right type of bus service offers advantages and possibilities, especially for Florida urban areas. For example, bus rapid transit can rival the time advantages of rail and driving in congested areas and is far less expensive to build. At least one study of the transit system in Chicago suggests that bus service is not necessarily less permanent than rail. Its lack of rigidity can be an advantage as bus service has more flexibility for route deviation and can serve dispersed areas.

\section{Travel Behavior}

- The nature and influence of non-work travel with respect to urban form is still poorly understood. For example, Boarnet and Crane (2001) ask how urban design influences non-work car trip speeds and distances. This is considered key to influencing a change in mode share.

- Niles and Nelson (2001) identify the need for more information about trip purposes and locations as a means to better assemble land uses. Part of this includes better understanding travelers' flexibility with regard to the locations where they stop for nonwork purposes in commute tours. They suggest doing this by geocoding the extent of route deviation in commute tours and location of stops relative to work and home.

- Niles and Nelson (1999) also conclude that retail structure strongly affects travel behavior, which is an association generally overlooked in travel behavior research.

\section{Study Methods}

- It is suggested that land use measures must be refined to correspond more closely to the various ideas that have been proposed in policy circles. Different levels of detail should be tested in empirical research and more instrumental variables and larger sample sizes would increase confidence in the statistical results. (Boarnet and Sarmiento, 1996; Boarnet and Crane, 2001) 


\section{In-Depth Analysis Techniques Used to Evaluate TOD}

There is an absence of definitive answers about the relationship between urban form and travel behavior. Subsequently, policy implementers have had to proceed using a number of quick techniques to provide "guesstimates". These techniques inform developers and planners how to develop a successful TOD based upon the best available information used within the real-world time constraints imposed by market forces and regulatory processes. Niles and Nelson (2001) summarize these to include structured discussion, which is simply a gathering of knowledgeable parties to talk about the issues. Visual simulation, using computer-generated images, is also a technique for better anticipating a development project outcome. Case studies are commonly used to learn from the interpreted experiences of others if the circumstances are transferable. Economic estimation is also identified by Niles and Nelson. Examples of these include the computing of travel demand elasticities by Ewing and Cervero (2001), discussed previously, and an estimation of the number and cost of TODs needed to accommodate new growth (Downs, 1994). Niles and Nelson also identified sketch planning, which is an abbreviated version of the commonly used four-step transportation planning process. Lastly, Niles and Nelson recommended an additional approach that has been used in Europe, which they call "Backcasting Delphi". This is a combination of the Delphi technique, which is a consensus building process accomplished in iterative steps. The Delphi technique is combined with the characterization of a desired future, then backing up to the present and identifying what policies must be in place to create that future.

While these techniques have been used for practical application, they fail to answer the underlying questions and concerns that policy makers have with regard to the impact of TOD on travel behavior. Of interest to this study are the travel behavior elements of mode selection, number of vehicle trips and length of vehicle trips. Policy makers commonly would like to see evidence that TOD shifts mode share away from SOV and toward transit, reduces the number of vehicle trips and reduces the length of vehicle trips. There are many vocal advocates of TOD and as many transportation professionals who raise serious doubts about TOD effectiveness. Transportation researchers have attempted to address these root concerns through several research designs discussed next. It is clear that no one approach can answer all questions raised. Each type of research design has strengths and weaknesses. Multiple approaches tend to complement each other and each adds a piece to the puzzle. Rather than deductive approaches, known methods applied to this topic have been empirical, which are those that attempt to understand relationships based upon the collection and analysis of data representing observed behavior.

\section{Study Methods}

The transportation profession tends to place greater credence in quantitative research methods, rather than qualitative. While quantitative research methods have many strengths, qualitative methods should not be dismissed. Qualitative methods include case study analyses that have been used extensively in the social sciences. Properly conceived case studies are a research method for attempting valid inferences from events outside the laboratory. For example, research continues at present, with one of the latest efforts 
including a follow-up study to Cervero's "Transit-Oriented Development in America: Experiences, Challenges, and Prospects”. Funded by the Transit Cooperative Research Program, the research method will use a case study approach on 20 locations of TODs to better determine their transportation performance. This study will include the involvement of the Institute of Transportation Engineers and the Urban Land Institute with preliminary results anticipated in 2007.

Case studies are used, as opposed to other research methods (such as experiments, surveys and archival histories) when three general conditions are met as explained by Yin (1984). First, we want to learn how or why something is happening. Second, the investigator has little control over events. Third, the focus is on contemporary events within circumstances that affect the outcome of those events (context). A study of TOD meets all three of these conditions and would lend itself well to the case study approach; however, case studies require rigorous adherence to its methodology to be more than anecdotal. Handy (1996a) recommends the use of qualitative methods to better understand the role of urban form in shaping travel behavior because the low explanatory power of existing models suggests there is much more to learn. Activity-based travel models also contain qualitative elements. Qualitative methods provide a strong exploratory foundation for specifying hypotheses.

\section{Simple Tests of Correlation}

More commonly, the study of the relationship between elements of urban form and travel behavior have used statistics, which are summary values calculated from a sample of observations. The most basic analysis involves the calculation of frequencies. The discussion below summarizes those procedures used where specifically applied to our topic of interest.

Simple tests of correlation have been used in the study of travel behavior. There is sometimes confusion between correlation and causality in interpretation of results. While two or more parameters move in parallel, the one is not necessarily causing the others. For example, many land use studies rely on density as the main measure of urban form but while there is correlation between density and travel behavior, is does not explain all observed travel behavior. Density may be standing in for and covering up the effects of a number of other more specific attributes that typically appear with higher densities. Simple tests of correlation do not demonstrate causality but rather some degree of association or relatedness. For example, Kitamura et al. (1994) used factor analysis to group responses to attitudinal questions into a smaller group of composite attitudinal factors. These factors were placed into estimated models and found to be strongly associated with travel characteristics, more so than neighborhood characteristics. Handy and Clifton (2001) used chi-square tests to explore the relationship between household accessibility to commercial activity and mode share for non-work trips. Chi-square tests can be used to test the association between two classifications (classifier variables) of a set of counts or frequencies. This two dimensional arrangement is commonly displayed as a contingency table or cross classification where rows represent one variable and 
columns represent the other. The null hypothesis is that there is no association between the two variables.

Handy (1993) also used the two-by-two matrix of comparisons to test the link between urban form and travel behavior in four neighborhoods representing various combinations of high and low local accessibility and high and low regional accessibility. The two-bytwo or fourfold contingency table represents two classifications of a set of counts or frequencies. The rows represent two classifications of one variable (e.g. outcome positive/outcome negative) and the columns represent two classifications of another variable (e.g. intervention/no intervention).

\section{Linear and Multivariate Statistical Analysis}

Regression models analyze the relationship between an explanatory variable and an outcome variable while controlling for the effects of other variables. The linear regression model applies only to cases where the dependent variable is continuous. Analysis of variance (ANOVA) techniques are a set of statistical methods used to compare the means of two or more samples. ANOVA techniques are a special case of general linear regression. Ewing et al. (1994) used ANOVA techniques to test the significance of variation between communities and within communities for travel characteristics including mode share. Kitamura et al. (1994) estimated linear regression equations for the number of person trips, number of transit trips and non-motorized trips, and mode share for auto, transit and non-motorized trips. The results suggested that the models associating neighborhood characteristics to travel behavior explained only a small portion of the overall variation. Hanson (1982) used a step-wise regression procedure to estimate equations for trip frequency by purpose. For trip distance, spatial factors were placed into the equation and the significance of socio-demographic factors was tested. The analysis indicated that socioeconomic factors explained more of the variation than did spatial characteristics. Frank and Pivo (1994) estimated multivariate regression equations with mode share as the dependent variable and urban form variables and average socio-economic variables as independent variables. Cervero and Gorham (1995) used negative binomial regression to analyze the relationship between built environment variables, self-selection and socio-demographic characteristics. A negative binomial regression is where there is a count outcome, such as the number of times something has happened. Multinomial logit regression has a nominal outcome, which represent more than two categories that are not ordered, such as different modes of transportation. In most studies, variation in travel behavior is still largely unexplained after the variables of land use, urban form and transportation are incorporated into regression or logit models.

Past research has used modeling to explain and predict travel behavior. These models are developed based upon the premise that if we know these relationships, we can control or influence various factors to bring about a desired outcome. Once we have a highly specified model, the precision aids our understanding of what needs to be done. Transportation planners want to know which combinations of elements, of particular magnitudes, combined in some order over time within various specified contexts, will reduce the need to travel and/or shift travelers out of private cars and into transit. The 
appeal of this approach is to create a model that simply requires specification and a precise understanding of the relationships among variables. The challenge of this approach is that there are a large number of interactive variables, which are difficult to control for in specifying the model.

\section{Simulation Studies}

Simulation studies have been used to test the outcomes of models. These models apply some assumed relationship between land use and travel behavior to test a particular land use arrangement or street network design. For example, the traditional "four-step" planning process includes the steps of trip generation, trip distribution using the gravity model, modal split and traffic assignment to the transportation network. Typically for travel forecasting, simulations incorporate assumptions about trip generation based on existing trends. Other scenarios are based on a manipulated future, such as changes in the transportation network, changes to transportation services, changes in assumptions about population and employment growth, and changes in urban form characteristics.

\section{Travel Choice Models}

Travel choice models predict the probability of an individual choosing a particular alternative based on the utility of that alternative relative to others. Travel choice models incorporate elements of urban form implicitly, such as using travel costs and destination attractiveness as measures of utility. Not many travel choice models have been developed; however, Cervero and Duncan (2002) used a nested logit analysis to study the impact of self selection (earlier decisions) on travel behavior with respect to TODs. Lund et al. (2004) applied a mode choice predictive model to test for self-selection. This was a disaggregate best fitting regression in the form of a binomial logit model. Also known as binary or dichotomous, this tests for a discrete choice or when the result is only one of two mutually exclusive outcomes. Handy (1996a) predicts that travel choice models will lend insight into the way urban form affects travel behavior because elements of urban form influence the travel choices that are available. A travel choice model might be a good option for exploring Boarnet and Crane's (2001) hypothesis that if urban form and land use design change travel behavior, they do so by changing the price of travel.

\section{Activity-Based Models}

Like travel choice models, fewer activity-based models have been developed. Activitybased models are those that attempt to better understand travel in its activity context. The models recognize behavioral factors that the traditional four-step planning process does not. They also have the capability of incorporating the effect of household interaction upon the individual traveler. Because previous research suggests the possibility that attitudes and perceptions play a stronger role in travel behavior outcomes, activity-based models may better contribute to our understanding. Activity-based models are more descriptive, favor elements of qualitative analysis, and hold the possibility for yielding more holistic results. Handy (1996a) suggests the development of activity-based models for the exploratory stages of quantitative studies as well as the final stages of studies in 
validating quantitative relationships that have been found. Activity-based models are derived from nested logit structures representing daily activity chains. They incorporate activity generation, destination and mode choice into decision making. Decisions that affect travel behavior can be shorter term, such as the decision to purchase a monthly transit pass, or longer term, such as the choice of work location. These kinds of decisions are accounted for in activity-based models.

Jonnalagadda et al. (2001) developed a microsimulation activity-based model for the San Francisco County Transportation Authority. This approach has many advantages over traditional four-step travel forecasting models, particularly with respect to destination choice and mode choice. The model has been shown to be useful in practical planning applications. This tour-based approach is disaggregate in both estimation and application, allowing the incorporation of many socioeconomic variables. The mode choice models determine the mode for tours and also for all trips made as part of tours. The mode choice models are the basis for an accessibility measure (logsum) used in the tour destination choice models. This approach provides interaction between trip distribution and mode choice by incorporating logsums from mode choice, which capture the utility of travel, considering all available modes as opposed to use of only highway travel time as in traditional models. The logsum from the mode choice model is the logarithm of the sum of the exponents of the individual modal utilities, which are the travelers' perceptions of the level of service characteristics of the various modes. Jonnalagadda et al. developed two sets of mode choice models. The tour mode choice model determines the primary mode for the tour. The trip mode choice model determines the mode for each individual trip made on the tour on the basis of the mode chosen for the tour. Each tour purpose has its own tour and trip model. Thirteen combinations of modes were defined and coded for trip mode choice model estimation, such as "autoBART-walk". Tour modes were defined to allow the traveler to switch between modes where such behavior is most common. However, an analysis of the combinations of modes that occur on tours indicated that just one mode is used for most tours. Where there is a combination, much of the mode-switching on tours occurs in modal combinations that include walking or automobile passenger with transit.

The researchers developed a synthesized population for every resident in San Francisco by randomly drawing from the Public Use MicroData Sample (PUMS). PUMS has been developed to meet the data demands for greater characteristic detail and greater geographic specificity. They are available from the Decennial Census and the American Community Survey. The PUMS data is available in two sets of files. The first set provides a fuller range of detailed characteristics, in which the minimum geographic population threshold must be above 100,000. This is the one percent national characteristics file. The second PUMS set provides greater geographic detail but less characteristic detail, in which the minimum geographic population threshold for the collapsed variables must be 10,000 to maintain confidentiality. These are the 5 percent state files. While the PUMS data were adequate for their study, a greater level of data specificity and detail would be useful. Axhausen (2000) notes that one of the challenges of developing activity-based models is the development of suitable data sets in content, quality and duration. Future data collection must reflect individual choices in scheduling 
activities as well as the process of spatial learning, in order for activity models to be developed.

\section{Dynamic Travel Models}

Many want to better understand the causal relationships that may exist between land use and travel behavior as the key to policy making that may influence mode share. What we have learned from the body of previous research is that the relationship between urban form, land use, TOD and travel behavior is complex, currently not well understood and is dependent on a number of other interacting socioeconomic variables, choice variables and perhaps other variables that researchers have not yet identified. These variables are set in motion and sustained by the ongoing chain of decisions made by individual travelers. Dynamic models are usually applied to studies of travel time functions, taking into consideration changing levels of traffic congestion over time. Dynamic models of travel behavior might provide an augmented source of travel forecasting information under various scenarios, including those providing different land use arrangements, such as TOD. A dynamic model needs longitudinal data to be constructed. A panel survey of data recorded at the individual and household levels would be most useful in developing dynamic models.

This has been a discussion of analytical methods where they have been specifically applied to defining the relationship between urban form, elements of land use, TOD and travel behavior. In summary, qualitative case study analysis is more difficult to do well than quantitative analysis. It requires rigorous adherence to methodology in order to rule out rival hypotheses and establish multiple sources of evidence. Simple tests of correlation are useful for establishing association but fall short of determining causality. Regression analysis has been used most extensively with the challenges of controlling for a large number of variables that are likely interactive. Simulation is only as strong as its underlying assumptions. Travel choice models, activity-based models and dynamic models all hold promise but are data intensive. There is a need to develop data sets that are suitable in content, quality and duration. Dynamic models require longitudinal data. Before discussing more in-depth about the topic of data, the next section provides an overview of the several issues of measurement that must be considered in an investigation of TOD's impact on travel behavior. 


\section{Issues of Measurement}

This section identifies several difficulties researchers experience in the study of the impact of TOD on travel behavior. The discussion below explores the challenge of defining TOD, including physical attributes, size and location. The discussion proceeds from there with an examination of defining elements of travel behavior, defining what TOD effectiveness means, selecting the timing of measurement, isolating the effects of the variable of interest, ensuring generalizability of results to the broader population, and data availability.

The first hurdle in evaluating TODs is simply finding examples to study. Belzer and Autler (2002) and Niles and Nelson (2001) cite the difficulty of finding developments to study that adequately approximate the TOD concept. In measuring the success of TOD, researchers have resorted to comparing older neighborhoods that approximate TOD with conventional suburban neighborhoods. TODs are different one from another, which generates special challenges in drawing comparisons. TODs that have a residential emphasis are necessary within a region in order to shift mode share to transit. There are especially few TODs with an adequate residential component. As Boarnet and Crane (2001) explain, residential-based TODs often are not supported by municipalities because they yield less property tax revenues than TODs with predominantly commercial land uses. Examples of regional networks of TODs, which enable examination of how TODs function within a larger system, are fewer still.

In addition, the availability of TODs for study partly depends on how they are defined. It also depends on whether part of the adopted definition of TOD includes success at increasing the overall proportion of travelers using transit (i.e., if it is not successful, then it is not a TOD).

\section{Defining TOD}

Definitions of TOD range from references merely about the physical infrastructure and extend to discussions of the social fabric inherent in "community." A TOD can be new construction or redevelopment. One planner for a Florida community commented that TODs are more difficult to build as redevelopment than as the clean slate of a greenfields development. However, extending a new service out to a new town holds more challenges than strengthening existing transit service to redevelopment. Other definitions differ in their specificity of density/intensity as well as land use mix. For example, according to some agencies, a TOD can be virtually any development, while others specify that it must be moderate to high density, and either primarily housing or mixed use. For planning purposes, definitions for TOD should not necessarily be the same because various municipalities may use the concept for different purposes and objectives. However, while it is thought that "We all know what we mean" when referring to TOD; there is disagreement about what constitutes TOD success. Part of the cause could be labeling a real estate project a TOD even though it does not possess the critical elements or those elements are not developed sufficiently for success. 
Table 2 below contains several definitions of TOD, developed primarily by transit agencies, which show a range of emphases and specificity. None of the variations in definition appear directly in conflict and they all focus on related themes. While perhaps suitable for planning purposes, this illustrates the necessity in a research design that attempts to isolate cause and effect to look beyond the composite concept of TOD to specify particular attributes. It also recognizes that any communication of the results must reference specific attributes rather than using the term "TOD" because transportation professionals define it differently.

Table 2: Variations in TOD Definition from a Sample of Sources

\begin{tabular}{|c|c|c|c|}
\hline What & Where & Result & How \\
\hline $\begin{array}{l}\text { Moderate and high- } \\
\text { density housing; } \\
\text { pedestrian-oriented } \\
\text { environment }\end{array}$ & $\begin{array}{l}\text { Located along transit } \\
\text { routes }\end{array}$ & $\begin{array}{l}\text { Encourages use of } \\
\text { public transportation }\end{array}$ & Location, Mix, Design \\
\hline A mixed-use community & $\begin{array}{l}\text { Within an average 2000- } \\
\text { foot walking distance of } \\
\text { a transit stop and core } \\
\text { commercial area }\end{array}$ & $\begin{array}{l}\text { Makes it convenient for } \\
\text { residents and employees } \\
\text { to travel by transit, } \\
\text { bicycle, foot or car }\end{array}$ & $\begin{array}{l}\text { TODs mix residential, } \\
\text { retail, office and public } \\
\text { uses in a walkable } \\
\text { environment }\end{array}$ \\
\hline Any development & $\begin{array}{l}\text { Proximate to a transit } \\
\text { facility }\end{array}$ & $\begin{array}{l}\text { Development benefits } \\
\text { from transit proximity; } \\
\text { generates significant } \\
\text { transit ridership }\end{array}$ & \\
\hline $\begin{array}{l}\text { Land development } \\
\text { pattern }\end{array}$ & & $\begin{array}{l}\text { Provides a high level of } \\
\text { mobility and } \\
\text { accessibility }\end{array}$ & $\begin{array}{l}\text { Land development } \\
\text { pattern supports travel } \\
\text { by walking, bicycling } \\
\text { and public transit } \\
\end{array}$ \\
\hline $\begin{array}{l}\text { A relatively high density } \\
\text { place with a mixture of } \\
\text { residential, employment, } \\
\text { shopping and civic uses }\end{array}$ & $\begin{array}{l}\text { Located within an easy } \\
\text { walk of a bus or rail } \\
\text { transit center }\end{array}$ & & $\begin{array}{l}\text { Development design } \\
\text { gives preference to the } \\
\text { pedestrian and bicyclist }\end{array}$ \\
\hline $\begin{array}{l}\text { High quality urban } \\
\text { environments }\end{array}$ & & $\begin{array}{l}\text { Attract and retain } \\
\text { ridership }\end{array}$ & $\begin{array}{l}\text { Carefully planned and } \\
\text { designed; provide for a } \\
\text { pedestrian-friendly } \\
\text { environment }\end{array}$ \\
\hline An environment & $\begin{array}{l}\text { Around a transit stop or } \\
\text { station }\end{array}$ & $\begin{array}{l}\text { Supports pedestrian and } \\
\text { transit use }\end{array}$ & $\begin{array}{l}\text { Provides a mix of land } \\
\text { uses in a safe, clean, } \\
\text { vibrant, active place }\end{array}$ \\
\hline Development & $\begin{array}{l}\text { Oriented to transit } \\
\text { service }\end{array}$ & $\begin{array}{l}\text { Influenced by transit } \\
\text { service }\end{array}$ & $\begin{array}{l}\text { Takes advantage of the } \\
\text { market created by transit } \\
\text { patrons }\end{array}$ \\
\hline $\begin{array}{l}\text { A sustainable, } \\
\text { economically viable, } \\
\text { livable community with } \\
\text { a balanced } \\
\text { transportation system }\end{array}$ & & & $\begin{array}{l}\text { Walking, biking, and } \\
\text { transit are as valued as } \\
\text { the automobile }\end{array}$ \\
\hline Projects & & Support public transit & $\begin{array}{l}\text { Enhance transit use, } \\
\text { improve the quality of } \\
\text { service provided to } \\
\text { transit riders or generate } \\
\text { revenue }\end{array}$ \\
\hline
\end{tabular}




\begin{tabular}{|l|l|l|l|}
\hline $\begin{array}{l}\text { Moderate to higher } \\
\text { density development, } \\
\text { generally with a mix of } \\
\text { residential, employment } \\
\text { and shopping } \\
\text { opportunities. New } \\
\text { construction or } \\
\text { redevelopment of one or } \\
\text { more buildings }\end{array}$ & $\begin{array}{l}\text { Within an easy walk of a } \\
\text { major transit stop }\end{array}$ & Facilitate transit use & $\begin{array}{l}\text { Designed for pedestrians } \\
\text { without excluding the } \\
\text { auto }\end{array}$ \\
\hline Projects & Near transit stops & & $\begin{array}{l}\text { Incorporate smart } \\
\text { growth principles: } \\
\text { reduced automobile } \\
\text { dependence, encourage } \\
\text { high shares of pedestrian } \\
\text { and bicycle access trips } \\
\text { to transit, foster safe } \\
\text { station environments, } \\
\text { enhance physical } \\
\text { connections to transit } \\
\text { stations from } \\
\text { surrounding areas, } \\
\text { provide a vibrant mix of } \\
\text { land use activities }\end{array}$ \\
\hline
\end{tabular}

Definition sources include: Community Green Line Planning Project, "Putting Neighborhoods on the Right Track", Chicago, December 30, 1994 and the California Planning Roundtable as compiled by the American Planning Association, "A Glossary of Zoning, Development, and Planning Terms, Planning Advisory Service, Report No. 491/492, Michael Davidson and Fay Dolnick, Ed., Chicago, IL, December 1999, p. 238. Definition sources also include those from transit agencies as compiled by Cervero et al., "Transit Oriented Development in America: Experiences, Challenges, and Prospects”, Transit Cooperative Research Program, Transportation Research Board, National Research Council, Washington, D.C., January 2004 p. 7 and as adopted by the California Department of Transportation.

Numerous guidebooks and manuals have attempted to develop physical standards for density, pedestrian access, building orientation, distances between transit stops and transfer points, parking and other features. There also are numerous attributes of TOD that are more difficult to standardize. To give one example, a key variable that influences ridership, according to a handbook on transit-friendly land use by New Jersey Transit (1994), are transit stations that are "visible points of identity." The transit station must accomplish a sense of place. This is achieved by several hard to measure factors, including the presence of visual corridors that also link the station to landmarks. Other important factors include "sufficient" open space that surrounds and buffers the transit station and which is attractive, well-maintained and supports surrounding land uses and activities. Other factors include the presence of round-the-clock uses that provide activity and sense of security. Some of these variables can be measured by "presence/absence of" but the presence of one all-night diner will likely not provide these attributes. There is a point at which the quantity of such uses in some effective combination sustains activity and sense of security. This provides an example of the challenges in developing a starting point for identifying and quantifying quality. 


\section{TOD Definition by Size}

Another defining parameter has to do with the size of the development served by transit. While land developers sometimes like to market their development proposals as TOD, Deakin (2004) points out that one building does not make a TOD. Is it useful to have a size threshold above which a development can be considered a TOD? TODs usually are created as private real estate projects with sizes ranging from one building to one or more city blocks and even an entire new town.

\section{TOD Definition by Location}

Some definitions provide no information on location. Others specify location along a transit route or at/near/around a transit stop. TODs cited most often in the literature occur near rail stations but most definitions prefer to use the term "transit" to allow for the possibility of TOD at bus stations. Some perceive bus stops/stations as impermanent and rail stations as a safer bet that public investments will remain in place to serve over the life of a development.

Cervero and Duncan (2002) believe that the presence of rail may signal a higher level of transit service, given that exclusive guideway is generally more time-competitive with the private automobile than conventional bus services and provides regional mobility benefits, especially during congested peak periods. For example, FannieMae's Smart Commute Initiative determines eligibility for a location-based mortgage if the property is $1 / 4$ mile from a bus stop or $1 / 2$ mile from a rail station. However, given that much TOD has abundant parking, it is not clear that the presence of transit service is even an important factor, from the developer's or consumer's point of view, in the selection of a site or home, respectively. Parsons Brinckerhoff Quade and Douglas, Inc. (1996) has found that since the availability of private automobiles beginning in the 1950's, it appears that the presence of transit, whether rail or bus, has generally not been the deciding factor in locational decisions. Distances of development from the transit service vary with examples of a 2000 -foot walking distance, $1 / 4$ mile walking distance, and $1 / 2$ mile walking distance. Some distances are defined in terms of time, such as a 10-minute walk.

\section{Defining Elements of Travel Behavior}

Not only is it necessary to specify elements of land use that play a role in TOD effectiveness, but it is also necessary to specify elements of travel behavior. Deakin (2002) observes that there are wide differences in definitions of key variables, making it difficult to compare and transfer findings across studies and between research and application. Axhausen (2000) suggests that there is a need for standardization of definitions in the collection of travel data for the purpose of eliminating ambiguities in communication among researchers as well as to enable sharing of data and comparing study results. He proposes a set of definitions that break down and distinguish between a stage, trip, tour, journey and activity, as well as detailed characterizations of activity types by kind, purpose, meaning, greater context, duration, effort, cost and urgency. 


\section{Defining Success}

What type of success is being measured? The circumstances of one municipality's success with regard to TOD implementation might describe another municipality's failure, as it relates to economic revitalization, affordable housing opportunities, or as in the case of this study's interest, transit ridership. Examples include financial solvency, degree of profit, the value of partnering arrangements, transportation performance, affordable housing, economic revitalization, and creation of livable community. A TOD project may succeed in supplying much needed affordable housing with a boost to transit ridership - a win for the community, but if the enterprise lost money, the development profession may experience TOD as a failure and not attempt it again.

Some definitions of TOD provide no information on results. Other definitions provide "soft" results, such as being able to offer convenience and encouragement to use transit. Other definitions provide more concrete and quantifiable results, such as attracting and retaining ridership. Attributes are also described in various degrees of specificity, from providing qualities such as safety, cleanliness, vibrance and activity to more functional means of accomplishing results, such as land use mix, design, walkability and connectivity to station areas, improved quality of transit service and harnessing market influences. Some definitions emphasize how development benefits by proximity to transit while others emphasize how transit benefits from the development.

No definitions were found that distinguish between impacts on commute (trips to and from work) and non-commute traffic. However, discussions concerning traffic congestion usually focus upon commuter traffic, which is concentrated during specific times of day and is generally associated with operational conditions at or beyond roadway capacity. Using TOD to address traffic congestion gives it entree into the discussion as a tool to meet Florida's transportation concurrency requirements. However, in the arena of transportation demand management, more attention is being given to reduce non-commuter traffic as a way to reduce total vehicle miles traveled. According to the NHTS, 80 percent of trips are noncommute trips. Furthermore, in the City of Seattle, Hendricks (2004) found perceptions by employee transportation coordinators that some of the worst traffic congestion is not during workdays but on Saturday afternoons when people are using their cars to run errands.

Commute trips are often more conducive to using alternative transportation, such as public transit, because commute trips are usually predictable and routine, occurring the same times every day. However, people who are comfortable riding transit to and from work, may be less so for trips to take care of personal business, such as grocery shopping and doctor appointments. As a result, most transit riders are still automobile owners. Transit needs to attract noncommute trips to enable day-long service and accomplish bidirectional flow. This reaps advantages of cleaner air quality, less wear and tear on roadway facilities and reduced congestion at other peak times. It is known that lower vehicle ownership rates are associated with higher transit ridership. If TOD also addresses travel needs beyond commuter trips to also include personal business, then the need to own a car will decrease and transit ridership should rise. Niles and Nelson (2001) 
suggest that a TOD's success must be measured at both the regional and local level. At the local level, station area development can induce more pedestrian and transit trips.

Most municipalities, including those in Florida, do not attempt to define explicit measurable performance objectives with respect to TOD's effect on transportation. As a result, those who choose to evaluate the merits of a TOD may not recognize their own implicit assumptions about success and jump to a conclusion of failure. It may be tempting to compare the experience of a Florida city with other cities that have heralded TOD programs; however, Florida's development history, regulatory climate, regional economies and other factors make such comparisons not instructive if the conclusion is failure because Florida TODs are not duplicating the experience on a scale of, say, San Francisco or Washington, D.C.

We may also address magnitude of success. How much change is enough? Other issues that may provide some parameters for the study include a definition of what percentage mode shift to transit is considered significant. Such a percentage may vary based on perspective. For example, a three percent mode shift from SOV travel to transit may be considered successful by a local municipality for purposes of reducing traffic congestion on the road system. From the perspective of the transit system, the mode shift may have to be rephrased in terms of a ridership that is enough to sustain a transit route serving a TOD without unacceptable financial loss to the transit agency. A retail establishment in a TOD might define success based upon the number of customers created by transit ridership that generates profit.

How do we benchmark for cities in Florida? Cervero and Kockelman (1996) estimated, using 1990 Census data, that only 18 percent of station-area residents who lived in the three San Francisco area counties served by Bay Area Regional Transit (BART) commute to work by rail transit. Approximately 10 to 15 percent of residents and employees from a sample of functional TODs nationwide will use transit. While we must be reasonable in our expectations regarding magnitude of mode shift, it is also known that small changes can be highly beneficial in reducing traffic congestion.

A particular TOD may possess most of the conventionally agreed upon necessary elements, such as pedestrian-friendly design, good transit service connecting the TOD to the region, and good land use mix, intensity and activity. One key element might be missing, such as carefully managed parking, which can sabotage transit ridership levels. Does one missing element render the entire TOD effort a failure? In this particular case, yes; however, the lack of a key element should not discredit the entire concept. Rather, it was a failure of implementation. Future research on TOD such as Phase II, should focus on identifying what combinations of elements are necessary and sufficient.

In most discussions relating to transportation performance, the goals are improved air quality and highway congestion reduction, as measured by reduction in vehicle miles traveled and a shift of mode share away from private vehicle usage toward transit. In order for this to happen, some number of car drivers must experience transit as providing greater accessibility than automobile travel. Lower-income persons are sensitive to 
accessibility, time savings and cost. Middle- and higher-income persons are also sensitive to accessibility and time savings; however, they are less sensitive to cost and are more willing to pay for (and may require) amenities and conveniences. In this respect, TOD success depends on how well it meets the needs of a particular market.

TOD performance can be interpreted in opposite ways. For example, Podobnik (2002) conducted a study about the Orenco Station located within 1/2 mile of Portland, Oregon's Westside MAX light rail. Podobnik noted the continued reliance on single occupant vehicle travel for commuting but found that 18.5 percent of Orenco Station residents commute by public transit. This is better than the 5 percent average for the region. Podobnik also found that 69 percent of Orenco Station area residents use public transit more often than they did in their previous community. Over 85 percent of survey respondents reported that the close proximity of neighborhood businesses and amenities has reduced their need to drive elsewhere. However, Charles and Barton (2003) interpreted the results in the opposite way. They emphasized that despite Orenco Station's TOD qualities, 74 percent of its residents continue to use their cars only. The research suggests a consensus that TOD shows promising potential to slow the rate of growth of traffic congestion and increase mobility although performance of TODs has not matched high expectations. Does this make TODs successful?

In discussion about measuring TOD success, the concept of self selection frequently arises. Self selection refers to those individuals who had already been using transit before their association with a TOD. It also refers to those individuals who actively chose to work or live in a TOD because it offers transit service. Those who measure TOD's ability to shift mode share from private auto use to transit will discount self selecters in order to isolate the true effect of land use elements on travel behavior. However, the chronology of personal decision making works against a switch in travel mode to transit because auto ownership and parking availability are key factors in the success of mode shift to transit. If someone moves into a TOD with the initial intention to continue driving their private auto, they will already have made the decision to own an auto and will purchase a property that allows for sufficient parking. Since they already own a car, the likelihood of switching to transit is decreased. In the case where they already have a car and a parking space, the motivation to use transit would have to come from some other constraining factor, such as roadway congestion for which light rail or BRT provides a faster commute, or parking constraints at the destination.

Transportation practitioners who plan for TOD at the municipal level want clear "recipes" for density thresholds and other standards to guarantee support for transit investment. Research suggests that in Miami, for example, 23 residents or employees per acre are required to support the most basic bus service (Ewing, 1996). This is a threshold where auto dependence begins to give way to multimodalism; however, there is a complex interplay of market forces that TOD guidance, including FDOT's Pedestrianand Transit-Friendly Design: A Primer for Smart Growth (1996) cannot codify. Much debate and consideration has involved developing a definition of TOD, with the reasoning that we cannot measure and compare outcomes unless we establish specific criteria on what constitutes a TOD. There also is the counterargument that 
circumscribing TOD is unhelpful not only because it may disqualify some worthy projects from receiving financing, but also because the more important aspect in new development is demonstrating a trend toward improvement of features conducive to transit riding that were not present before. This is a more useful resolution to the question of defining TOD and is more responsive to evaluating Florida's changing development environment. This approach has been adopted for use as part of Phase II of this proposed study.

\section{Timing of Measurement}

Another issue of measurement relates to the maturity of the TOD and the transit that serves it; when does one measure effectiveness? How should researchers take into account real property life cycles and fluctuation of circumstances over time? A related issue involves the staging of the TOD project, particularly in reference to the timing in which residential, retail, office and institutional developments are completed and occupied, in relation to each other.

The more immediately the results are required, the more elaborate the orchestration of many factors to jump start performance. In some cases, mixed use developments proceed in phases that may take years until build out due to market forces. For example, there may be a brisk demand for multifamily housing but less so for office and retail space. New occupants of the housing will search outside the TOD for employment since the adjacent commercial opportunities are not yet available. Once the office and retail space is fully developed, years later, the housing/jobs balance in the TOD may not show high internal trip capture if residents have already established their employment elsewhere. It is not unreasonable to consider a time frame of 20 years or more after a development is completed to evaluate its success as a TOD. This provides the time for recovery from economic downturns, development infill in response to local policies and regulations, and for the TOD to develop an identity as an attractive destination within the larger region. Likewise, successful TODs, as with any type of development, may lose investors eventually due to a development's life cycle and the confluence of factors that are not entirely in any one entity’s control.

\section{Isolating the Effects of the Variable of Interest}

Perhaps the most difficult challenge in measuring the impact of TOD on public transit ridership is to isolate the effect of variables. For example, Ewing and Cervero (2001) cite the difficulty of isolating the effect of individual variables as they contribute to pedestrian-friendly qualities. Researchers observe and classify variables as exogenous or endogenous. Exogenous variables are those that might affect TOD performance but they are not a component of TOD. The price of fuel is an example. Exogenous variables can easily confound results and lead to incorrect conclusions about causative factors if they are not properly controlled in a study. Likewise endogenous variables can also confound study results if not properly separated out. They are factors within the TOD that affect TOD performance, such as land use mix. Endogenous variables can have interactive qualities that may influence the outcome at any one point in time. Research designs 
attempt to control for variables not of interest, such as stratifying according to household income, by establishing control groups. For example, Cervero and Gorham (1995) grouped matched pairs of study sites with similar socioeconomic characteristics, with the control group representing a site not related to TOD.

\section{Ensuring Generalizability of Results to the Broader Population}

By careful selection of individuals, households, or neighborhoods, attempts are made to compare units of study that are similar in one respect in order to control for that characteristic. This often has been done to control for socioeconomic characteristics, usually income. As more and more characteristics are controlled for, the sample size of measurable units that remains available to test quickly decreases. In anticipation of this result, sample size initially must be quite large in order to develop a study group and a control group similar enough in all aspects except the variable of interest. A second way to ensure generalizability is to select a random sample of the population that is of sufficient size.

\section{Availability of Data}

A final issue of measurement concerns the need for better data of sufficient amount, content, quality and duration. Kuzmyak et al. (2003) cites the concern that land use and travel behavior studies usually do not record enough kinds of data in sufficient detail to accurately describe whether an outcome is related to land use, transportation service characteristics or population characteristics. Data about land use characteristics and other types of data are limited due to cost constraints. A most recent study of the National Cooperative Highway Research Program (NCHRP) by Renne and Wells (2005) builds upon the New Jersey Transit Village Initiative and provided recommendations for developing a strategy to monitor the success of TOD. The study method employed a national survey of state and local government, metropolitan planning organization (MPO) and transit agency staff to determine, in the opinion of those surveyed, how they rate the usefulness of a comprehensive list of 56 different performance indicators identified for TOD, which illustrates the potential complexity of evaluating TOD. Survey participants were also asked to rate the degree of difficulty in collecting data for these indicators and how often their agency actually does collect data. These performance indicators were categorized into five groups, including travel behavior, economic, environmental, built environment, and social diversity/equity. Those travel behavior indicators that were rated most useful by at least 50 percent of survey respondents were pedestrian activity counts, number of transit boardings, number of bus, ferry, shuttle, or jitney services connecting to the transit station, number of parking spaces for residents and number of shared parking spaces. From this list of useful travel behavior indicators, at least 50 percent of survey participants rated just two of these as easy data to collect. These two indicators are number of bus, ferry, shuttle or jitney services connecting to the transit station, and the number of transit boardings. This research concentrated on those regions in the United States that were perceived to have significant experience with TOD. This did not include the Southeast. The study conclusions suggested the need for funding of TOD evaluation 
and a regular schedule for data collection at the local level with a state level database to establish baselines and track progress annually.

California is the location of numerous developments highlighted as TODs. The California Department of Transportation (2002) also identified the need for better data:

The lack of evidence documenting a track record of TOD as a successful development product is an obstacle in convincing stakeholders and bankers about the benefits of projects. And, the lack of accurate or up-to-date information on the potential benefits of TOD in shifting travel from the automobile to transit and non-motorized modes in local analysis tools (such as traffic models) has become a serious impediment to the broader implementation of TOD, infill development, and affordable housing that meets market demand. New or revised transportation analytical tools and data are needed to enable local and regional agencies to more accurately project the transportation performance of proposed TOD projects, as is required by CEQA [California Environmental Quality Act] and local development planning and approval processes. (pp. 143-144.)

There are differences between the statewide planning processes of California and Florida. However, the outcome is no different for Florida in its statutory requirements to engage the Development of Regional Impact (DRI) process for developments meeting size thresholds and having multijurisdictional impacts. Local governments must satisfy transportation concurrency requirements as well as for any size development resulting in greater than de minimus impacts. The challenge to Florida communities, as identified by Hendricks (2002), is posed by the DRI Application for Development Approval that instructs applicants to '...clearly document any estimate of mode split to transit or nonmotorized transportation...Change in mode split must be supported by the developer based on data collected on projects of similar intensity and use.'

The burden of proof is placed upon the underdeveloped alternative mode, to demonstrate a shift in mode split. The new project is not likely to be permitted to set a precedent, if projects of similar intensity and use that demonstrate a higher transit mode share cannot be found.” (p. 63) 


\section{Panel Surveys}

\section{An Overview of Data Forms and Collection Methods}

Data is collected in a number of different ways and this partly depends on the type of data needed. In a discussion of TOD, there are different categories of data, such as:

- Elements of urban form

- Socioeconomic

- Behavioral: attitudes, preferences

- Consumer utility (price, quality, variety) for transportation services and built environment

One decision that researchers make is at what level of disaggregation the data need to be collected in order to answer the study question. Handy (1997) describes the use of aggregate studies of TOD as those that compare average travel characteristics of population samples of a small number of communities with different land use designs. Sometimes researchers will aggregate factors into a composite variable. For example, Cambridge Systematics used principle components analysis to characterize work sites based on a set of five composite variables. PBQD also designed a study of TOD by developing an index of pedestrian factors composed of numerous characteristics. Aggregate studies have advantages. Data collection is usually easier and less expensive because the data is being collected at a level of lesser detail. Aggregate studies are the right choice if greater detail is unnecessary. However, generalized measures may proxy for other as yet unidentified influences. Deakin (2002) identifies numerous issues with regard to TOD research designs, including the use of aggregate studies based on a small number of cases. This places reliance on a very small sample. The averaging of data across cases may hide wide ranging variations. There also are problems of scale and aggregation level, where averages mask variations in characteristics. Aggregate studies are less equipped to provide information on how and why auto travel is reduced, which is what is needed to develop sound policy.

Disaggregate studies collect and analyze data on the scale of the individual traveler, to see how urban form affects travel choices. These studies use micro-level data collected to represent various cross sections of the population. Examples of disaggregated data include individuals, households, and elements of urban form unique to a household location, such as distance to a food store. Disaggregate studies are better suited to describing the complexity of individual travel choices. Handy (1997) recommends collection of a greater range of urban form variables at the disaggregated scale. Regional surveys should include larger samples in fewer selected areas.

One major difficulty occurs when mixing disaggregated data with aggregated data in an analysis, such as using travel behavior characteristics from surveys of individuals (disaggregate) to compare with urban form characteristics at the city level (aggregate). This is problematic because it does not faithfully recreate the situation where interaction 
between urban form and travel behavior is taking place. Therefore, results of such an analysis are difficult to interpret.

Other forms of data collection are event histories, panel surveys and surveys collecting cross sectional data. Most of the work done in travel behavior modeling uses cross sectional data, in which the data is a random sample of the larger population taken at one point in time. Alternatively, longitudinal data are necessary to identify and estimate dynamic processes. Van Wissen et al. (1991) observe that longitudinal data allow the estimation of model parameters conditional on non-observed stationary characteristics and variations in individual preferences. Panel surveys collect longitudinal data, which involves taking samples of data at several points across time. Retrospective surveys ask study participants to recall past travel behavior. The major drawback of this approach is the limited ability of participants to accurately remember. Prospective surveys collect data of travel behavior and preferences in the present. Panel surveys are an example of a prospective data collection regimen. The limitations of prospective surveys are the difficulties in controlling for changes over time, not only to the environment, but also aging and lifestyle changes of the participants.

Surveys are one of the primary methods of data collection for quantitative analyses of travel behavior. These are commonly in the form of mail-out surveys to randomly selected households in selected neighborhoods. Such surveys can collect socioeconomic data, travel characteristics, attitudes, perceptions and preferences. Household travel surveys including questionnaires on personal and household characteristics and travel diaries. Travel diaries have traditionally used booklets or journals where study participants make data entries.

\section{Panel Surveys}

One thing that is apparent from the research on travel behavior is that the collection of relevant, accurately measured, and sufficient travel data appropriate to the questions under study is a fundamental first step albeit an expensive one. In the case of travel behavior, surveys are most often used. They are also costly, time consuming and dependent on the willingness of study subjects to participate. Most travel surveys collect only one day or sometimes two days of travel data. Because of travel variations across days and weeks, a large data sample must be collected in order for the data to be representative of travel behavior as a whole. According to Long (1997), conventional travel demand forecasting practices based on cross-sectional data have potentially large systematic biases and low prediction accuracy. A retrospective survey also would be insufficient because individuals will not be able to remember each trip and mode for any period of time.

Alternatively, panel surveys are repeated measurements on the same sets of households or individuals over time, to study the effects of a particular event or change in conditions. The more robust panel surveys employ a control group that is not affected by the change. Panel surveys are different from other kinds of longitudinal surveys in that longitudinal 
surveys conduct periodic measurements on the same variables but different samples are drawn.

Raimond and Hensher (1997) note that panel surveys have the ability to capture behavioral changes over time in a level of detail that is necessary to unravel true causality. They note that panels can estimate net changes with greater accuracy than a repeated cross-section because the variance of change is reduced by a positive correlation of values between waves. Kitamura (1990) observes that measurement of gross change is another advantage of panel data in contrast to repeated cross-sections, which can only measure net changes in the level of a variable. He asserts also that by observing the same individuals across time, unobserved contributing factors are controlled for, enabling a better measure of behavior changes. Hsiao (1986) notes that panel data also provide a larger number of data points, increasing degrees of freedom and reducing collinearity among explanatory variables.

As noted earlier, panel surveys can capture dynamic changes in travel behavior and the factors that underlie those changes better than can conventional cross sectional surveys. In addition, panel surveys can collect changes in the variables themselves. As such, Long (1997) argues that panel surveys can help us understand how and why people choose to travel as they do as well as how their travel behavior may change in the future. Panel surveys have been used extensively in the social sciences but just a few have been conducted in transportation since the 1980s. They can be used to evaluate the impact of a change in the transportation system. In this case the changes include maturation of TOD and transit services. Panels can capture behavioral changes at a level of detail that can help us determine causality and forecast future changes. Kitamura (1990) notes that panels uniquely allow researchers to observe changes in travel-related behavior. Panels can relate those changes to contributing factors, including individual life stages and household life cycle.

Panel survey data also can enable the development of dynamic models for forecasting travel behavior changes by extrapolating longitudinal trends in the data into the future. Dynamic models compute changes in demand that may take place over time after changes in the environment can be forecast. The evolution of households and changes in household travel behavior can also be forecast because model components replicate decisions by the individual and the household as well as the chain of events that results in those decisions.

In the field of transportation, the Dutch National Mobility Panel (DNMP) has been the largest and perhaps the longest-running transportation panel conducted, beginning in the early 1980s. The Puget Sound Transportation Panel (PSTP) survey, begun in 1989, is one of the very few sources of longitudinal travel data available today in the United States. It was the first general-purpose transportation panel survey in the U.S. Other panel surveys in the U.S. have included the Southern California Transportation Panel and the San Francisco Bay Area travel survey, and those conducted in New York City and Montgomery County, MD for more narrowly focused purposes. 


\section{Data Quality Issues of Panel Surveys}

\section{Attrition}

Attrition is expected but the goal is to reduce it as much as possible. Attrition introduces non-response bias, which can compromise valid inferences from panel data. For example, in three different transportation panels in the U.S. and abroad, attrition levels were highest among households that were lower-income, single-adult households, less educated, childless households, and without cars (Golob and Meurs, 1986). As a result, special effort must be placed to reduce the effects of non-response bias. These efforts may include some combination of panel recruitment and refreshment techniques so that the panel remains representative of the population. Other efforts include the use of control groups, split and rotating panels and questionnaire design. A split panel is when a non-overlapping cross-sectional sample is run at the same time as a panel. Another potential problem is panel conditioning (also known as pre-testing), which occurs when respondents are affected in some way by participation in the survey, such as anticipating and supplying the "right" answer. This also can be addressed by the use of a rotating panel design or a split-panel survey. Panel stagnation arises when the panel is no longer representative of the population at large. This requires systematic refreshment of the panel with new survey participants.

Panel fatigue occurs when survey responses decrease or get sloppy due to participant boredom. To address fatigue, some researchers call for limiting the length of the survey period to the minimum necessary (Kitamura, 1990). The PSTP panel participants experienced some measurable panel fatigue, even with a 2-day diary. Meurs and Ridder (1997) recommend using first-wave diary data to separate repetitive from non-repetitive trips, to reduce biases resulting from respondent conditioning and fatigue. If there continues to be a need for pre-analysis data adjustments, applying a model of attrition behavior can also correct for bias, such as that developed by Brownstone and Chu (1997) or by Pendyala and Kitamura (1997) for the PSTP.

Florida transportation professionals may be able to benefit and learn from the welldocumented PSTP panel survey design and study results. There were three objectives of the PSTP, which collected travel data from participants in a four-county region. They were to monitor changes in household composition, location and employment characteristics; secondly, to monitor changes in travel behavior and responses to changes in the transportation environment; and thirdly to examine the effects of changes in attitudes on mode choice. The analysis of the data for waves 1 and 2 (years 1989 and 1990) by Murakami and Ulberg (1997) showed pronounced aggregate changes in household composition, employment location and residential location in just one year's time. They found that there was a general outward movement of households away from the region's center (downtown Seattle) and households with lower income and those that had increased in size had higher rates of relocation. Approximately 20 percent of panel participants changed employment location. For people who lived within the region but worked outside the region, the tendency was to get a new job closer to home. If they both lived and worked within the region, central city workers had more stable work locations 
than their suburban counterparts. A residential location change generally caused a greater change in work trip length; however, a work relocation to center city tended to decrease commuting distance while a work relocation to the suburbs tended to increase commuting distance. From waves 1 to 2, 85 percent of the panel participants continued to use the same travel mode. The greatest net shift in mode was from transit use to SOV. Those who changed mode tended to have just recently changed work location.

The PSTP used a two-day trip diary completed by each member of a household aged 15 years and older. These data were supplemented by periodic surveys of travel attitudes and perceptions. The PSTP was started in 1989 and now includes ten waves of data with the latest from 2002. According to the Puget Sound Regional Council, the first wave started with a sample of 1,712 participants. By wave ten, 264 of the original participants (15 percent) remained. To maintain the integrity of sample characteristics, study participation was refreshed with each new wave, by recruiting new respondents to maintain the total number of participants of like characteristics and to account for the inmigration of new individuals into the study area. The PSTP used household phone interviews and mail-out/mail back travel diaries as well as mail-out/mail-back surveys of perceptions and attitudes. 


\section{Puget Sound Transportation Panel (PSTP) Survey Design and Study Results}

\section{What We Can Learn from PSTP Attrition}

Survey analysts for the PSTP found patterns of those study participants who agreed to participate versus those who declined. Those who agreed tended to be younger, had more children, used transit more and had lived for less duration in their current county of residence. However, of those who agreed to participate, those who actually turned in a completed travel diary tended to be the reverse profile of those who had initially agreed. Participants who followed through were generally older, had fewer children, used transit less and had lived longer in their current county of residence. Attrition was also observed in the PSTP. During wave 2, 81 percent of the original participants responded. By year 10, just 15 percent of the original participants were still participating in the study. Murakami and Ulberg found patterns of attrition that were also found by Chung and Goulias (1995). They found that wave 1 participants who were more likely to participate in wave 2 had higher levels of auto ownership, higher levels of employment, and a longer term of residence. Those less likely to participate in wave 2 were lower income, singleadult households, childless households, and younger households. Especially since these attrition patterns were found in more than one panel study, it points to the need for compensatory actions to either balance the study sample through recruitment or conduct weighting analysis after the sample is taken to address sources of bias due to both initial non-response as well as from dropping out. These findings suggest that attrition is some times not random. Finding replacement households to refresh the panel is challenging. The goal is to find replacements that resemble the lost households as closely as possible. Murakami and Ulberg (1997) discuss options, such as the use of real estate transaction records, driver license records, motor vehicle registrations, new residential telephone service applications and new residents who move into dwelling units vacated by former panel members. 


\section{Should Florida Conduct a Transportation Panel Survey?}

Should Florida consider doing a panel survey of travel behavior? There are many methodological and implementation challenges with panel surveys. They are expensive and the pay-off is not immediate. Shouldn't the PSTP data, which represents regionally all individuals aged 15 and older within a household, be adequate for Florida planning purposes? Chu (2005) suspects that as the level of travel data disaggregation increases (moving closer toward the individual level), they become more transferable from one geographic area to another, because people make travel decisions in much the same way anywhere. The PSTP data was collected at the individual level within households, and so if Chu is right, the PSTP data should be generally transferable to urban areas in Florida. A basic principle of microeconomics in support of Chu's assertion and elaborated by Anderson and McChesney (2003) is that individuals will act rationally in their own best self-interest and this holds true for people everywhere throughout the world.

However, Murakami and Ulberg (1997) concluded that while the DNMP has made possible a large volume of research on public transportation policy, the data was not readily transferable to U.S. cities due to differences in transportation systems, travel behavior and household characteristics. This justified the implementation of the PSTP, which was funded by the U.S. Department of Energy and the Puget Sound Regional Council. Golob et al. (1997) also raise the question regarding the transferability of panel survey results from one urban area to another but do not offer an opinion. Instead, they devote an entire textbook to describing the multiple ways in which panel survey data are useful and recommend its consideration by urban areas. It is suggested here that the PSTP data, while derived from a U.S. city, may not be readily transferable to the Florida experience. While people are people no matter what city they live in and they may make travel decisions in a similar manner based on the marginal costs and marginal benefits of the available choices, it is possible that the personal decision making process is influenced in different ways by the unique circumstances of the region. Florida is different in many ways from the West Coast in terms of its transportation infrastructure, policy environment, development history, unique cultural influences, and socioeconomic and household characteristics. Florida's aging population is an outstanding example of this. Past modeling efforts suggest that the many variables that influence travel behavior are interactive. Individuals, based on their age, culture and household circumstances may make different cash savings versus time savings trade-offs because they may value these two resources differently. 


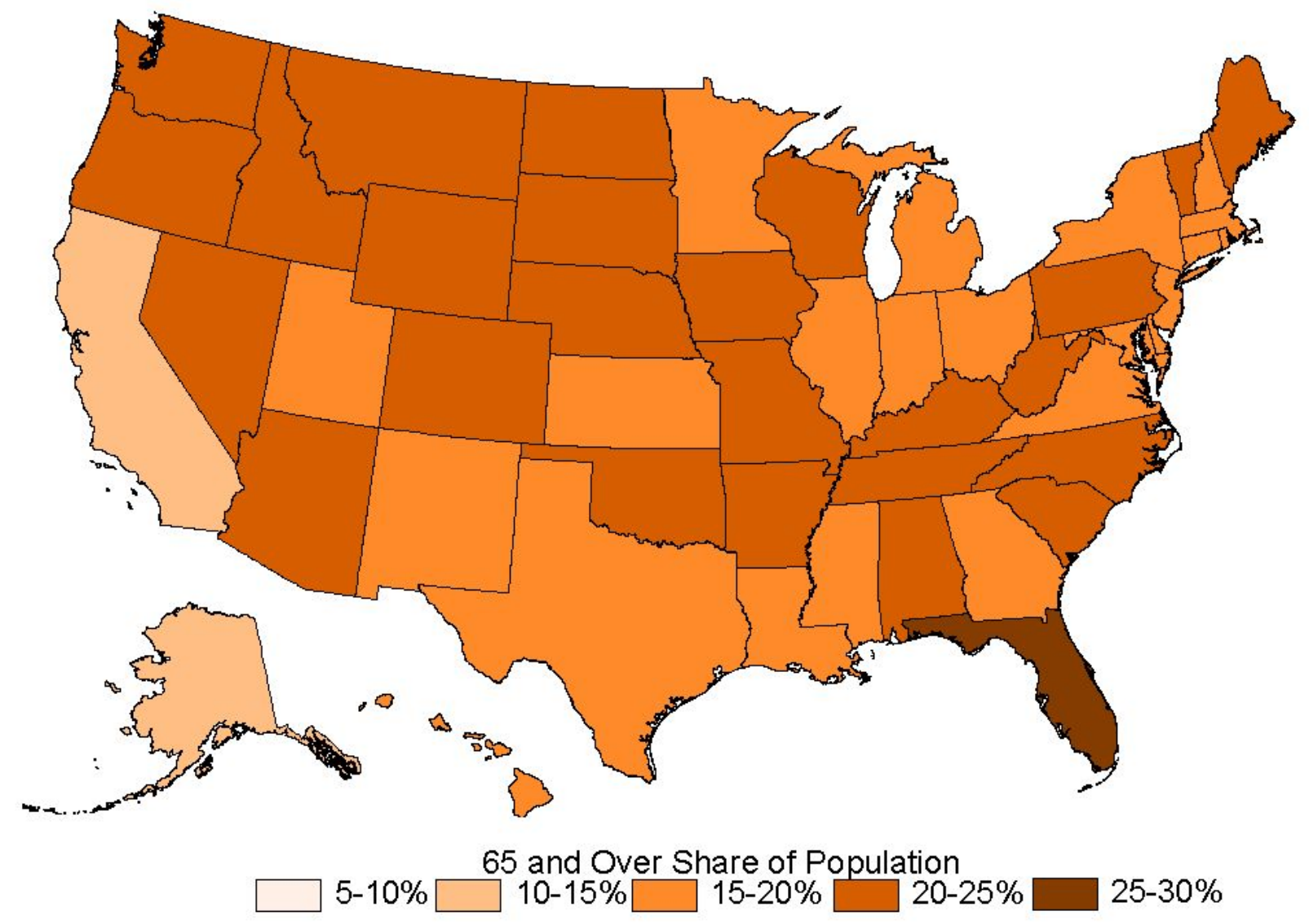

Figure 1: Year 2025 Estimates of Population Aged 65 and Over

U.S. Census data indicate that in 2002, 12 percent of the U.S. population was aged 65 years or older. By the year 2025, that will dramatically increase to 18 percent or 62 million people. As shown in Figure 1, it is estimated that Florida will lead the nation in having the highest proportion of senior citizens at over 26 percent of the state's population (U.S. Census, A Series). There are serious problems ahead in Florida and in our nation with regard to providing a transportation system that is usable by our growing elderly population. While the Federal Highway Administration has design guidelines that states and municipalities can implement to assist more seniors who drive, at some point, the ability to safely drive ends while many seniors continue to lead healthy and active lives that require transportation services. Unfortunately, the end of driving renders many seniors house bound. According to National Household Travel Survey (NHTS) 2001, as compiled by the Surface Transportation Policy Project, 19 percent of persons aged 65 and older do not drive and 51 percent of non-drivers aged 65 and older stay home. An extensive transit system serving TOD is one potential solution. 


\section{Hypothesis Development}

\section{Purpose of Phase II}

The purpose of Phase II is to collect sufficient data to model causal relationships at the individual and household level among socioeconomic characteristics, home and work location, trip generation, trip distance and mode.

\section{Development of Hypothesis Statement}

The initial hypothesis formulated at the beginning of this study was: "Good quality TOD combined with good quality transit will increase mode share of transit." As a result of study findings, it is proposed that the hypothesis statement be changed. The original hypothesis statement would not be easily testable in Florida because good quality transit that can compete with time savings of private auto travel is not easy to find. Systems in Florida have varying degrees of service quality and most are underdeveloped with regard to competing with auto travel. A second reason for changing the original hypothesis statement is that even with excellent quality TOD combined with excellent transit service, it is likely that there still will not be an appreciable change in transit mode share, based on the evidence found in the literature. The literature strongly suggests that there are requirements beyond the simple combination of good TOD design with excellent transit service. These include auto disincentives, transit incentives, marketability of the TOD based upon non-transportation features, auto ownership rates and other sociodemographic characteristics of the population. As a result, it would be more useful to specify a hypothesis that examines the present combinations of qualities that exist in Florida development and predict that as those qualities conducive to transit strengthen, auto mode share will decrease over time.

An initial idea was to figure out a way to establish personal travel habits of individuals before the move to a TOD to determine whether they are self-selecting. Such a survey process could conceivably be incorporated into the homebuying process in partnership with a lending agency that participates in location based mortgages. The proposed Phase II research design could potentially capture pre-TOD travel habits of those individuals in the control group who move to the TOD prior to later waves of data collection.

An alternative hypothesis could be: "As transit-friendly qualities of a development increase and as transit service improves, vehicle miles traveled and private auto travel mode share decrease." ${ }^{2}$ This gets away from having to define quality thresholds for "good" TOD. While attempting to control for parking, income, and self selection, there are numerous other identified variables (Table 3 ) as well as unidentified variables that may influence transit ridership and may fluctuate over time. With a moderate degree of confidence, based on past studies identified in the literature review, we already can

\footnotetext{
${ }^{2}$ The null hypothesis would state that: "As transit-friendly qualities of a development increase, VMT and private auto travel mode share stay the same or increase.” A nil hypothesis would state that there is no relationship whatever between an increase in transit-friendly qualities of a development and the level of VMT or private auto travel mode share.
} 
anticipate some of the influencing factors that more strongly influence transit ridership within a TOD. One example is the price of automotive fuel, which might be expected to cause an increase in ridership as fuel prices rise somewhere above \$5.00 per gallon.

It is proposed that this study design concentrate less on measuring aspects of land use and site design, and focus more on the travel behavior itself within the context of an environment in which persons have a choice of travel modes (i.e., in a TOD). The study would look more closely at their decision processes and the factors that influence them, so that the role of land use elements can be better discerned relative to other factors, such as socio-economic characteristics.

Practically every study design has methodological weaknesses. In this case, we cannot control for all variables (which makes this study a candidate for a qualitative research design using rigorous case study methodology). However, we can still document combinations of qualities that provide a benchmark for transit readiness in Florida cities. To the knowledge of the researchers, this has not been done before in Florida. We can also measure transit ridership that results from this environment of aggregate qualities, then measure environmental changes over time in conjunction with changes in transit ridership.

"As transit-friendly qualities of a development increase and as transit service improves, vehicle miles traveled, vehicle trips and private auto travel mode share decrease." This statement is an alternative hypothesis that is difficult to demonstrate because of the many variables that must be controlled. It is likely that the most transit-friendly development and the best transit service may not be sufficient by itself to reduce VMT, vehicle trips and private auto travel mode share and may not even be necessary in some cases, although these qualities are likely important and at least helpful in most cases.

\section{Population of Interest}

People who both live and work within the regional transit service area. The individuals in this population could conceivably choose to commute by transit as well as use transit for other trip purposes. They may or may not live or work within $1 / 4$ mile walking distance of a major transit hub.

A major transit hub and development within $1 / 4$ mile radius will represent an existing or potential TOD site for this study. Some might say that what is being isolated is proximity to transit, rather than elements of land use (such as density, land use mix). However, it is argued here that the quality of proximity is generated by adequate densities and the arrangement of land uses.

\section{Study Group and Unit of Measure}

The unit of measure for this study would be at its most disaggregate: the individual. The study group is a random sample of people who both live and work within the transit service area and their home and/or place of employment are within $1 / 4$ mile walking 
distance of a major transit hub. If good quality TOD affects mode choice, then these are the individuals who we might expect to see choose transit more often. According to Cervero's work, up to 40 percent of these individuals may be self selected. This means the other 60 percent are not. Survey questions can be devised to distinguish between the two groups.

\section{Control Group}

The control group is a random sample of people who have access to transit service but are not influenced by changes in land use that are most proximate to good quality transit service. In other words they are those who both live and work outside the $1 / 4$ mile walking distance from a major transit hub.

This proposed research design would call for a fully randomized control group. The ideal for a control group requires 100 percent random selection and also 100 percent identical measurement. This may be difficult to achieve due to self selection with regard to participation in the study.

The panel survey design used with a control group is also known as the pre-test-post-test control group design. This design, if effectively carried out, controls for seven threats to internal validity (the experimental treatment made the difference rather than extraneous variables). These threats include history, maturation, measuring instrument, statistical regression, differential selection, experimental mortality and interaction of factors (Key, 1997).

\section{Sample Size}

O'Fallon and Sullivan (2003) discuss the challenges of evaluating the impact of programs designed to affect travel behavior. They clarify options for determining and achieving adequate sample size.

The statistical power to detect significant differences between before- and aftermeasurements is determined not only by sample size but also by the variability of behavior. If people vary greatly in the number of trips driven and/or distance driven on a day-to-day or week-to-week basis (even in the absence of an intervention), then larger sample sizes (and/or longer data collection periods than the usual one-day trip diary) are needed. (p.2)

O'Fallon and Sullivan found that day-to-day travel variability is greater for people who ride transit than for people who drive their personal vehicles. This would call for a larger sample size of transit riders. However, day-to-day variability is lower for panel surveys than for a test group/control group pair. Their measure of variability for a panel survey would be the standard deviation of the difference in what was being measured (such as number of trips, trip length or use of a mode) between the two time periods recorded, divided by the mean for those two time periods. For example, they calculated that for a travel survey without a control group, in order to reliably detect a 10 percent change in 
car driving trips on weekdays for a one-day trip diary, there would need to be 727 persons (or 345 households) who successfully completed both before- and after-surveys. In our random sample, there would be mostly automobile drivers but the sample would need to be large enough to contain sufficient numbers of transit riders to detect any statistically significant changes from one wave to the next at reasonable statistical confidence intervals. O'Fallon and Sullivan also found that if effort is expended to get complete responses from all eligible respondents in a household, measurements averaging across all people in a household require lower sample sizes. However, it is especially difficult to get all members of a household (ages 15 and older) to participate in a study. Richardson (2003) found that sample size requirements must be higher for measuring change in vehicle miles traveled than for vehicle trips. It is recommended that the before- and after- measurements be compared in such a way so that days of the week are matched.

Demonstrating statistical significance costs more money. To reduce variability, the sample size should be increased from a one-day survey to one full week or more to capture variability. However, as a result, the cost to analyze the survey increases. To stay on budget, one option is to lower the number of persons or households surveyed. However, because the survey takes longer to fill out, the response rate drops. As a means to reduce variability, it is proposed that the use of the cell phone technology may enable an extended travel diary for one week or more, at far lower cost because it would enable a lower sample size. Using the cell phone technology would be far less onerous, since most of the data is recorded simply by the participants carrying the cell phones with them. It would also allow study of net change in behavior at the individual level.

We would want the study and control groups to contain a number of transit riders of adequate magnitude to ensure a valid statistical analysis. This number should be thirty transit riders at minimum, based on the Central Limit Theorem. Because the journey-towork mode share of transit for Florida municipalities is generally around two percent, the minimum sample size for the study group might need to be 1,500 for a two-day travel diary. While the PSTP used a panel containing 1,700 to 1,800 individuals, the proposed use of cell phone technology by participants for this study for a longer period of time, such as a month, can reduce this sample size.

Panels also allow the segmentation of study participants into customer groups. Kitamura notes that panel surveys can capture rates of change in population subgroups, for which stratified sampling can be undertaken. Pendyala et al. (1993) analyzed change in mode choice over time using the PSTP data. Because a stratified random sampling method was used to ensure adequate numbers of transit riders were present in the sample, households with different initial mode choices were unequally likely to be included in the sample. Pendyala computed weights to be applied to the panel in order to analyze travel behavior of Puget Sound households in general. This method might also be considered for this panel design.

A sizable body of research that has demonstrated that travel behavior of individuals is influenced by characteristics of the household, such as income, vehicle availability and 
the presence of children. This study would capture the variation of travel behavior within the household and be able to relate that variation to household characteristics. It also recognizes that individuals leave and join households. This study would aim to follow these same individuals as they leave or join households.

While there is no doubt that school age children can operate a cell phone, the younger age limit would depend on the degree to which they travel independently of the adults in their household, and can remember to carry the device. A younger age limit of 15 should be considered. 


\section{Performance Measures of Interest}

Research concludes only modest changes in mode split from TOD. However, other performance measures can point to alternative ways to evaluate TOD. Below are three examples.

$\checkmark$ Some transit riders use transit for commute trips but use a car for shopping or other personal business. Might TOD enable existing transit riders to ride transit for more trip types?

$\checkmark \quad$ Is an auto purchase by first-time buyers postponed or avoided by enabling TOD dwellers to meet their transportation needs by transit for a longer duration?

$\checkmark$ With greater internal capture of trips in a TOD, people who drive might seek to live in a TOD to extend the useful life of an older vehicle by choosing to live in a place where trip length is shorter.

Even though these transportation outcomes of TOD do not include a shift in mode share, all three do reduce total vehicle miles traveled (VMT) by private auto and the first two increase transit ridership. It is proposed as part of the next steps to develop a means to measure the above strategies as part of a Phase II research design.

Performance measures would include those found below in Table 3.

Table 3: Measures of Transportation Performance of TOD

\begin{tabular}{|l|l|l|}
\hline Performance Measure & $\begin{array}{l}\text { Direction of Value that } \\
\text { Supports Hypothesis }\end{array}$ & $\begin{array}{l}\text { Method of Data } \\
\text { Collection }\end{array}$ \\
\hline $\begin{array}{l}\text { Vehicle miles traveled } \\
\text { (VMT) (length of trips } \\
\text { by private auto) }\end{array}$ & Fewer VMT (shorter trips) & Travel diary \\
\hline $\begin{array}{l}\text { Number of vehicle trips } \\
\text { overall }\end{array}$ & $\begin{array}{l}\text { Fewer vehicle trips by private } \\
\text { auto (possible indication of } \\
\text { pedestrian-friendly quality, } \\
\text { compact physical form of } \\
\text { development or degree of } \\
\text { isolation of TOD)) }\end{array}$ & Travel diary \\
\hline $\begin{array}{l}\text { Number of trips made } \\
\text { by transit }\end{array}$ & More trips by transit & Travel diary \\
\hline Auto ownership & Fewer autos owned & Participant Survey \\
\hline Auto ownership & Delayed purchase of private auto & Participant Survey \\
\hline
\end{tabular}

While the scope proposed examining commuter trips only, the literature points to increasing traffic congestion caused by noncommute travel. In many urban areas, such as Seattle, the worst traffic congestion is not during the a.m. and p.m. weekday peaks but on weekend afternoons when travelers who commute by transit use their private cars for personal business. While noncommute travel is not concentrated at the peak periods, it comprises 86 percent of trips overall. Travelers are less willing to relinquish their cars because of the need for them to conduct personal business trips. One key variable may 
hinge on adequate development of linkages to retail, medical and other land uses that comprise destinations for personal services.

Transit-friendly qualities of the development environment as well as the users include those listed below by category. This list has been compiled based upon the review of the literature. Some are necessary for a decrease in private auto mode share to occur. None are sufficient by themselves. Previous research, particularly attempts to model the relationship between travel behavior and various features, suggest that some qualities have greater explanatory power than others. Other qualities, such as density, may be a proxy for other characteristics. Some of these characteristics are related and influence others. For example, women are found to chain trips more than men. Some characteristics related to choices people make result in the narrowing of later outcomes. For example, the selection of a job where transit service is not available might preclude one from commuting by transit. These characteristics would form the basis for describing and measuring transit-friendly qualities as part of participant survey questions and data collection on TOD physical attributes.

Demographic characteristics of the study sample would be measured through a written survey. Such characteristics that have been identified in the literature as having significant effect on travel behavior, especially with respect to riding transit, include the following:

- Auto ownership

- Income

- Gender

- Age

- Household composition

- Presence of children

- Number of adults

- Home/work location preferences

- Attitudes, including desire to use transit

- Attitudes about walking

- Shopping preferences, including variety, bargains, convenience

- Life style

It is proposed that one useful focus for the Phase II inventory be to examine the historical record of repayment on LEMs with some focus on the Smart Commute LEM program in South Florida. LEM programs are useful to examine because some have clauses regarding the number of vehicles that a household may own in order to quality for a LEM. Vehicle ownership is profoundly linked to transit ridership. A program that postpones vehicle purchase or requires reduction in the number of vehicles in a household can demonstrate shift in mode share to transit. This shift would not be a result of self selection (an existing transit rider relocating to a new place) but genuinely would be a shift to transit. 
Table 4: Inventory of Attributes Influencing Transit Mode Share

\begin{tabular}{|c|c|c|}
\hline$\underline{\text { Attribute }}$ & $\begin{array}{l}\text { Alternative measures of } \\
\text { attribute }\end{array}$ & $\begin{array}{l}\text { Sources or methods of } \\
\text { data collection } \\
\end{array}$ \\
\hline \multicolumn{3}{|l|}{$\begin{array}{l}\text { Institutional, Political, and } \\
\text { Economic Factors }\end{array}$} \\
\hline 1. Development goals & $\begin{array}{l}\text { Are goals in support of or at } \\
\text { odds with desired } \\
\text { transportation performance? }\end{array}$ & $\begin{array}{l}\text { Interviews with city } \\
\text { planners and developers }\end{array}$ \\
\hline $\begin{array}{l}\text { 2. Financial support of TOD } \\
\text { by banking community }\end{array}$ & Terms of financing & Interviews with bankers \\
\hline $\begin{array}{l}\text { 3. Government support of } \\
\text { TOD }\end{array}$ & $\begin{array}{l}\text { Certainty of review and } \\
\text { permitting process } \\
\text { Expedited review } \\
\text { Streamlined permitting }\end{array}$ & $\begin{array}{l}\text { Case study review of land } \\
\text { development process in the } \\
\text { vicinity of transit hubs }\end{array}$ \\
\hline 4. Neighborhood reaction & $\begin{array}{l}\text { Nature of public comment } \\
\text { Number of appeals, lawsuits }\end{array}$ & $\begin{array}{l}\text { Tenor of public meetings } \\
\text { and media coverage } \\
\text { Presence of problem- } \\
\text { solving and dialogue }\end{array}$ \\
\hline Transit Quality & $\begin{array}{l}\text { “Good Quality Transit” as } \\
\text { highlighted in hypothesis } \\
\text { statement }\end{array}$ & \\
\hline $\begin{array}{l}\text { 1. Availability of transit } \\
\text { service }\end{array}$ & $\begin{array}{l}\text { Existence of transit service } \\
\text { Frequency of service, } \\
\text { headways } \\
\text { Weekly and daily duration } \\
\text { of service }\end{array}$ & Transit schedules \\
\hline 2. Regional accessibility & $\begin{array}{l}\text { Number of transit stations } \\
\text { in the region, around which } \\
\text { TOD can develop } \\
\text { Number of transit stops in } \\
\text { the region }\end{array}$ & Transit system maps \\
\hline $\begin{array}{l}\text { 3. Local accessibility within } \\
\text { TOD }\end{array}$ & $\begin{array}{l}\text { Adequacy of connective } \\
\text { sidewalks to transit stops }\end{array}$ & $\begin{array}{l}\text { Site observations } \\
\text { Capital improvements } \\
\text { programming }\end{array}$ \\
\hline 4. Level of service & $\begin{array}{l}\text { Speed relative to private } \\
\text { auto including transfer wait } \\
\text { time } \\
\text { Ease of transfers } \\
\text { Use of appropriate transit } \\
\text { technologies }\end{array}$ & $\begin{array}{l}\text { Cell phone travel diaries } \\
\text { Site observations } \\
\text { Interviews with transit } \\
\text { agency }\end{array}$ \\
\hline 5. Comfort and safety & $\begin{array}{l}\text { Number of covered shelters } \\
\text { with sitting areas } \\
\text { Degree of } \\
\text { visibility/isolation }\end{array}$ & $\begin{array}{l}\text { Site observations } \\
\text { Capital improvements } \\
\text { programming }\end{array}$ \\
\hline
\end{tabular}




\begin{tabular}{|l|l|l|}
\hline 6. Parking & $\begin{array}{l}\text { Adequate parking for park- } \\
\text { and-ride users }\end{array}$ & $\begin{array}{l}\text { Site observations } \\
\text { Parking inventory }\end{array}$ \\
\hline Urban Spatial Structure & 1. Location of transit nodes \\
relative to each other & $\begin{array}{l}\text { Degree of centrality and } \\
\text { compactness of urban form } \\
\text { Number of networked } \\
\text { TODs across a region } \\
\text { Rate of suburbanization }\end{array}$ & $\begin{array}{l}\text { Transit and regional maps } \\
\text { GIS analysis }\end{array}$ \\
\hline Disincentives to Drive & Degree of delay & $\begin{array}{l}\text { Existing traffic study results } \\
\text { for concurrency } \\
\text { management }\end{array}$ \\
\hline 1. Traffic congestion & $\begin{array}{l}\text { Parking availability at } \\
\text { destination } \\
\text { Parking pricing }\end{array}$ & $\begin{array}{l}\text { Parking ordinance } \\
\text { Available parking counts } \\
\text { Municipal parking office }\end{array}$ \\
\hline 2. Parking & $\begin{array}{l}\text { “Good Quality TOD” as } \\
\text { highlighted in hypothesis } \\
\text { statement }\end{array}$ & Site observations \\
\hline 3. Price of fuel & $\begin{array}{l}\text { Residential density, } \\
\text { commercial land use } \\
\text { intensity }\end{array}$ & Municipal planning office \\
\hline Design & $\begin{array}{l}\text { Land use types } \\
\text { Degree of fine grain }\end{array}$ & $\begin{array}{l}\text { Municipal planning office } \\
\text { Site observations }\end{array}$ \\
\hline 1. Development intensity and & Ratio & Municipal planning office \\
\hline 2. Land use mix & $\begin{array}{l}\text { Access to regional market } \\
\text { Visibility of retail to } \\
\text { customers } \\
\text { Clustering (agglomeration) } \\
\text { Economies of scale (big } \\
\text { box) }\end{array}$ & $\begin{array}{l}\text { Regional managers of } \\
\text { commercial properties in } \\
\text { TOD }\end{array}$ \\
\hline 3. Jobs to population & $\begin{array}{l}\text { Limited in residential and } \\
\text { destination land uses }\end{array}$ & $\begin{array}{l}\text { Site observations } \\
\text { Municipal parking office }\end{array}$ \\
\hline 4. Retail siting & $\begin{array}{l}\text { Maximize pedestrian access } \\
\text { and appeal (rather than } \\
\text { vehicular access) }\end{array}$ & $\begin{array}{l}\text { Municipal planning maps } \\
\text { GIS analysis }\end{array}$ \\
\hline $\begin{array}{l}\text { 6. Street network } \\
\text { configuration } \\
\text { 7. Quality of walking } \\
\text { interesting building facades } \\
\text { and large window displays, } \\
\text { landscaping, sun/wind/rain } \\
\text { protection, daily street } \\
\text { cleaning, street activity }\end{array}$ & $\begin{array}{l}\text { Interview with municipal or } \\
\text { MPO bicycle and pedestrian } \\
\text { coordinator } \\
\text { Local Government } \\
\text { Comprehensive Plan } \\
\text { transportation element } \\
\text { Site observation }\end{array}$ \\
\hline
\end{tabular}




\begin{tabular}{|c|c|c|}
\hline $\begin{array}{l}\text { Housing Attractiveness to } \\
\text { Targeted Markets }\end{array}$ & & \\
\hline $\begin{array}{l}\text { 1. Properties available for } \\
\text { purchase as well as to lease }\end{array}$ & Available real estate & Local realtors \\
\hline 2. Housing quality & $\begin{array}{l}\text { Housing prices } \\
\text { Variety of housing types } \\
\text { Square footage } \\
\text { Neighborhood amenities }\end{array}$ & Local realtors \\
\hline 3. Neighborhood quality & $\begin{array}{l}\text { Crime } \\
\text { Community participation } \\
\text { Public school quality }\end{array}$ & $\begin{array}{l}\text { Neighborhood Watch } \\
\text { Homeowner association } \\
\text { School district }\end{array}$ \\
\hline \multicolumn{3}{|l|}{ Incentives for Transit } \\
\hline 1. Flex time & $\begin{array}{l}\text { Number, proportion, and } \\
\text { size of employers who offer } \\
\text { it in TOD }\end{array}$ & $\begin{array}{l}\text { Regional commuter } \\
\text { assistance program } \\
\text { Transportation management } \\
\text { association } \\
\text { Written survey of study } \\
\text { participants }\end{array}$ \\
\hline 2. Transit subsidies & $\begin{array}{l}\text { Number, proportion and } \\
\text { size of employers who offer } \\
\text { it to employees }\end{array}$ & Transit agencies \\
\hline
\end{tabular}

*Retail siting criteria as a measure of TOD effectiveness as well as the units of measure come from John Niles and Dick Nelson, "Measuring the Success of Transit-Oriented Development: Retail Market Dynamics and Other Key Determinants”, American Planning Association National Conference, Seattle, 1999.

Regarding street network, Crane and Crepeau(1998), Handy (1996b) and others have observed that the conventional notion that a grid street pattern is better for pedestrians is unclear. Generally, a grid street pattern would appear to provide greater accessibility, and it does for vehicles. Studies have shown that vehicle trips increase in areas with a grid street pattern. Pedestrian activity decreases as more vehicle activity increases. We do not really know what it is about grid street patterns that are important to pedestrians, if anything. Could it be the increased site distance of a straight street? Does a predictable pattern of streets and blocks of similar size enhance wayfinding? This is a topic for future research. If in fact the grid street pattern has qualities that are better for pedestrians than other street layouts, research demonstrates that it should be paired with traffic calming strategies to temper vehicular activity and give pedestrians priority and right-of-way.

Institutional, political and economic factors are listed first in the table above because conditions must be right in order for the TOD to come into existence. Without the right conditions for TOD to be developed and maintained as a successful venture, there will otherwise be nothing to measure. Secondly, the particular transportation objectives of state highway advocates for the TOD (reduced SOV, VT and VMT) might not be shared with the power brokers and funders who make the TOD possible and for whom the success of the TOD is financial in nature. For example, most developers do want more trips to and from the TOD from the region, preferably by people who have more money 
to spend. This is in conflict with the objective to reduce trips. Given existing conditions, people with more money to spend will generally not be the transit riders, nor will they be driving compact vehicles.

In addition, a control group or groups must be set up to correspond with the study participants above. The control groups, randomly selected and of similar size, represent transit riders of the same income category but live and work outside the TOD or otherwise have no association with the TOD. 


\section{Identifying Florida Study Locations}

Florida is inching toward the use of TOD through multiuse development. There is very little trip generation data available for multiuse development. The Trip Generation Handbook: An ITE Recommended Practice (2001) by the Institute of Transportation Engineers (ITE) contains a chapter on how to estimate trips generated from multiuse development, recognizing the potential for the internal capture of trips. The ITE Trip Generation, $6^{\text {th }}$ Edition (1997) otherwise provides vehicle trip rates generated from traffic counts for free standing single use facilities. This is based on the premise that these average trip rates can be applied to other similar facilities to predict vehicle trip generation. The Handbook defines a multiuse development as a single real estate project of between 100,000 and 2 million square feet in size, with two or more land uses. The multiuse development demonstrates some internal trip capture that does not use the external street system. The multiuse development is not a central business district (CBD), a suburban activity center or an existing ITE land use classification, such as a shopping center, hotel, or office park.

FDOT District IV sponsored a study in 1995 of six Florida multiuse sites to develop a database to identify internal capture rates for multiuse developments and pass-by capture rates. Site sizes ranged from 26-253 acres (four of the six sites were less than 75 acres) with variable combinations of office, commercial, hotel and residential. Actual pm peak hour trips generated by the entire multiuse sites were on average 20 percent less than the aggregate site estimates based on ITE rates. This result was consistent across all six study sites. Investigators also found that a high percentage of internal trips was observed at all six sites. However, the study measured little effect on the daily vehicle trip generation rates for the overall multiuse site even though ITE's definition for multiuse development anticipates a net reduction of trips external to the site. Information was not available on site characteristics other than size. It is suspected that all six multiuse sites had ample parking which would help explain the lack of effect on vehicle trip generation rates.

Some definitions provide no information on location. Others specify location along a transit route or at/near/around a transit stop. TODs cited most often in the literature occur near rail stations but most definitions prefer to use the term "transit" to allow for the possibility of TOD at bus stations. Some perceive bus stops/stations as impermanent and rail stations as a safer bet that public investments will remain in place to serve over the life of a development. However, Niles and Nelson (1999) report no findings of documentation indicating that rail is more permanent and instead cite one unpublished study of bus routes in Chicago that found routes largely remained unchanged since they were established in the early 1990s. In this Phase I study of transit service in Florida, it was found that the backbone of routes have almost always stayed the same. If the bus route serves a commercial area, this portion of a route is unlikely to change. Routes have been observed to change in the form of brief diversions from the main route to circle through a neighborhood before going back onto the main route. Another type of observed route change, to accommodate customer demand, is either the combining of two routes or the division of one route into two. It is unlikely that bus service will disappear 
from corridors with commercial development but if service is cut it is more likely at the outskirts in predominantly residential areas and not in areas of dense mixed use.

Gainesville is an exception to these generalities in that some entire routes have been removed. However, the transit system primarily functions to transport patrons to the University from the outlying residential areas. Rather than a development pattern of a network of TODs along corridors, there is one main central destination which is the University. Overall, bus service impermanence has not been demonstrated in Florida even while the perception may persist. Alternatively, the downside to fixed guideway transit may very well be the inflexibility of its physical permanence. The origins and destinations are fixed. This has not helped rail transit ridership on routes that serve urban downtowns as jobs and retail leave downtowns and settle in suburban locations. It would appear that bus service has some advantages for serving dispersed development.

Models require sound data on which to predict the trip characteristics of the TOD.

Collecting data in Florida would give us the best information about trip characteristics for Florida TOD.

It is proposed that an outcome is to develop a method for examining a location on the cusp of introducing BRT at a node where TOD is likely to develop.

Ideally, we would like to locate transit riders of the profiles described in Table 5. However, the vast majority of our study group will likely be existing riders (Group 1 from Table 1) or self-selected (columns 2A and 2AA in Table 5). Because it is not common to find transit service that can compete with the time advantages of the private automobile, the vast majority of the study group will also likely be lower income and it will not be easy to find examples of TOD representing Row 1 in Table 5. Lastly, because parking is overabundant in most developments, it will be difficult to find TOD that represents examples for Rows 5 and 7 in Table 5. However, Table 5 does describe TOD profiles to aim for, based upon markets by income. 
Table 5: Group 2, New Transit Riders

\begin{tabular}{|c|c|c|c|c|}
\hline $\begin{array}{l}\text { TOD with } \\
\text { good transit } \\
\text { and... }\end{array}$ & $\begin{array}{l}\text { 2A: New } \\
\text { transit rider, } \\
\text { moves to TOD } \\
\text { with intention } \\
\text { to ride transit, } \\
\text { (self-selecting) } \\
\text { low income }\end{array}$ & $\begin{array}{l}\text { 2AA: New } \\
\text { transit rider, } \\
\text { moves to TOD } \\
\text { with intention } \\
\text { to ride transit, } \\
\text { (self-selecting) }\end{array}$ & $\begin{array}{l}\text { 2B New transit } \\
\text { rider, moved } \\
\text { to TOD } \\
\text { initially for } \\
\text { reasons other } \\
\text { than transit, } \\
\text { low income }\end{array}$ & $\begin{array}{l}\text { 2BB: New } \\
\text { transit rider, } \\
\text { moved to TOD } \\
\text { initially for } \\
\text { reasons other } \\
\text { than transit }\end{array}$ \\
\hline $\begin{array}{l}\text { 1. Ample } \\
\text { parking }\end{array}$ & & $\begin{array}{l}\text { This is higher } \\
\text { income tenant }\end{array}$ & & $\begin{array}{l}\text { This is a higher } \\
\text { income tenant }\end{array}$ \\
\hline $\begin{array}{l}\text { 5. Limited or } \\
\text { no parking }\end{array}$ & & $\begin{array}{l}\text { Tenant will } \\
\text { choose to live } \\
\text { here }\end{array}$ & & \\
\hline $\begin{array}{l}\text { 7. Limited or } \\
\text { no parking, } \\
\text { Affordable } \\
\text { housing }\end{array}$ & $\begin{array}{l}\text { Ideal for } 2 \mathrm{~A} \text {, } \\
\text { efficient for } \\
\text { developer and } \\
\text { municipality }\end{array}$ & & $\begin{array}{l}\text { Tenant might } \\
\text { not choose to } \\
\text { live here }\end{array}$ & \\
\hline
\end{tabular}

The recommended locations of TOD are those that exhibit the most characteristics (developing in a positive direction) from Table 3. This will ensure selection of TODs that most resemble conditions to support transit ridership and a decrease in private auto travel mode share. This will benchmark the maximum extent to which Florida TOD is presently transit-ready. TOD locations are also recommended to be selected based on Table 5 which segments TODs by residential income. The study implementers could choose one or more TODs that will address those five market segments of new transit riders. Based upon the research in Phase 1, urban areas that may provide the best opportunities include Broward County, Miami-Dade County and Gainesville. A fourth category could also be added to the left column in Table 5. This would represent developments without transit service but are mixed-use "New Towns" built for internal capture of trips and could conceivably be "transit-ready" when transit service is put in place. This type of development is far more common in Florida presently. An example of such a multi-use development under design is Ave Maria in Collier County.

Most examples of potential functional TOD are located in rail corridors, including locations within the Transit Oriented Development District in the City of South Miami, Florida. The Westchase development in Tampa is held up due to the stalling of the light rail project. Nevertheless, TOD guidebooks propose that development should be configured as "transit-ready" to support sufficient ridership when the decision to expand transit service is approved.

With an emphasis upon reasonable expectations of TOD, the focus is put more on cost/benefit analyses of TOD-do the benefits of TOD outweigh the costs? A recent study on location efficient mortgages (LEM) in Chicago, a tool often paired with TOD, suggests that loan default rates will increase, resulting in unanticipated costs to society. Because the LEM concept is relatively new, there are few results reported. 
In order for TOD to be successful, there needs to be regional access by transit. The theme is "seamless intercounty service". Regarding TOD in Florida, it is not as well developed as in other parts of the nation but there is evidence of local land development activities throughout the state that are moving in the direction of TOD, particularly with respect to bus rapid transit corridor planning in Broward County, Jacksonville, Miami, Orlando and most recently as evidenced in the 2025 Regional Long Range Transportation Plan for West Central Florida (MPO Chairs Coordinating Committee). This plan calls for BRT/express bus service on major thoroughfares providing regional connections among the counties of Pinellas, Hillsborough, Manatee, Sarasota, Hernando and Pasco. Rail stations in California have tended to get the most attention regarding TOD success but there are differences in the development climate between Florida and California, primarily with respect to the market for developing land in sufficient densities. More so in Florida, there is still great momentum in suburban land development. As a result, we may need to choose some other more specific attribute of a development that qualifies it for study, such as proximity to transit or land density. This is also where the location based mortgage concept can be useful in serving as a proxy for TOD. Staff are in contact with programs that have location based mortgages, including those in Miami, Seattle, Chicago, the San Francisco Bay area and Los Angeles and Orange Counties in California. Other key attributes include vehicle ownership of residents and employees of the site as well as the availability of parking (especially free parking).

Florida also has some unusual examples, such as Gainesville, in which strides in ridership have been accomplished without conscious effort to establish TOD, but where there has been the confluence of several factors, including high residential densities, limited parking, one major destination and university funding of a bus pass. The City of Destin is an example of a small coastal town that is pursuing designation as a multi-modal transportation district (MMTD). This is representative of part of the state's growth management policies as they have a bearing on TOD. Three other Florida towns are also designated, Deland, Winter Park and Key West. The key element in MMTD is not necessarily transit service but the creation of a pedestrian environment, which appears to be a precondition to shifting mode share to transit. The development of these early MMTDs more closely resembles the Florida experience and may provide practical lessons for more towns in the future since much of Florida is smaller cities and towns. On the opposite end of the spectrum in Florida is Miami. While Miami has rail service, it is also a highly decentralized city. Miami-Dade Transit owns large tracts of acreage around rail stops in which joint development opportunities are being negotiated. However, the difficulty in Miami is the trade-off between developing the area surrounding the rail stations with TOD versus providing park and ride lots for regional commuters. To maintain reasonable farebox returns, transit agencies providing rail need to attract a larger regional ridership than what can be provided by development immediately surrounding the rail station. The more TOD is established, the less parking that can and should be provided surrounding the station, which could also affect transit ridership. 


\section{Panel Recruitment}

Based upon the experience of the PSTP, random-digit telephone dialing would be effective to recruit most study participants that are not transit riders. Murakami and Ulberg (1997) estimate that it would require 20 telephone calls to recruit one transit household. Other tactics that can be used are to re-contact respondents of previous transit surveys and distribute letters on random bus routes requesting volunteers. Murakami and Ulberg also found that offering a financial incentive to study participants was more effective at recruiting than offering no incentive and yet these incentives were modest at $\$ 1$ per participant. Modest financial incentives can be offered.

The interval at which waves of travel surveys are administered depends on the variable under study. Intervals spaced too closely will fatigue study participants, cost too much, and may not provide sufficient time for the variable to affect travel behavior. Intervals spaced too far apart may cause study participants to lose interest and researchers to lose touch with participants. It may also fail to chart the effects of a change on travel behavior. For purposes of studying the effects of land use change on travel behavior, the study may need to span at least ten years with waves spaced 1-2 years apart.

In the case of Florida urban areas, adequate survey resources must be devoted to professional survey questionnaire translation into other languages spoken in the study areas, such as Spanish and Creole. Reliable survey administration requires adequately trained and capable staff that is bilingual where needed. Survey participants need encouragement and regular contact. Implementation of the survey should also include reminder calls and tracing efforts to maximize response. For example, the PSTP made use of written and telephone contact of each household throughout the study period, including New Year's greeting postcards, written summary of data, reminders of impending new wave of data collection, and a phone call prior to diary mail-outs. The PSTP surveyors recommend gathering the name and phone number of someone outside the immediate household who always knows where the study participant will be.

It is anticipated that the population to be studied-transit riders, and especially new transit riders resulting from their association with TOD-will be a small group to begin with and securing participation will be a challenge. While an effort will be made to engage the participation of as many participants as possible, it is assumed that the total study group will be small. The emphasis will be on getting more complete information for each participant rather than getting limited data from many. With the exception of one before and after study conducted at Center Commons in Portland (Spitzer), no other studies that attempted to collect in-depth before and after data of individuals in relation to a TOD have been found. This study is proposed to track individuals by first identifying those who access a TOD location (by residence or work place), then study the travel behavior of that individual over time, even as that person may move away from the TOD. Data collection will be conducted using three elements. These include an inventory of environmental conditions, a written survey of present socioeconomic characteristics, attitudes and perceptions, and a cell phone travel diary of present travel behavior. 
As shown in the data collection schedule below, additional waves of study participants are included in future years to offset the anticipated loss in numbers of study participants from previous waves. The goal is to be able to compare cell phone travel diary data of the same individuals over time to better link the change in travel behavior to its specific cause. However, as expected attrition occurs, refreshment of the panel through recruitment of new participants to restore its representation of the population will enable longitudinal analysis to proceed.

For each set of Group 2 (new) transit riders identified above, Table 6 below identifies how a participant could be identified, key conditions for eligibility, format for determining eligibility, and agencies to assist in identifying potential participants, in addition to the regional commuter assistance program. A market research firm could be hired to conduct a telephone survey to identify and invite prospective participants that fit the profile of a new transit rider in the TOD.

Table 6: Identifying Potential Study Participants

\begin{tabular}{|l|l|l|l|l|}
\hline $\begin{array}{l}\text { Potential } \\
\text { participants }\end{array}$ & TOD employees & Bus riders & $\begin{array}{l}\text { TOD } \\
\text { residents }\end{array}$ & $\begin{array}{l}\text { Homebuyers } \\
\text { in TOD }\end{array}$ \\
\hline Eligibility & $\begin{array}{l}\text { Do you ride } \\
\text { transit? }\end{array}$ & $\begin{array}{l}\text { Do you live } \\
\text { and/or work in } \\
\text { TOD? }\end{array}$ & $\begin{array}{l}\text { Do you ride } \\
\text { transit? }\end{array}$ & $\begin{array}{l}\text { Are you } \\
\text { buying a } \\
\text { house in the } \\
\text { TOD? Do } \\
\text { you ride } \\
\text { transit? }\end{array}$ \\
\hline $\begin{array}{l}\text { Assisting } \\
\text { Agencies }\end{array}$ & TOD employers & Transit Agency & $\begin{array}{l}\text { Neighborhood } \\
\text { associations, } \\
\text { Property } \\
\text { managers }\end{array}$ & $\begin{array}{l}\text { Banks, } \\
\text { Association } \\
\text { of Realtors }\end{array}$ \\
\hline Format & Work site survey & $\begin{array}{l}\text { Survey } \\
\text { administered on } \\
\text { transit or at ticket } \\
\text { window }\end{array}$ & $\begin{array}{l}\text { Door-to-door } \\
\text { survey, mail } \\
\text { survey }\end{array}$ & $\begin{array}{l}\text { Written } \\
\text { survey as } \\
\text { part of home } \\
\text { buying } \\
\text { process }\end{array}$ \\
\hline
\end{tabular}

\section{Transit Mode Share Increase}

Florida population is increasing. As total population increases and their number of trips increase correspondingly, the absolute number of transit riders and their transit trips must also increase to at least maintain the present transit mode share. As some people become new transit riders, other existing transit riders will stop using transit. In order for there to be an increase in transit mode share, the absolute number of transit users and trips must keep pace with population growth. Additionally, the number of travelers that begin using transit also must exceed the number of travelers that stop using transit. 


\section{Regional Versus Station Area Impact}

The literature that takes a critical view of TOD transportation effectiveness argues that the regional travel impacts of TOD are more important than station area impacts. Station area impacts include potential increased internal trip capture within the TOD area as well as potential increased localized traffic congestion resulting from more internal trips generated. A favorable regional impact would be a net increase in new transit riders, resulting in a decreased regional auto mode share and an increased regional transit mode share. In the context of this proposed study design, "regional” means travel mode share immediately outside the bounds of the TOD. A measure of the impact of the TOD upon areas external to the TOD (the region) will necessitate documenting, within the defined limits of the TODs associated with study participants, the total numbers of trips entering and exiting the TOD. This will involve traffic counts at the intersections located along the perimeter of the TOD to determine total number of trips. It will also require counting the number of bus boardings and disembarkings at each transit stop located within the TOD. 


\section{Phase II Research Design}

Phase 1 of this research, as contained herein, describes what is known about the relationship between land use and TOD. Phase I developed a proposed research design for helping to answer a large number of questions still posed. These are questions for which answers would shed light on actions that can be taken through the development of land development policies.

\section{Phase 2, Wave 1, 2007, Study Steps}

What Wave 1 of Phase 2 will accomplish is the development of baseline data with respect to the physical TOD sites. These TODs would be selected as representing the most effectively transit-ready and coming closest to the concept of TOD. The data collection effort will proceed in three steps for each wave as follows.

1. Inventory of environmental conditions

1. Written survey of present socioeconomic characteristics, attitudes and perceptions

2. Cell phone travel diary of present travel behavior

\section{Study Steps}

1. Select a region and identify study locations of two or more transit hubs with existing or planned mixed use development. Broward County is recommended because of its demonstrated sustained efforts to coordinate land use with transit development. A study boundary will demarcate a radius $1 / 4$ mile from each transit hub. This effort will be as a means of defining a regional network of potential and existing TOD sites or developments as close to the concept as we can find in Florida. These sites may fit in with one or more of the profiles defined in Table 1. This helps answer the questions, "What is the current status of transit-readiness of development?" and "Are there any new transit riders as a result of TOD and of these, are any not selfselected but rather transit riders as a result of TOD?"

2. Hire a professional market research firm to locate potential study participants through a telephone random digit dialing process. These participants will constitute Wave 1 of data collection. The purpose of telephone calling will be twofold. The first purpose is to ask for study participation. All Institutional Review Board procedures for obtaining informed consent will be followed. The second purpose will be to screen participants into two groups. The first group is the study group who lives and/or works within the $1 / 4$ mile radius of one or more identified transit hubs. The control group will be all other individuals who live within the region served by transit but do not live or work within $1 / 4$ mile radius of any transit hubs. The incidence of all influencing characteristics will be equally present in both randomly selected study and control groups. The only difference will be their association with or lack of association with the TOD. This design should help identify any differences in travel behavior due to the TOD. 
3. Administer a written survey to Wave 1 study participants of both study and control groups to collect all socioeconomic characteristics and attitudes/preferences identified in List A above.

4. Document attributes for all selected TODs, as listed in Table 3. This effort will include a combination of activities, as itemized in Table 3. These include document review, interviewing and site observation. It may also include GIS analysis if such information is unavailable from the local or regional planning agencies.

5. Conduct training sessions for all survey participants in the use of the cell phone travel diary. Have participants keep travel diaries for one month using cell phone technology. Sample size?

\section{Phase 2, Wave 2, 2009, Study Steps}

1. For all selected TOD sites, document physical attributes as listed in Table 3 with special attention to any elements of land use or physical form that may have changed in the past two years.

2. Reestablish contact with Wave 1 study participants. Use telephone market research firm to recruit and refresh panel of study participants to restore original sample size. All Institutional Review Board procedures for obtaining informed consent for new as well as returning participants will be followed. Participants will again be grouped into the study group and the control group using the criteria followed for Wave 1.

3. Administer written survey to Wave 2 participants to update file on present home/work locations and collect socioeconomic characteristics and attitudes/preferences. This allows a comparison with Wave 1 characteristics.

4. Have Wave 2 participants keep a cell phone travel diary for one month.

This data collection process is recommended every 1-2 years to establish a database of travel characteristics of a population sample associated with a TOD, as the TOD matures and as transit service improves over time. Regarding issues of measurement, this addresses the question about when one should measure effectiveness, whether the measures taken are spaced too frequently or too far apart. This disaggregated data, collected for individuals, may lend insight into the conditions and decisions leading to travel behavior choices. 


\section{Cell Phone Travel Diary}

From tests conducted by researchers at the Center for Urban Transportation Research (CUTR) and the Computer Science and Engineering Department at the University of South Florida (USF), a person's position can be tracked to within 2-3 meters when they are carrying a Personal Digital Assistant (PDA) with the TRAC-IT® software and a Global Positioning System (GPS) device. As illustrated in Figures 2 and 3, the TRACIT® user interface provides easy and logical steps for entering personal travel characteristics data. The following information can be recorded during a trip automatically using the GPS device:

1) Latitude

2) Longitude

3) Altitude (currently not implemented)

4) Time/Date measurement was taken

5) Speed

6) Heading (represents North, South, East, etc. using numbers 0-360 with $0=$ North and $180=$ South)

As a result, a PDA and GPS system will collect for Phase II the following data:

1. Date and time of trip

2. Beginning and end trip locations

3. Route of trip

4. Travel purpose of each trip link (capturing both commute and noncommute trips)

5. Travel mode (based upon speed of travel) 


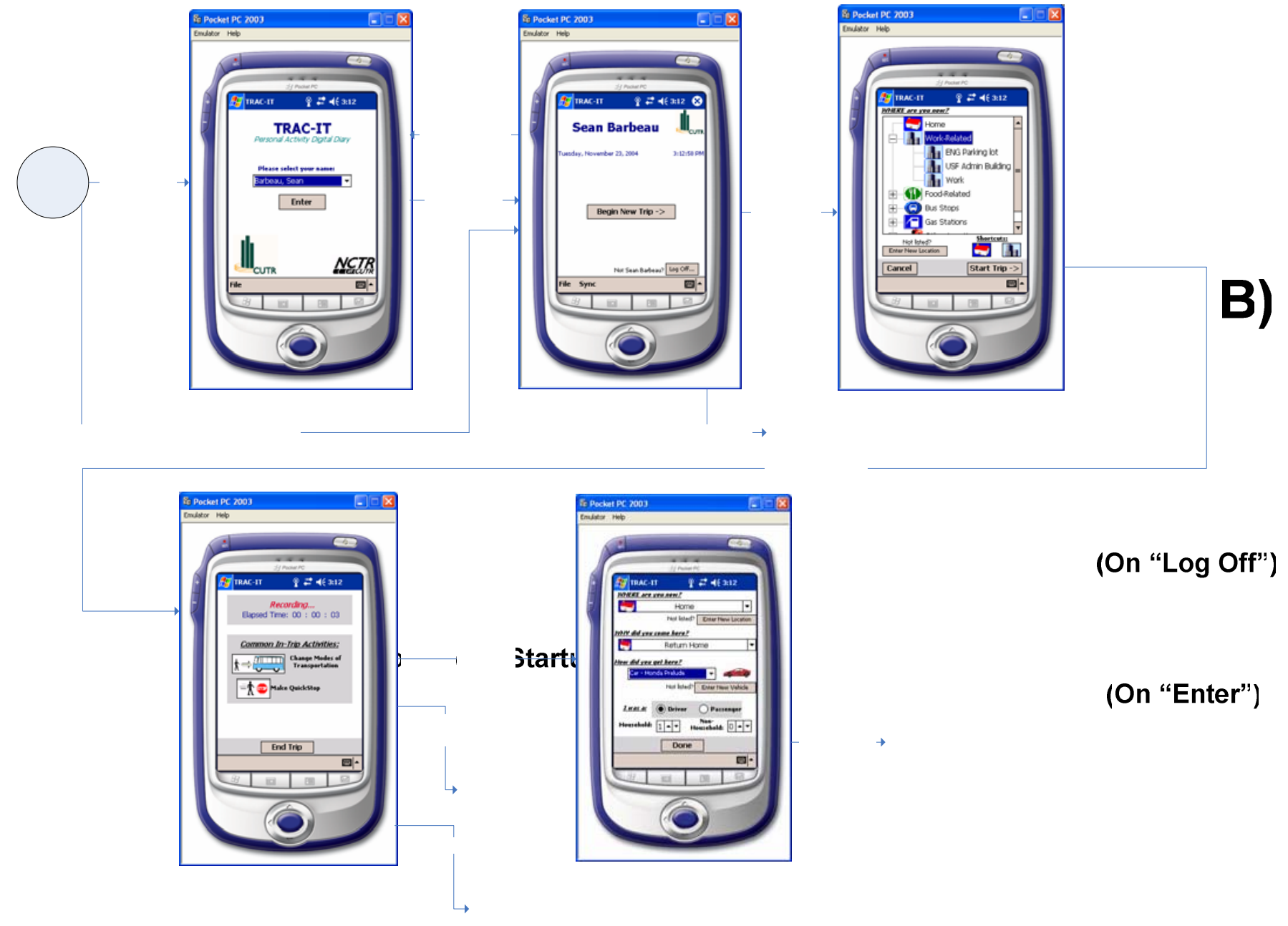

Figure 2: TRAC-IT ${ }^{\circledR}$ User Interface

User logs in

Main Screen

(On Startup if User has previously logged in)

(On "Sy 

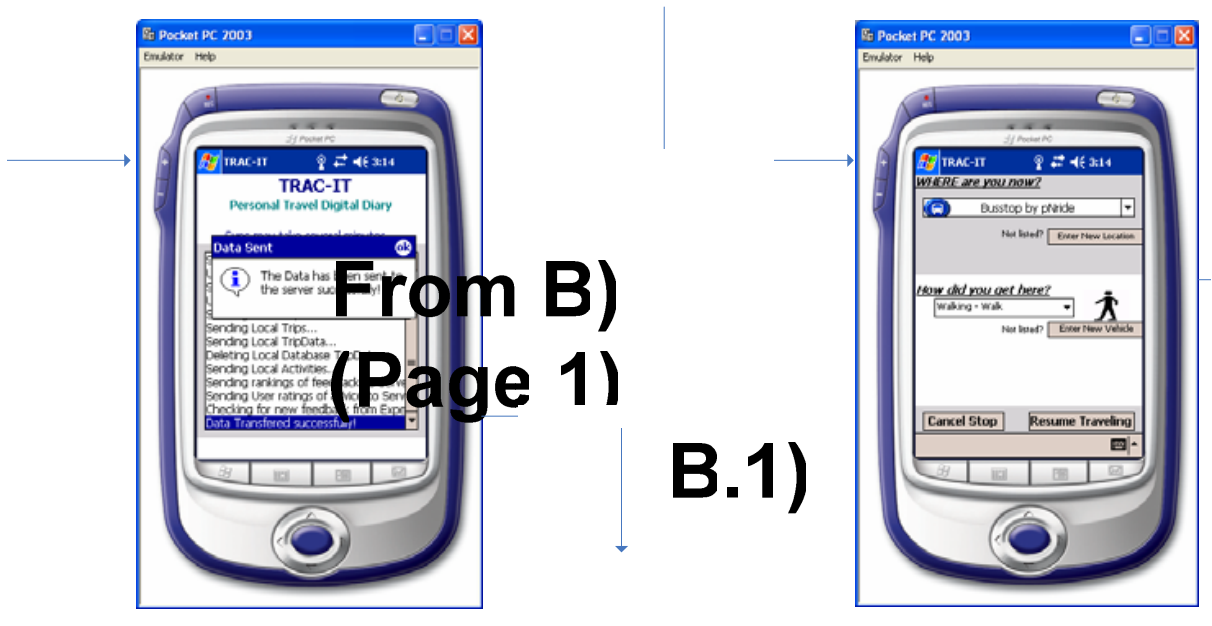

\section{From D) (Page 1)}

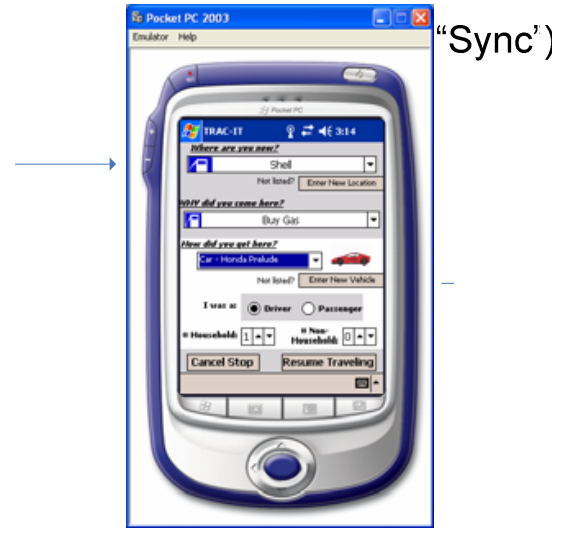

(On "Change Modes")

From D) (Page 1)
69 Synchronization (User data is transferred to server) 
This information is recorded every four seconds while the user is traveling. The following information is input manually by the participant:

1) Start Location Description (once they enter a description such as "Work" or "Home", the next time they travel they can select it from a drop-down box)

2) End Location Description (same as above)

3) Mode of Transportation (one they enter a description such as "Honda Accord", the next time they travel they can select it from a drop-down box)

4) Purpose of trip (They select from pre-determined purpose category list, with 9 purpose categories and 16 different specific purposes scattered among the 9 categories)

5) Occupancy (\# of people in vehicle, both Household and NonHousehold)

The starting time/date and ending time/date is recorded automatically when a participant chooses to start/stop a trip. As reflected on the PDA user screen, algorithms are used to attempt to "guess" the users location, mode, and purpose of trip. This "guess" is then prefilled in the selection box so the user can simply confirm the information or change it if they wish. For example, when a user starts a trip the PDA compares their current (in GPS coordinates) to the past record of all locations this person has visited. If their current position is near one of their previously visited locations, the PDA selects that location and shows it in the selection drop down box. Regarding issues of measurement with respect to defining elements of travel behavior, the developed software could be used as is or could be altered to address Axhausen's (2000) proposed definitions characterizing trip segments and activity types.

GPS devices are functional only in areas where there is direct line-of-sight between the device and the sky, since it uses satellites signals to determine the location of the user. If the GPS device is located near a vehicle window (inside a car or bus), a signal is received most of the time, but the signals are blocked upon entering a building. There may be reception problems in "urban canyons", where tall buildings block signals. GPS signals free to everyone so there are no subscription fees.

Recently cell phones have been seen as the next device to provide location based services (LBS) such as directions and information based on your current location. Federal electronic 911 (e911) mandates have pushed cell phone carriers towards providing LBS services. This agenda got an even bigger push from the government after 9/11 when none of the cellular 911 calls could be traced to the victims.

A possible advantage to using cell phones to track people is that you could potentially track them wherever a cell signal is present (ex. inside buildings, etc.). There are two ways cell phones determine their location 1) through a GPS chip (same way general use GPS device works) or 2) through triangulating its position using cellular radio signals broadcast from nearby towers (usually a little less accurate but can be used inside buildings). If a cell phone uses only method 1 , then it gets the same quality of reception that standard GPS device does and depends on a view of the sky. Some companies are using combinations of both methods to provide more accurate location information that 
takes advantages of the cellular triangulation method and the accuracy of the GPS device. Currently, Nextel is the only carrier that enables access of location by cell phone. However, due to rapid advances in technology, the use of cell phones is anticipated to be available for a Phase II start time.

\section{Advantages of Using Cell Phone Technology}

In conjunction with the panel survey design, the cell phone interface proposed to be used to collect travel diary data, as developed by Winters et al. (TRAC-IT®, 2005) has many distinct advantages. The technology is changing rapidly, providing increased capabilities and greater user-friendliness at decreasing cost. Panel fatigue can be better addressed because most of the trip data is collected automatically without the study participants having to input anything. Participants simply must remember to carry their cell phone with them. As a result of the ease of trip data collection, this releases the necessity to have travel diaries of minimal duration. Instead, the diaries can be kept for a week or even month to chart temporal variation in travel patterns. This ease of trip data collection can also allow for a smaller sample size. 


\section{Study Implementation Cost}

As stated earlier panel surveys are expensive and require a long-term financial commitment. Many cost categories would have to be considered in the development of a budget. A total yearly budget is estimated in the range of $\$ 150,000$ to $\$ 200,000$. Considering that this is a panel survey, total study costs over the course of a ten-year period may approximate \$2 million. Categories would include salaries, benefits, and overhead for:

- Design of surveys, including the retrospective surveys, the attitude surveys and surveys of socioeconomic characteristics

- Participant recruitment and refreshment for each wave, likely with assistance from a professional telemarketing consultant

- $\quad$ Ongoing contact and address update of study panel

- Cell phone data download

- Daily availability of technical assistance to participants with regard to operation of cell phones

- $\quad$ Project management

Other expenses would include:

- Printing and mailing of written correspondence and surveys

- Incentives

- Cell phones and related computer equipment 


\section{Conclusions}

\section{Resolving Issues of Measurement}

In a previous section, several issues of measurement were described as it relates to studying how TOD affects travel behavior. The proposed Phase II research design, as previously described attempts to resolve these issues. Table 7 below provides a summary.

Table 7: Phase II Research Design Response to Issues of Measurement

\begin{tabular}{|l|l|}
\hline Issue & Response \\
\hline Availability of TOD to study & $\begin{array}{l}\text { Phase II will describe and evaluate samples } \\
\text { of Florida development currently in place. } \\
\text { The panel study design will document } \\
\text { physical changes over time. }\end{array}$ \\
\hline $\begin{array}{l}\text { Defining TOD based on quality, size and } \\
\text { location }\end{array}$ & $\begin{array}{l}\text { Phase II will describe current conditions as } \\
\text { a baseline of transit readiness and chart a } \\
\text { trend of improvement, decline or stasis. }\end{array}$ \\
\hline Timing of study measurements & $\begin{array}{l}\text { Because this is a panel study, several series } \\
\text { of measurements will be taken over time to } \\
\text { detect change. }\end{array}$ \\
\hline $\begin{array}{l}\text { Isolating the effects of the variable of } \\
\text { interest }\end{array}$ & $\begin{array}{l}\text { Phase II will establish a control group } \\
\text { composed of individuals not associated } \\
\text { with any TOD origins or destinations that } \\
\text { represent residence or work. }\end{array}$ \\
\hline $\begin{array}{l}\text { Ensuring generalizability of results to the } \\
\text { broader population }\end{array}$ & $\begin{array}{l}\text { Phase II will draw a random sample of } \\
\text { sufficient size. Collecting data in Florida } \\
\text { would yield the most reliable information } \\
\text { about trip characteristics for Florida TOD. } \\
\text { A panel survey design will lessen data } \\
\text { amount requirements. The use of a } \\
\text { PDA/GPS combination or cell phone } \\
\text { technology will also lessen data amount } \\
\text { requirements. }\end{array}$ \\
\hline Availability of data & $\begin{array}{l}\text { The main focus of Phase II is to retrieve } \\
\text { and organize a suitable database in } \\
\text { adequate content, quality, amount and } \\
\text { duration, for numerous analysis purposes, } \\
\text { including better understanding the } \\
\text { relationship between TOD and travel } \\
\text { behavior. }\end{array}$ \\
\hline
\end{tabular}




\section{Uses of Collected Data}

\section{Collecting Data on the Other 80 Percent of Travel Purposes}

Little is known about nonwork travel which comprises 80 percent of travel purposes. Liu et al. (1998) recommended that travel behavior surveys involving the gathering of trip information include specific instructions and trip purpose categories to capture changes in travel mode and transfers within the same travel mode during a trip. This research study design proposes to collect such detailed trip chaining data, including trip mode, travel speed, purpose, times of day of travel, and origins and destinations, which would result in a wealth of information about nonwork travel. Coupled with socioeconomic characteristics of the participants, analysis can be conducted on household characteristics and household member interactions as they affect travel behavior.

\section{Collecting Data Particular to Florida's Urban Form}

The careful development of new data sets specific to Florida communities would generate increased interest in the study and analysis of the impacts of urban form and other factors upon travel behavior particular to Florida. It would be a sound investment in future research that would be better positioned to both explain the relationship between urban form and travel behavior as well as quantify the impacts for urban areas in Florida. Examples are as follows.

\section{Gauging Attitudes and Lifestyles as Explanatory Variables}

Written surveys administered to study participants during Phases 2 through 4 of the study are an opportunity to collect not only present socioeconomic data but also attitudes, perceptions and information about lifestyles, which were identified by Bagley and Mokhtarian (2002) as having the greatest impact on travel demand among all explanatory variables examined in their study. Similarly, a study by Kitamura found evidence that land use may be a proxy for attitudes that determine residential location and subsequently travel behavior. A better understanding of attitudes and lifestyle factors may further explain the relative importance of urban form and TOD to travel behavior as well as how these variables interact.

\section{Determining Former Mode of New Transit Riders}

One concern of those interested in quantifying impacts has been that in some cases, such as Gainesville, transit ridership has increased over recent years; however, many new transit riders were formerly pedestrians and bicyclists rather than single-occupant vehicle motorists. While the transit increases are a positive sign from the transit agency standpoint, this change does not necessarily provide the traffic congestion relief desired by highway advocates. In this study, the combination of retrospective and prospective study elements in tracking individuals over time is also capable of collecting information regarding the extent to which gains in transit ridership were formerly single-occupant vehicle travelers.

\section{Gauging the Effect of Regional Access on TOD Effectiveness}

Regional access and network access to and from a TOD has been identified as crucial to the effectiveness of transit serving a TOD. Depending upon the particular interests of 
study funders, this study could be adapted to compare the impacts of regional access and network access of a TOD by selecting two or more TODs of similar size and characteristics representing different urban areas in Florida that provide different levels of regional transit access.

\section{Understanding Trip Chaining and Route Deviation}

This type of travel diary will greatly enhance our understanding of pedestrian trip making, route choice, and trip linking. Niles and Nelson (2001) argue the importance of better understanding trip chaining as a means to identify the best combinations of retail properties within a TOD or any mixed-use development. Such knowledge could help maximize efficiency of trip linking, saving customers time and make it easier to use transit for more trips. It could also serve to contain trips within a TOD, thereby increasing internal capture and reducing regional traffic impact. Understanding better combinations of retail properties could also improve commercial business success. Retail structure is the manner in which goods and services are distributed and provided to the final consumer. This includes the combination and variety of goods and services provided by a particular retail store, the locations and dispersal of these retail stores and the combinations of different types of retail stores clustered together to draw a larger market. These factors affect nonwork travel behavior as well as trip chaining on work based trips by consumers in pursuit of a particular product or service. While the NHTS shows that approximately 80 percent of all trips are nonwork trips, Kaufman (2005) has found that household and individual trips to grocery stores and other food outlets alone contribute a large portion to urban transportation volume. His summary of the literature found that 20 percent of all car trips and traffic in Toronto are estimated to be generated by food choice trips (Roberts, W., 2001). Nearly 23 percent of all trips by San Franciscans were made to shop for food and non-food items in 1990; approximately 85 percent of them by automobile (Purvis, C.L., 1994). The primary shoppers in U.S. households make 2.44 trips per week on average to shop for groceries, the great majority by car (Urbanski, 2002). Researchers found that few people would substitute walking for driving to the grocery store, even if access were excellent (Handy and Clifton, 2001). Food consumed away from home has increased considerably. In 2003 restaurant dining and takeout food accounted for $41 \%$ of household food spending, double what it was in 1960 (Johnson, B., 2005). When people eat out more, the number of auto trips increase. Study funders interested in the impact of retail structure on travel behavior would obtain valuable information from this proposed study design. With its geocoding and detailed trip chaining information, the data could greatly contribute to an understanding of urban form with respect to trip chaining for shopping trips. Researchers could track how flexible travelers are to deviate from their commute route and the locations of stops relative to work and home. This could inform decisions on how to assemble land uses not only to attract more customers but also to reduce or shorten trips.

\section{Collection of Travel Data for Use in Activity-Based Models}

The detailed travel data for individuals to be collected by the PDA/GPS system can be used in the development of activity-based models, which attempt to better understand travel in its activity context and better recognize behavioral factors than other models. For example, the data could be applied using the tour-based microsimulation approach 
developed by Jonnalagadda et al. (2001) This activity-based model described in a previous section can provide more detailed forecasts of travel demand for various planning applications. The approach requires disaggregate travel data. Jonnalagadda et al. used PUMS data in their study. While the PUMS data was effective for their study, a greater level of specificity and detail could be achieved through the data collected by this project.

\section{Fine Tuning Traffic Calming For Optimal Effect}

Boarnet and Crane found that when car trip speeds were lowered sufficiently, car trip generation and vehicle miles traveled decreases. This proposed research design is set up to collect data on travel mode, trip distances and travel time per trip. Analysis could examine whether a causal relationship exists between travel speed and car trip generation and whether travel speed reduction lowers the number of all trips or if it has the effect of switching travelers to other modes. This might have policy implications relating to the implementation of traffic calming measures and speed limits. Further investigation could examine at what traffic speed trip generation is optimally lowered without adverse impacts on economic activity.

\section{Learning How To Support More Walking Trips Through Urban Design}

Boarnet and Crane also tested and confirmed in their study that most travelers will not walk much farther than one quarter mile and yet many "pedestrian-friendly" developments do not place enough destinations within the quarter mile limit. This proposed study would collect travel data of individuals who are associated with a TOD, either through work or their residence. A study analysis could measure the performance of the TOD by its ability to increase walking trips relative to travelers in a control group who are not associated with a TOD. Results of such an examination could refine urban design concepts related to supporting walking trips.

\section{Understanding Longer Term Decisions That Affect Travel Behavior}

The panel survey data intended to be tracked by the PDA/GPS system of the same individuals over a period of years can develop an understanding about how short term decisions and long term decisions affect travel behavior. The PDA/GPS data collection effort could capture individual choices in scheduling activities as well as the process of spatial learning over time.

\section{Developing TOD Within a Bus Service Context}

Most TOD studies have been done in relation to the location of development proximate to rail stations. Most Florida communities are not served by rail. The standard thinking is that TOD can only be properly supported by rail and so TOD has not been given serious attention in Florida. At least in the near future, a more likely scenario for Florida communities is for bus transit to be further developed rather than rail. It is by no means evident that bus transit cannot support TOD. Rail transit has been thought to be vital due to its ability to compete with the private automobile with respect to travel time and also due to its permanence. However, bus rapid transit (BRT) has been shown to rival time advantages of rail. Five Florida communities either have elements of BRT already in place or are in the process of discussion and/or planning for BRT. Bus transit is also not 
necessarily less permanent. A study conducted in Chicago indicated that bus routes since the beginning of the $20^{\text {th }}$ century, while having expanded, have not significantly changed their core route locations. Our survey of local bus routing in urban areas of Florida also suggests that the elimination of bus service is uncommon, especially in commercial corridors. Bus service may also have advantages over rail. Bus service is less expensive and can serve dispersed areas. An encouragement of study of TOD in Florida, through the development of Florida data sets, will provide more reliable information about what policies will work best for Florida.

\section{Better Specifying Impact of Urban Form on Travel Behavior}

While travel behavior research as a whole strongly suggests that urban form plays some role in affecting travel behavior, we do not yet have an understanding of the specific relationship. For example, while high density development is generally considered a crucial variable in TOD effectiveness, Kuzmyak (TCRP 95) suspects that density may be a proxy for a number of other attributes. And while a grid street system is generally thought to be preferable to TOD as it increases accessibility, Crane suspects that a grid system may simply increase auto trips due to increasing accessibility. In response to these questions, this proposed study could employ a multinomial logit model, constructed as a travel choice model that would include variables representing mode specific characteristics as well as variables on urban form. Such a model could help determine what aspects of urban form and mode would lead to differences in travel, if socioeconomic characteristics were controlled. This could be accomplished by selecting neighborhoods with similar socioeconomic characteristics, such as income. The mode choice model would specify utility functions for each of the possible choices and combinations of travel modes. Reliable empirical data could be collected using PDA travel diaries.

\section{Concluding Remarks}

The question of what needs to be done through policy making to improve transportation performance may be partially answered by statistical and econometric models that describe travel behavior. However, carrying out the solution(s) lies in the hands of that host of political entities who control the variables.

The results of this Phase I study examining the impact of TOD on public transit ridership, and more generally, on reducing traffic congestion on the State Highway System, indicate that elements of urban form, especially those combined to form TOD, play some positive role. Still much is not known that could be investigated through the proposed Phase II study design presented in this report. The emphasis is upon the development of a reliable and sufficient data set, specific to a Florida urban area. The proposed research strategy is a multi-year panel survey using the pre-test post-test design. This design provides the indepth travel data needed using an available new technology that has the capability to lower needed sample size to achieve statistical confidence. The development of such a data set, while initially expensive, would be a sound investment because it could be used for multiple purposes, including enhancing travel forecasting capabilities, as well as 
attract the interest of transportation researchers nationwide and abroad whose research could directly benefit Florida. 


\section{References}

American Planning Association, "A Glossary of Zoning, Development, and Planning Terms, Planning Advisory Service, Report No. 491/492. Michael Davidson and Fay Dolnick, Eds., Chicago, IL, December 1999, p. 238.

Anderson, T. and F. McChesney, eds. 2003. Property Rights: Cooperation, Conflict and Law, Princeton University Press, Princeton, NJ.

Axhausen, K. 2000. "Activity-Based Modelling: Research Directions and Possibilities", Draft-Paper in D. Simmonds and J. Bates, New Look at Multi-Modal Modelling, prepared for Department of Environment, Transport and the Regions, London, Cambridge and Oxford.

Bagley, M. and P. Mokhtarian. 2002. "The Impact of Residential Neighborhood Type on Travel Behavior: A Structural Equations Modelling Approach”, The Annals of Regional Science, Vol. 36, pp.279-297.

Belzer, D. and G. Autler. 2002. "Transit Oriented Development: Moving from Rhetoric to Reality", a discussion paper prepared for The Brookings Institution Center on Urban and Metropolitan Policy and The Great American Station Foundation. June.

Boarnet, M. and R. Crane. 2001. Travel By Design: The Influence of Urban Form on Travel, Oxford University Press, Inc., New York.

Boarnet, M. and S. Sarmiento. 1996. "Can Land Use Policy Really Affect Travel Behavior? A Study of the Link Between Non-Work Travel and Land Use Characteristics”, Working Paper. UCTC No. 342. The University of California Transportation Center. University of California at Berkeley. December.

Brownstone, D. and X. Chu. 1997. "Multiply-Imputed Sampling Weights for Consistent Inference with Panel Attrition”, Chapter 10 from Golob, T. R. Kitamura and L. Long, eds. 1997. Panels for Transportation Planning: Methods and Applications, Transportation Research, Economics and Policy Vol. 5, Kluwer Academic Publishers, Norwell, MA, pp. 259-273.

California Department of Transportation. 2002. "Statewide Transit-Oriented Development Study: Factors for Success in California", Final Report, Business, Transportation and Housing Agency, Division of Mass Transportation, September, pp. 143-144.

Cao, X., S. Handy, and P. Mokhtarian. 2005. "The Influences of the Built Environment and Residential Self-Selection on Pedestrian Behavior", Transportation Research Board, Annual Meeting, Washington, D.C., revised paper on CD-ROM. 
Cervero, R, S. Murphy, C. Ferrell, N. Goguts, Y. Tsai, Parsons Brinckerhoff Quade and Douglas, Inc., Bay Area Economics, Urban Land Institute. 2004. Transit Oriented Development in America: Experiences, Challenges, and Prospects, Transit Cooperative Research Program, Transportation Research Board, National Research Council, Washington, D.C., p. 7.

Cervero, R and K. Kockelman. 1996. "Travel Demand and the 3Ds: Density, Diversity and Design”, Transportation Research D. pp. 199-219.

Cervero, R. and M. Duncan. 2002. "Residential Self Selection and Rail Commuting: A Nested Logit Analysis”, Working Paper, University of California Transportation Center, Berkeley, CA, p. 9.

Cervero, R. and R. Gorham. 1995. "Commuting in Transit Versus Automobile Neighborhoods”, Journal of the American Planning Association, Vo. 61, pp. 210-225.

Cervero, R. 1993. "Ridership Impacts of Transit-Focused Development in California”. Monograph 45, Institute of Urban and Regional Development, University of California, Berkeley, CA.

Charles, J. and M. Barton. 2003. “The Mythical World of Transit-Oriented Development: Light Rail and the Orenco Neighborhood, Hillsboro, Oregon”, Cascade Policy Institute, Portland, OR. April.

Charles River Associates. 1997. TCRP Report 27, Building Transit Ridership: An Exploration of Transit's Market Share and the Public Policies That Influence It, Transportation Research Board, National Research Council, Washington, D.C.

Chu, X., PhD. 2005. Senior Research Associate, Center for Urban Transportation Research. University of South Florida, Tampa. Conversation, June 8.

Chung, J-H and K. Goulias. 1995. Sample Selection bias with Multiple Selection Rules: Application with Residential Relocation, Attrition and Activity Participation in the Puget Sound Transportation Panel. Transportation Research Record 1493, pp 128-135.

Community Green Line Planning Project. December 30, 1994. "Putting Neighborhoods on the Right Track”, Chicago, IL.

Crane, R. and R. Crepeau. 1998. "Does Neighborhood Design Influence Travel?: A Behavioral Analysis of Travel Diary and GIS Data”, Transportation Research D 3,4, pp. 225-38.

Deakin, E. 2004. “Transit-Oriented Development: Possibilities for TDM Professionals”, Netconference held jointly by the National TDM and Telework Clearinghouse at the University of South Florida and the Association for Commuter Transportation. Funded by the National Center for Transit Research. January 27. 
Deakin, E. 2002. University of California at Berkeley, as reported to Kuzmyak, J., R, Pratt, G. Douglas, and F. Spielberg. 2003. TCRP Report 95, “Traveler Response to Transportation System Changes”, Chapter 15-Land Use and Site Design, Transportation Research Board, Washington, D.C., p. 7.

Dittmar, H. and G. Ohland, eds. 2003. Transit Town: Best Practices in Transit-Oriented Development, Island Press, Washington, D.C.

Downs, Anthony. 1994. New Visions for Metropolitan America. The Brookings Institution and the Lincoln Institute of Land Policy, Washington, D.C.

Ewing, R. and R. Cervero. 2001. “Travel and the Built Environment, A Synthesis”, Transportation Research Record 1780, National Research Council, Washington, D.C., pp 87-114.

Ewing, R. 1996. Pedestrian- and Transit-Friendly Design: A Primer for Smart Growth. Smart Growth Network. Based on a manual prepared for the Florida Department of Transportation and published by the American Planning Association.

Ewing, R. 1996. Pedestrian- and Transit-Friendly Design, Appendix B, Mode Share Analysis-Land Use Influences, Joint Center for Environmental and Urban Problems, Florida Atlantic University/Florida International University, prepared for the Public Transit Office, Florida Department of Transportation, March. Found at http://www.dot.state.fl.us/planning/systems/sm/los/pdfs/ped_tran.pdf

Ewing, R., P. Haliyur and G. Page. 1994. "Getting Around a Traditional City, A Suburban Planned Unit Development, and Everything in Between”, Transportation Research Record 1466, pp 53-62.

Frank, L and G. Pivo, 1994. "Impacts of Mixed Use and Density on Utilization of Three Modes of Travel: Single Occupant Vehicle, Transit, and Walking”, Transportation Research Record 1466, pp 44-52.

Gardenhire, A., M. Sermons. 2001. "Understanding Automobile Ownership Behavior of Low-Income Households: How Behavioral Differences May Influence Transportation Policy”, Transportation Research Circular E-C026-Personal Travel: The Long and Short of It. Transportation Research Board, National Research Council, Washington, D.C. pp. 179-192.

Golob, T. R. Kitamura and L. Long, eds. 1997. Panels for Transportation Planning: Methods and Applications, Transportation Research, Economics and Policy Vol. 5, Kluwer Academic Publishers, Norwell, MA.

Golob, T. and H. Meurs. 1986. "Biases in Response Over Time in a Seven-Day Travel Diary”, Transportation, Issue 13. pp.163-181. 
Governor's Growth Management Study Commission, 2005. Senate Growth Management Workshop, University of South Florida, public comments. February 11.

Haddock. 2003. Chapter author as found in Anderson, T. and F. McChesney, eds. 2003. Property Rights: Cooperation, Conflict and Law, Princeton University Press, Princeton, NJ.

Handy, S. and K. Clifton. 2001. "Local Shopping as a Strategy for Reducing Automobile Travel”, Transportation 28. Kluwer Academic Publishers. pp. 317-46.

Handy, S. 1997. Travel Behavior Issues Related to Neo-Traditional Developments-A Review of the Research. Urban Design, Telecommuting and Travel Forecasting Conference, Williamsburg, VA: Summary, Recommendations and Compendium of Papers. Prepared by Day, L., Texas Transportation Institute, prepared for the U.S. Department of Transportation.

Handy, S. 1996a. "Methodologies for Exploring the Link Between Urban Form and Travel Behavior”, Transportation Research-D, Transport and Environment, Vol. 1, No.2, Pergamon, Exeter, U.K., pp. 151-165.

Handy, S. 1996b. "Urban Form and Pedestrian Choices: A Study of Austin Neighborhoods”, Transportation Research Record 1522, pp.135-144.

Handy, S. 1993. "Regional Versus Local Accessibility: Implications for Nonwork Travel”, Transportation Research Record 1400, pp.58-66.

Hanson, S. 1982. “The Determinants of Daily Travel-Activity Patterns: Relative Location and Sociodemographic Factors”, Urban Geography, Vol.3, pp 179-202.

Hendricks, S. 2004. "Commuter Choice Program Case Study Development and Analysis”, funded by the National Center for Transit Research with sponsorship from the Florida Department of Transportation. Prepared by the Center for Urban Transportation Research, University of South Florida, Tampa, August.

Hendricks, S. 2002. "Land Developer Participation in Providing for Bus Transit Facilities/Operations", funded by the National Center for Transit Research with sponsorship from the Florida Department of Transportation. Prepared by the Center for Urban Transportation Research, University of South Florida, Tampa, March, p. 63.

Hsaio, C. 1986. The Analysis of Panel Data. Cambridge University Press. Cambridge, Massachusetts.

Institute of Transportation Engineers. 2001. Trip Generation Handbook: An ITE Recommended Practice, K. Hooper, Principal Editor., Washington, D.C. 
Institute of Transportation Engineers. 1997. Trip Generation, $6^{\text {th }}$ Edition, An Informational Report, Washington D.C.

Johnson, B. 2005. "What U.S. consumers buy and why". http://www.adage.com/news.cms?newsld=44262

Jonnalagadda, N., J. Freedman, W. Davidson, and J. Hunt. 2001. "Development of Microsimulation Activity-Based Model for San Francisco: Destination and Mode Choice Models”, Transportation Research Record 1777, Transportation Research Board, National Research Council, Washington, D.C. pp. 25-35.

Kaufman, J. 2005. "The Role of Planners in the Emerging Field of Community Food System Planning”, Emeritus Professor, Department of Urban and Regional Planning, University of Wisconsin-Madison, Louis B. Wetmore Lecture on Planning Practice, University of Illinois Planning Institute, March 2.

Kelley, K. 2005. USDA Farm Service Agency. Comments made at the 2005 Public Policy Workshop, Florida Chapter of the American Planning Association, Tallahassee, February 16, as reported in Florida Planning newsletter.

Key, J. 1997. "Research Design in Occupational Education, Module R13, Experimental Research and Design”. Oklahoma State University

Kitamura, R. 1990. "Panel Analysis in Transportation Planning.: An Overview". Transportation Research, 24A, pp.401-415.

Kitamura, R., L. Laidet, P. Mokhtarian, C. Buckinger, and F. Gianelli. 1994. "Land Use and Travel Behavior”. Report No. UCD-ITS-RR-94-27, Institute of Transportation Studies, University of California at Davis, October.

Kulkarni, A. 1996. "The Influence of Land Use and Network Structure on Travel Behavior”, unpublished Masters thesis. University of California, Irvine.

Kuzmyak, J., R. Pratt, G. Douglas, and F. Spielberg. 2003. Transit Cooperative Research Program Report 95, “Traveler Response to Transportation System Changes, Chapter 15-Land Use and Site Design”, Transportation Research Board, National Research Council, Washington, D.C., pp. 7-8.

Liu, R., S. Polzin, and R. Pendyala. 1998. "Simulation of the Effects of Intermodal Transfer Penalties on Transit Use”, Transportation Research Record 1623, Transportation Research Board, National Research Council, Washington, D.C., pp. 8895.

Long, L. 1997. "Panels for Transportation Planning: Theoretical Issues and Empirical Challenges”, Institute of Transportation Studies, University of California, Irvine. As contained in Panels for Transportation Planning: Methods and Applications, T. Golob, 
R. Kitamura and L. Long, eds., Transportation Research, Economics and Policy Vol. 5, Kluwer Academic Publishers, Norwell, MA,

Lund, H., R. Cervero, and R. Willson. 2004. "Travel Characteristics of Transit-Oriented Development in California”, Final Report, Funded by Caltrans Transportation Grant"Statewide Planning Studies"-FTA Section 5313(b).

McGuckin, N. and E. Murakami. 1999. "Examining Trip-Chaining Behavior: Comparison of Travel by Men and Women”. Paper presented at the $78^{\text {th }}$ Annual Meeting of the Transportation Research Board, National Research Council, Washington, D.C. January.

Meurs, H. and G. Ridder. 1997. "Attrition and Response Effects in the Dutch National Mobility Panel”, Chapter 8 of Panels for Transportation Planning: Methods and Applications, T. Golob, R. Kitamura and L. Long, eds., Transportation Research, Economics and Policy Vol. 5, Kluwer Academic Publishers, Norwell, MA, pp.211-232.

Murakami, E. and Ulberg, C. 1997. “The Puget Sound Transportation Panel”, Chapter 6 of Panels for Transportation Planning: Methods and Applications, T. Golob, R. Kitamura and L. Long, eds., Transportation Research, Economics and Policy Vol. 5, Kluwer Academic Publishers, Norwell, MA, pp. 159-192.

National Cooperative Highway Research Program, Project 20-45. “Scientific Approaches to Transportation Research”, CD-22, Volumes 1 and 2, Transportation Research Board, National Research Council, Washington, D.C. prepared by Georgia Institute of Technology, Atlanta, GA. 2001. Web-based document available at http://gulliver.trb.org/publications/nchrp/cd-22/chapters.html

New Jersey Transit. 1994. Planning for Transit-Friendly Land Use: A Handbook for New Jersey Communities. Skidmore, Owings \& Merrill; Lehr \& Associates; Edwards and Kelcey; Jane Lyle Diepeveen; Joyce Wilson Graphic Design. Newark, NJ. June.

Niles, J., and D. Nelson. 2001. "Enhancing Understanding of Non-work Trip Making: Data Needs for the Determination of TOD Benefits”, Transportation Research Circular, Transportation Research Board, Washington, D.C., March.

Niles, J. and Dick Nelson. 1999. "Measuring the Success of Transit-Oriented Development: Retail Market Dynamics and Other Key Determinants”, prepared for the APA National Planning Conference, Session S-180: Will Retailing Collide with TOD? Seattle, WA, April 24-28.

O’Fallon, C. and C. Sullivan. 2003. "Personalized Marketing-Improving Evaluation”, Paper presented at the $26^{\text {th }}$ Australasian Transportation Research Forum, October 1-3, Wellington, New Zealand. 
Parsons Brinckerhoff Quade and Douglas, Inc. 1993. Volume 4A: The Pedestrian Environment, LUTRAQ Project, 1000 Friends of Oregon, Portland.

Parsons Brinckerhoff Quade and Douglas, Inc. 1996. Transit and Urban Form, Transit Cooperative Research Program Report No. 16, Transportation Research Board, Washington, D.C., Vol. 1, Part 1.

Pendyala, R. and R. Kitamura. 1997. "Weighting Methods for Attrition in Choice-Based Panels”, Chapter 9 from Panels for Transportation Planning: Methods and Applications, T. Golob, R. Kitamura and L. Long, eds., Transportation Research, Economics and Policy Vol. 5, Kluwer Academic Publishers, Norwell, MA, pp. 233-257.

Pendyala, R., K. Goulias, R. Kitamura and E. Murakami. 1993. "Development of Weights for a Choice-Based Panel Sample with Attrition”. Transportation Research, 27A(6), pp. 477-492.

Phillips, R. and M. Guttenplan. 2003. “Assessing Multimodal Quality of Service” prepared for the Florida Department of Transportation.

Podobnik, B. 2002. "The Social and Environmental Achievements of New Urbanism: Evidence from Orenco Station”, Lewis and Clark College, Department of Sociology, Portland, Oregon, November 7.

Polzin, S., X. Chu, and L. Toole-Holt. 2003a. "The Case for Moderate Growth in Vehicle Miles of Travel: A Critical Juncture in U.S. Travel Behavior Trends”, prepared for the Florida Department of Transportation by the Center for Urban Transportation Research, University of South Florida, Tampa, September.

Polzin, S. and O. Page. 2003b. "Ridership Trends of New Start Rail Projects," Final Report, Funded by the National Center for Transit Research. Prepared by the Center for Urban Transportation Research, University of South Florida, Tampa, for the U.S. DOT and the Florida Department of Transportation. August.

Porter, D. 1997. Transit Cooperative Research Program Synthesis 20, "Transit-Focused Development: A Synthesis of Transit Practice”, sponsored by the Federal Transit Administration, prepared for the Transportation Research Board, National Research Council, National Academy Press, Washington, D.C.

Purvis, C.L. 1994. "San Francisco Bay Area 1990 Regional Travel Characteristics”, Working Paper \#4, MTC Travel Survey, Metropolitan Travel Commission, Oakland CA.

Raimond, T. and D. Hensher. 1997. “A Review of Empirical Studies and Applications”. Chapter 2 from Panels for Transportation Planning: Methods and Applications, T. Golob, R. Kitamura and L. Long, eds., Transportation Research, Economics and Policy Vol. 5, Kluwer Academic Publishers, Norwell, MA, pp. 15-72. 
Renne, J. and J. Wells. 2005. “Transit-Oriented Development: Developing a Strategy to Measure Success”, National Cooperative Highway Research Program Project 20-65(5), conducted by the Alan M. Voorhees Transportation Center, Edward J. Bloustein School of Planning and Public Policy, Rutgers University, Research Results Digest 294, February.

Rice, D. 2005. Farm Credit of South Florida. Comments made at the 2005 Public Policy Workshop, Florida Chapter of the American Planning Association, Tallahassee, February 16, as reported in Florida Planning newsletter.

Richardson, A. 2003. "Temporal Variability of Car Usage as an Input to the Design of Before \& After Surveys", Paper presented at the $82^{\text {nd }}$ Annual Meeting of the Transportation Research Board, National Research Council, Washington, D.C.

Roberts, W. 2001. “The Way to a City's Heart is Through its Stomach: Putting Food Security on the Urban Planning Agenda”, Toronto Food Policy Council.

Schwanen, T. and P. Mokhtarian. 2005. "What If You Live in the Wrong Neighborhood? The Impact of Residential Neighborhood Type Dissonance on Distance Traveled.” Transportation Research D, 10, Elsevier, pp. 127-151.

Shiftan, Y., D. Shefer and G. Avraham. 2002. "The Impact of Auto Restrain Policies on the Location of Businesses in City Centers", original paper submitted for the Transportation Research Board 2003 Annual Meeting, Washington, D.C.

Urbanski, A. 2002. “Progressive Grocer Annual Report”, Progressive Grocer, Vol. 69.

Van Wissen, L, T. Golob, and Meurs, H. 1991. “A Simultaneous Dynamic Travel and Activities Time Allocation Model”, Working Paper No. 21, The University of California Transportation Center, University of California at Berkeley, CA.

Wells, J. and J. Renne. 2004. "Implementation of the Assessment Tool: Measuring Economic Activity, Assessing the Impacts of the New Jersey Transit Village Initiative”, Alan M. Voorhees Transportation Center, Edward J. Bloustein School of Planning and Public Policy, Rutgers University, October.

WilsonMiller, Inc. 2005. Sustainable Treasure Coast Rural Lands Subcommittee, “An Overview of Rural Lands Stewardship”, Powerpoint presentation. April 6.

Winters, P. and R. Perez. 2003. “Trip Reduction Model and Manual”, prepared for the National Center for Transit Research with sponsorship from the Florida Department of Transportation. Prepared by the Center for Urban Transportation Research and the Computer Science and Engineering Department, University of South Florida, Tampa. Found at http://www.nctr.usf.edu 
Winters, P., R. Perez, N. Georggi, and S. Barbeau. 2005. “Traveling Smart: Increasing Transit Ridership by Automatic Collection (TRAC) of Individual Travel Behavior Data and Personalized Feedback", draft Final Report. Funded by the National Center for Transit Research with sponsorship from the Florida Department of Transportation. Prepared by the Center for Urban Transportation Research in collaboration with the Computer Science Engineering Department, College of Engineering, University of South Florida, Tampa.

Yin, R. 1984. Case Study Research, Design and Methods. Applied Social Research Methods Series Volume 5, SAGE Publications, Inc., Newbury Park, CA. 